\title{
Allocation of human capital and innovation at the frontier: firm-level evidence on Germany and the Netherlands
}

\author{
Eric Bartelsman*, Sabien Dobbelaere ${ }^{* * *}$ and Bettina Peters ${ }^{\dagger}$
}

This article examines how productivity effects of human capital and innovation vary at different points of the conditional productivity distribution. Our analysis draws upon two large unbalanced panels of 6634 enterprises in Germany and 14,841 enterprises in the Netherlands over the period 2000-2008, considering five manufacturing and services industries that differ in the level of technological intensity. Industries in the Netherlands are characterized by a larger average proportion of high-skilled employees and industries in Germany by a more unequal distribution of human capital intensity. In Germany, average innovation performance is higher in all industries, except for low-technology manufacturing, and in the Netherlands the innovation performance distributions are more dispersed. In both countries, we observe nonlinearities in the productivity effects of investing in product innovation in the majority of industries. Frontier firms enjoy the highest returns to product innovation whereas for process innovation the most negative returns are observed in the best-performing enterprises of most industries. We find that in both countries the returns to human capital increase with proximity to the technological frontier in industries with a low level of technological intensity.

\footnotetext{
${ }^{\star}$ Eric Bartelsman, Department of Economics, VU University Amsterdam, De Boelelaan 1105, 1081 HV Amsterdam, The Netherlands; Tinbergen Institute (TIA), Gustav Mahlerplein 117, 1082 MS Amsterdam, The Netherlands and IZA, Schaumburg-Lippe-Strasse 5-9, 53113 Bonn, Germany. e-mail: e.j.bartelsman@vu.nl

**Sabien Dobbelaere, Department of Economics, VU University Amsterdam, De Boelelaan 1105, 1081 HV Amsterdam, The Netherlands; Tinbergen Institute (TIA), Gustav Mahlerplein 117, 1082 MS Amsterdam, The Netherlands and IZA, Schaumburg-Lippe-Strasse 5-9, 53113 Bonn, Germany. e-mail: sabien.dobbelaere@vu.nl

${ }^{\dagger}$ Centre for European Economic Research (ZEW), MaCCI Mannheim Centre for Competition and Innovation, L7 1, 68161 Mannheim, Germany and University of Zurich, Rämistrasse 71, 8006 Zürich, Switzerland. e-mail: b.peters@zew.de.

"Main author for correspondence.
} 
Strikingly, a negative complementarity effect between human capital and proximity to the technological frontier is observed in knowledge-intensive services, which is most pronounced for the Netherlands. Suggestive evidence suggests an interpretation of a winner-takes-all market in knowledge-intensive services.

JEL classification: C10, 120, 014, 030.

"The most important discovery [from microeconometric investigations] was the evidence on the pervasiveness of heterogeneity and diversity in economic life" - James J. Heckman, Nobel Lecture, December 8, 2000 (see Heckman 2001).

\section{Introduction}

Over the past two decades, studies on productivity using longitudinal micro-level data sets have revealed two stylized facts. First, there exist tremendous differences in productivity across firms, even within narrowly defined industries, which are fairly persistent through time (see Bartelsman and Doms, 2000 for a survey and Haltiwanger et al., 2007 for recent evidence). Second, within-industry firm productivity differences are larger than between-industry differences (Foster et al., 2001). This ubiquity of firm-level productivity variation and persistence has spurred research into the underlying factors (Syverson, 2011). This article reconsiders the relationship between innovation and human capital on the one hand and productivity on the other hand.

More specifically, combining firm, industry, and country-level perspectives for two countries, we first investigate firm-level heterogeneity in the productivity effects of investments in innovation and human capital in manufacturing and service industries in Germany and the Netherlands. Motivated by the increasing prominence of services in European countries and the central role played by knowledge-intensive services in knowledge-based economies, we focus on high- versus low-technology industries. Given that $(i)$ even within these industries, there is significant heterogeneity between firms and (ii) the returns to innovation and human capital are highly skewed, we use quantile regression $(\mathrm{QR})$ techniques to study the relationship between innovative activity and human capital on the one hand and productivity on the other hand at different points of the conditional productivity distribution. In a subsequent, more descriptive step, we exploit the degree of heterogeneity in the returns to innovation and human capital to reexamine differences in the productivity distribution between industries.

From a policy perspective, our study contributes to deepening our understanding of policies that affect aggregate productivity outcomes in European knowledge-based economies. It starts from the observation that over the past decade, serious concerns 
have been expressed about the increasing productivity gap of European firms to US firms (OECD, 2010; Roeger et al., 2010). ${ }^{1}$ Numerous reports view Europe's unsatisfactory growth performance as a signal of its failure to transform into a knowledgebased economy (Kok, 2004; Sapir et al., 2004; European Commission, 2008). As a response, policy instruments have been introduced to stimulate investment in R\&D and education (Lisbon Strategy 2000-2010, Europe 2020 and its Flagship Initiative Innovation Union). Given that empirical studies have shown that high-growth firms (the so-called "superstars" or "gazelles") are crucial for net job creation (see Henrekson and Johansson, 2010 for a survey; Acs, 2011), high-growth firms have received increasing attention among policymakers in recent years (European Commission, 2010; Hölzl, 2014). Research into the policy drivers of a knowledgebased economy has taken many disparate routes, from theoretical modeling using an aggregate (macro) perspective to empirical explorations using firm-level (micro) data. Given that neither micro evidence nor meso evidence per se conclusively identifies the drivers that boost productivity, this article takes an integrated micro-meso approach to examine the role of innovation and human capital in shaping industry productivity distributions.

Pursuing a highly comparable cross-country industry analysis is valuable for explaining different patterns of economic phenomena across countries. The selection of our two countries is driven by the following three reasons. First, there are inherent institutional differences in the two countries. In Germany, the education system is characterized by a well-established, successful dual education system-combining general, transferable skills and structured learning on the job-supportive for providing high-quality technical skills and for creating a high degree of specialization of skilled employees. ${ }^{2}$ Second, there are marked differences in the nature of innovation activity in the two countries. In contrast to the Netherlands, the innovation and production system in Germany is largely based on incremental customization of products rather than on radical innovation, which in turn maintains an existing industrial structure rather than stimulating the emergence of new industries (Streeck, 1997). Third, highly comparable microdata sets are available in these countries, allowing us to conduct a reliable international comparative study.

Our analysis draws upon specific elements of recent endogenous growth models confirming that economy-wide technological improvements occur through the

\footnotetext{
${ }^{1}$ Since the mid 1990s, the productivity gap between Europe and the United States has risen dramatically: GDP per hour worked in the EU has decreased from $98.3 \%$ of the US level in 1995 to $82.5 \%$ in 2012 .

${ }^{2}$ A unique feature of the German education system is that the principle of the dual system of vocational training is applied to tertiary education. Vocational education is the most relevant category of training in Germany: about two-thirds of the workforce have a vocational degree. Another distinguishing characteristic is that the vocational pathway is regarded as a high status route into employment (Cedefop, 2008).
} 
channel of innovation in advanced economies. Benhabib and Spiegel (1994), Acemoglu et al. (2003, 2006), and Vandenbussche et al. (2006) share the underlying idea that technological improvements are the result of a combination of innovation and imitation. In particular, Acemoglu et al. $(2003,2006)$ show that innovation becomes more important than imitation as an economic entity approaches the technological frontier. Inspired by the argument of Nelson and Phelps (1966) that education facilitates the implementation of new technologies and adapting their framework to allow for the catch-up of technology to the technology of the leading country, Benhabib and Spiegel (1994) provide cross-country evidence that countries with higher education tend to close the technological gap faster than others and experience higher economic growth. Vandenbussche et al. (2006) go one step further and show that the contribution of human capital to productivity growth can be decomposed into a level effect and a composition effect. In line with Acemoglu (2006), they assume that unskilled labor is better suited to imitation whereas more intensive use of skilled labor is required for innovation. Taking into account endogenous labor reallocation across these imitation and innovation activities, they argue that one needs to account for both an economy's distance to the technological frontier and the composition of its human capital, which they empirically confirm at the macro level.

A detailed look at our data uncovers three stylized facts about human capital, innovation, and productivity in Germany and the Netherlands. First, irrespective of their level of technological intensity, industries in the Netherlands are characterized by a higher average share of employees possessing a college or university degree and industries in Germany by a more unequal distribution of human capital intensity. Second, average innovation performance-measured by the logarithm of real innovative sales per employee for product innovators - is higher in all industries, except for low-technology manufacturing in Germany and the innovation performance distributions are more dispersed in all Dutch industries, except for low-technology manufacturing. Third, average productivity is higher in all manufacturing industries in the Netherlands, and productivity is more unequally distributed in all industries, except for high-technology manufacturing in Germany.

Allowing the productivity effects of human capital and innovation to vary at different points of the conditional productivity distribution, our two main findings are summarized as follows. First, we find increasing marginal returns to product innovation as we move up the productivity distribution but negative marginal returns to process innovation for the best-performing enterprises in the majority of industries in both countries. Apparently, the best strategy for frontier firms is to focus on product rather than on process innovation. Second, the returns to human capital increase with proximity to the technological frontier in industries with a low level of technological intensity in both countries, thereby providing micro-evidence on the positive complementarity effect put forward by Vandenbussche et al. (2006). Strikingly, we find a negative complementarity effect between human capital and 
proximity to the technological frontier in knowledge-intensive services. The latter finding is most pronounced for the Netherlands. ${ }^{3}$ We provide suggestive evidence in support of a winner-takes-all interpretation for the Netherlands. Investment in intangibles in knowledge-intensive services, making use of human capital intensely, might lead to a profitable breakthrough for one firm which could compensate the losses of many competitors.

We proceed as follows. Section 2 provides a short review of the related literature. Section 3 elucidates our empirical strategy. Section 4 discusses the data for Germany and the Netherlands. Section 5 presents some stylized facts. Section 6 reports the results. Section 7 concludes.

\section{Related literature}

There is a vast empirical literature on the effect of investments in R\&D and innovation on firm productivity. On average, the private returns to $R \& D$ are strongly positive and somewhat higher than for ordinary capital (see Mairesse and Sassenou, 1991 for an early comprehensive survey, and Wieser, 2005 and Hall et al., 2010 for recent surveys). However, there is mixed evidence on heterogeneous returns to R\&D expenditures. For example, Coad and Rao (2008) find strongly increasing productivity effects for high-growth firms in US high-technology manufacturing. Segarra and Teruel (2011) show that the returns to internal R\&D are higher for low-productive firms, while the returns to external R\&D are only positive for high-productive firms in Catalan manufacturing and services. Mata and Wörter (2013) report only positive returns to external R\&D for high-growth firms in Swiss manufacturing. Peters et al. (2013) reveal that the long-run net benefits of R\&D are increasing with higher levels of productivity in German manufacturing firms. Pisu (2006) does not report any effect, neither for high- nor for low-productive firms in UK manufacturing and services. On average, there are substantial positive impacts of product innovation on revenue productivity whilst the impact of process innovation is more ambiguous (see Hall, 2011 for a survey). However, there is very limited evidence on heterogeneous returns to product and process innovation. Coad and Rao (2008) find a positive effect of innovativeness for high-growth firms in the upper tail of the distribution but not for the average firm's sales growth. Goedhuys and Sleuwaegen (2010) estimate positive product innovation returns but negative process innovation returns for high-productive entrepreneurial firms in Africa.

Likewise, there is a vast empirical literature on the effects of human capital on firm productivity. On average, human capital returns are found to be significantly positive at the micro level. Using matched employer-employee data sets, Lebedinski

\footnotetext{
${ }^{3}$ The latter result no longer holds for Germany in regressions that also control for unobserved firm heterogeneity.
} 
and Vandenberghe (2014) for Belgium, Turcotte and Rennison (2004) for Canada, Fox and Smeets (2011) for Denmark, Abowd et al. (1999) for France, Galindo-Rueda and Haskel (2005) and Haskel et al. (2005) for the UK, Hellerstein et al. (1999), Haltiwanger et al. (1999, 2007), and Moretti (2004) for the United States, and Van Biesebroeck (2011) for Zimbabwe all find positive effects of workers' skills on firm/ plant productivity. Using cross-country industry-level data for 26 industries in 5 countries (France, Germany, the Netherlands, UK, and United States) over the period 1979-2000, Mason et al. (2012) provide evidence of positive human capital returns, particularly when using a composite human capital variable accounting for both certified skills (educational attainment) and uncertified skills acquired through on-the-job training and experience. ${ }^{4}$ To our knowledge, our study is the first to examine human capital returns at different points of the conditional productivity distribution. Existing QR studies have focused on changes in the returns of skills at different points of the wages/earnings distribution (see e.g. Buchinsky, 1994, 2001; Mwabu and Schultz, 1996; Arias et al., 2001; Hartog et al., 2001; Machado and Mata, 2001, 2005; Pereira and Martins, 2002; Tobias, 2002; Harmon et al., 2003; Chevalier et al., 2004; Martins and Pereira, 2004; Choi and Jeong, 2007; Denny and O'Sullivan, 2007 and Flabbi et al., 2008). Under the assumption of competitive labor markets, they capture heterogeneous productivity effects of workers' skills. ${ }^{5}$

In a broad sense, our study fits into the empirical literature advocating that growth-maximizing policies should depend on the distance to the technological frontier. Traced back to the seminal papers of Gerschenkron (1962) and Atkinson and Stiglitz (1969), the distance-to-frontier literature has its roots in studies on development and technological capabilities. In macro/meso studies, the unit of analysis is national economies or specific industries and one identifies the national technology frontier for a specific industry or the global frontier for a specific industry

\footnotetext{
${ }^{4} \mathrm{Up}$ to the first half of the nineties, macro evidence pointed to a positive relationship between human capital and output growth. However, this evidence was refuted by subsequent studies during the second half of the 90s (see Sianesi and van Reenen, 2003 and de la Fuente, 2011 for a survey). The latter finding is largely explained by methodological difficulties related to measuring skills and modeling the channels through which skills impact on economic performance. Starting with Krueger and Lindhal (2001), considerable progress has been made to tackle these methodological problems (see e.g. de la Fuente and Doménech, 2001, 2006; Cohen and Soto, 2007; Barro and Lee, 2010). As a result, the latter studies find again positive impacts of education on economic growth. Another set of recent studies, focusing on the quality of education rather than its quantity, show even larger productivity effects (e.g. Hanushek and Kimko, 2000; Coulombe et al., 2004; Hanushek and Wößmann, 2008, 2012).

${ }^{5}$ Hellerstein et al. (1999) pioneered an approach of jointly estimating a plant-level wage equation with a production function aimed at investigating the divergence between productivity premiums associated with worker characteristics (such as education, age, gender) and the corresponding wage premiums. Many longitudinal studies on matched worker-firm data have applied this method (see van Ours and Stoeldraijer, 2011 and Vandenberghe et al., 2013 for references).
} 
in a specific country. Existing articles include Griffith et al. (2003b, 2004) on R\&D intensity in a panel of industries across 12 OECD countries, Nicoletta and Scarpetta (2003) on product market regulation in a cross-country cross-industry panel of 18 OECD countries, Aghion et al. (2004) on threat of entry in UK industries, Aghion et al. (2005) on product market competition in UK industries, Acemoglu et al. (2006) on openness to trade, entry costs, and schooling level in a cross-country panel of about 100 non-OECD countries, Kneller and Stevens (2006) on human capital and R\&D in a panel of industries across 12 OECD countries, Aghion et al. (2008) on the liberalization of product entry in India, Chandra et al. (2009) on competition in a panel of industries in Brazil, India, China, and Korea, Amable et al. (2010) on competition in a cross-country cross-industry panel of 17 OECD countries, Bourlès et al. (2010) on competition in a panel of industries across 10 OECD countries, and D'Costa et al. (2013) on how the impact of nation-wide structural policies on regional productivity growth depends on a region's distance to the frontier using a panel of regions in OECD countries.

At the micro level, one identifies a national or within-industry frontier that reflects the best technology in (an industry within) a country and evaluates how a firm's or establishment's distance to this frontier affects its economic performance. Applying the distance-to-frontier concept at the micro level acknowledges the large and persistent productivity dispersion across firms in many countries and advocates that heterogeneous firms should select strategies that depend on their relative performance. Three distinct methods are used in micro-level studies: (i) evaluating the impact of a firm's distance to the industry frontier and its interaction with relevant variables on economic performance/decisions thereby closely following the macro approach, (ii) assessing the influence of various strategies on a firm's economic performance at different points of the conditional performance distribution, and (iii) estimating a technology convergence equation. ${ }^{6}$ Existing studies using the first method include Aghion et al. (2004) on the influence of distance to the frontier and its interaction with foreign firm entry on incumbent performance using a panel of UK establishments, Acemoglu et al. (2007) on the impact of distance to the frontier on decentralization of investment decisions in panels of British establishments and French firms, Alder (2010) on the impact of distance to the frontier (in levels and interacted with competition) on product innovation using a panel of enterprise data in 40 developing and transition countries, Arnold et al. (2011) on the impact of distance to the frontier when evaluating the impact of product market regulation on

\footnotetext{
${ }^{6}$ At the macro level, a country/industry's distance to the technology or productivity frontier are two closely related concepts. At the micro level, however, a firm's distance to the industry frontier might be operationalized in different ways depending on the question under investigation (see Coad, 2011 for a discussion). Following the tradition in the productivity convergence literature, we operationalize the concept of distance to the industry frontier by sorting firms according to their value of labor productivity.
} 
firm-level productivity using a panel of European firms, and Ben Yahmed and Dougherty (2012) on the impact of import penetration on firms' productivity growth taking into account heterogeneity in firms' distance to the frontier using a firm panel of OECD countries. In addition to the studies mentioned above, existing studies using the second method include Coad and Rao (2006) on the impact of $\mathrm{R} \& \mathrm{D}$ expenditures and patents on a firm's market value at different points of the conditional Tobin's $q$ distribution and Hölzl and Friesenbichler (2010) on the differential impact of R\&D and innovation for high-growth firms in countries close to the technological frontier using firm data from the third Community Innovation Survey in 16 countries. Existing studies using the third method include Griffith et al. (2003a) on the role of foreign presence in raising the speed of convergence to the technological frontier using a panel of British establishments, Nishimura et al. (2005) on the speed of convergence-taking explicitly into account possible biases caused by exits-in IT and non-IT industries using a panel of Japanese firms, Sabirianova Peter et al. (2012) on whether more efficient firms have a higher probability than less efficient firms of moving up in the overall distribution of productive efficiency in any given year and on factors affecting the evolution of the efficiency gap using a panel of firms in the Czech Republic and Russia, and Bournakis et al. (2013) on the role of investment in $\mathrm{R} \& \mathrm{D}$ in achieving productivity convergence using a panel of British firms. Combining the first and second method, we evaluate how the impact of human capital and innovation vary at different points of the conditional productivity distribution while controlling for a firm's distance to the industry frontier. Linking country-specific firm-level data to examine which countries and industries are at the global frontier to single country microdata to construct distances to both the global and national frontier, Bartelsman et al. (2008) bridge the macro and micro approaches by assessing how the productivity growth of UK firms is influenced by both the global and national frontiers.

In a more narrow sense, our study is most closely related to Vandenbussche et al. (2006), Inklaar et al. (2008), Madsen et al. (2010), and Madsen (2014). Using a panel data set covering 19 OECD countries between 1960 and 2000, Vandenbussche et al. (2006) provide evidence of skilled labor having a higher growth-enhancing effect closer to the technological frontier. Using EUKLEMS industry data on multifactor productivity covering the period 1995-2004, Inklaar et al. (2008), however, do not find support for the argument that there are productivity externalities from employing university-educated workers for leaders in market services industries. Using a panel of 23 OECD countries and 32 developing countries covering the period 19702004, Madsen et al. (2010) show that R\&D intensity, its interaction with distance to the frontier, educational attainment interacted with distance to the frontier and technological gap influence total factor growth positively and point to different effects for developed versus developing countries. Using a panel of 21 OECD countries covering the period 1870-2009, Madsen (2014) finds that-controlling for innovation variables and international knowledge spillovers-changes in educational 
attainment and the interaction between education and the distance to the world technology frontier have been influential for productivity growth over the past 140 years.

\section{Econometric framework}

Our empirical analysis consists of two parts. In the first part, we estimate the returns to human capital and innovation at the firm level. Our econometric framework is based on an augmented standard Cobb-Douglas production function approach. The logarithmic specification of the production function in intensity form is given by:

$$
\begin{aligned}
& \ln \left(\frac{Q}{L}\right)_{i t}=\beta_{0}+\beta_{K} \ln \left(\frac{K}{L}\right)_{i t}+\beta_{M} \ln \left(\frac{M}{L}\right)_{i t}+\beta_{L} \ln L_{i t} \\
& \quad+\beta_{H C} H C_{i t}+\beta_{C T F} C T F_{i t-1}+\beta_{P D} P D_{i t}+\beta_{P C} P C_{i t}+\alpha \text { Controls }+u_{i t}
\end{aligned}
$$

where $Q_{i t}$ is output of firm $i$ in year $t$, and $L, K$, and $M$ denote the number of employees, physical capital, and material, respectively. Although productivity is measured in intensity form, firm size $(\ln L)$ is additionally included. It allows testing for the hypothesis of constant returns to scale which corresponds to $\beta_{L}=0$. The production function is extended by including human capital $(H C)$, the technological position of the firm $(C T F)$, product innovation $(P D)$, and process innovation $(P C)$. We further account for the productivity impact of some additional control variables (Controls) that will be explained in more detail in Section 4.4. $\beta_{K}$ and $\beta_{M}$ measure the output elasticity of capital and material whilst $\beta_{H C}, \beta_{P D}$, and $\beta_{P C}$ capture the returns to human capital, product, and process innovation, respectively.

We estimate this production function at the country-industry level using four different estimation methods that differ in the degree of firm-level heterogeneity they account for. Standard ordinary least squares regression techniques (OLS) provide point estimates for the average productivity effect of the independent variables in a "representative enterprise". Unobserved heterogeneity among firms, however, may make it difficult to isolate the productivity effects of human capital and innovation as both variables are likely to correlate with unobserved firm characteristics such as managerial ability. As an additional source of heterogeneity, we therefore account for firm-specific effects in estimating the average returns to human capital and innovation by using the fixed effects $(F E)$ estimator.

The exclusive focus on mean effects of OLS and FE may be misleading since it seems unlikely that most firms obtain the "average" return to human capital and innovation or even close to it. In order to obtain a more detailed picture of heterogeneous returns, we therefore use $Q R$ techniques to model the conditional productivity distribution at various quantiles $\theta(0<\theta<1)$, conditional on the explanatory variables. The use of $\mathrm{QR}$ techniques provides two other major advantages. First, whilst the optimal properties of standard regression estimators are not robust to 
modest departures from normality, QR results are characteristically robust to outliers and heavy-tailed distributions. In fact, the QR solution is invariant to outliers of the dependent variable that tend to $\pm \infty$ (Buchinsky, 1994). Second, a QR approach avoids the restrictive assumption that the error terms are identically distributed at all points of the conditional distribution.

The QR model for cross-sectional data, first introduced in Koenker and Bassett's (1978) seminal contribution, can be written as:

$$
y_{i t}=x_{i t}^{\prime} \beta_{\theta}+u_{\theta i t} \quad \text { with } \quad Q_{\theta}\left(y_{i t} \mid x_{i t}\right)=x_{i t}^{\prime} \beta_{\theta}
$$

where $y_{i t}$ is the dependent variable, $x_{i t}$ a $(K \times 1)$-vector of regressors, $\beta_{\theta}$ the $(K \times 1)$ vector of parameters to be estimated and $u_{\theta i t}$ the error term. $Q_{\theta}\left(y_{i t} \mid x_{i t}\right)$ denotes the $\theta^{\text {th }}$ conditional quantile of $y_{i t}$ given $x_{i t}$. The $\theta^{\text {th }}$ conditional quantile function can be estimated by solving the following minimization problem:

$$
\min _{\beta} \frac{1}{n}\left\{\sum_{i, t: y_{i t} \geq x_{i t}^{\prime} \beta} \theta\left|y_{i t}-x_{i t}^{\prime} \beta\right|+\sum_{i, t: y_{i t}<x_{i t}^{\prime} \beta}(1-\theta)\left|y_{i t}-x_{i t}^{\prime} \beta\right|\right\}=\min _{\beta} \frac{1}{n} \sum \rho_{\theta} u_{\theta i t}
$$

where $\rho_{\theta} u_{\theta i t}$, known as the "check function," is defined as

$$
\rho_{\theta} u_{\theta i t}=\left\{\begin{array}{lll}
\theta u_{\theta i t} & \text { if } & u_{\theta i t} \geq 0 \\
(\theta-1) u_{\theta i t} & \text { if } & u_{\theta i t}<0
\end{array}\right.
$$

Equation (3) is solved by linear programming methods. As one increases $\theta$ continuously from 0 to 1 , one traces the entire conditional distribution of $y$, conditional on $x$ (Buchinsky, 1994). In our study, the parameter estimate for the $k^{\text {th }}$ exogenous variable, let us say human capital, is interpreted as the marginal change in productivity due to a marginal change in human capital conditional on being on the $\theta^{\text {th }}$ quantile of the distribution. This is also called the $\theta^{\text {th }}$ quantile return to human capital. We are particularly interested in how these returns change along the distribution.

The standard QR method allows the impact of all explanatory variables to vary along the conditional productivity distribution. However, it does not account for other unobserved firm-specific variables $\alpha_{i}$ that might affect productivity. The estimation of a quantile model with FE is not trivial because its intrinsic nonlinearity implies that standard demeaning techniques are not feasible. In order to take unobserved heterogeneity into account, QR models for panel data have recently been developed:

$$
y_{i t}=x_{i t}^{\prime} \beta_{\theta}+\alpha_{i}+\epsilon_{\theta i t}
$$

Following the seminal paper of Koenker (2004) on the estimation of QR models for longitudinal data, most of the literature on QR estimators for panel data propose inference procedures based on the assumption that the number of periods goes to 
infinity when the sample size goes to infinity. Under this assumption, Koenker (2004) and Lamarche (2010) suggest a penalized QR estimator that simultaneously estimates QR coefficients for a set of quantiles and FE. Galvao (2011) extends the approach to dynamic panel data models with individual-specific intercepts. Abrevaya and Dahl (2008) suggest a correlated random-effects model based on the ideas of Mundlak (1978) and Chamberlain (1984). Canay (2011) proposes a simple two-step estimator that does not require specifying a penalty parameter and that is consistent and asymptotically normal when both the number of firms $n$ and the number of periods T approach infinity. ${ }^{7}$ Chernozhukov et al. (2013) provide identification and estimation of quantile effects in nonseparable models. Koenker (2004), Lamarche (2010), and Canay (2011) assume that the FE $\alpha_{i}$ are pure location shifters, i.e. they affect all quantiles in the same way.

Given that the Canay (2011) estimator eliminates the FE beforehand, making its implementation computationally simple regardless of the number of FE included in the analysis, we apply this estimator to obtain the quantile returns to human capital and innovation taking into account unobserved firm heterogeneity (FEQR). More specifically, the Canay (2011) estimator consists of the following two steps. The first step involves a within estimation of the linear regression $y_{i t}=x_{i t}^{\prime} \beta_{\mu}+\alpha_{i}+u_{i t}$ with $E\left(u_{i t} \mid x_{i}, \alpha_{i}\right)=0$. From the estimation of $\beta_{\mu}$, one computes the firm-specific effects $\hat{\alpha}_{i} \equiv \frac{1}{T} \sum_{t=1}^{T}\left(y_{i t}-x_{i t}^{\prime} \hat{\beta}_{\mu}\right)$. The second step involves running a standard QR of $\tilde{y}_{i t} \equiv$ $y_{i t}-\hat{\alpha}_{i}$ on all explanatory variables $x_{i t}$ in order to obtain $\mathrm{QR}$ estimates for $\beta_{\theta}$. Inference is based on bootstrapped standard errors from individual resampling. As mentioned above, the Canay (2011) estimator treats $\alpha_{i}$ as a simple location shift and, therefore, does not depend on the quantiles. This implies that the firm FE affect the productivity of all firms within the same industry in the same way regardless of where the firms are located in the productivity distribution. Other recent studies implementing the Canay (2011) estimator include e.g. FosterMcGregor et al. (2013), Ohinata and van Ours (2013), Binder et al. (2014), and Cingano et al. (2014).

Based on our firm-level results, we examine in the second part of our empirical analysis whether heterogeneous productivity effects of human capital and innovation significantly change productivity distribution characteristics at the industry level. We follow an approach proposed by Machado and Mata (2000) and recently used by Mata and Wörter (2013) to investigate the effect of internal and external $R \& D$ strategies on the distribution of profits. Main attributes of the productivity

\footnotetext{
${ }^{7}$ Using Monte Carlo simulations, Canay (2011) shows that (i) already with $T=10$, the bias is fairly low irrespective of the value of $n$ and (ii) the Canay (2011) estimator performs as well as the Koenker (2004) estimator.
} 
distribution are the dispersion, skewness, and kurtosis. Quantile-based definitions of these attributes are as follows (see Oja, 1981 and Ruppert, 1987):

$$
\begin{aligned}
\text { dispersion } & =\left(q_{0.75}-q_{0.25}\right) /\left(q_{0.75}+q_{0.25}\right) \\
\text { skewness } & =\left(q_{0.75}+q_{0.25}-2 q_{0.50}\right) /\left(q_{0.75}-q_{0.25}\right) \\
\text { kurtosis } & =\left(q_{0.90}-q_{0.10}\right) /\left(q_{0.75}-q_{0.25}\right)
\end{aligned}
$$

The dispersion is a ratio of the width of the distribution between the upper and lower quartiles over a measure of location. The skewness compares the difference between the upper quartile and median and the median and the lower quartile over the width of the distribution. This measure is zero for symmetric distributions. A negative value implies that the productivity distribution has longer tails on the left side but that the mass of the distribution is concentrated on the right. The kurtosis measures the weight of the tails by comparing the distance between the 0.10 and 0.90 quantiles with the distance between the upper and lower quartiles. A high kurtosis points to a productivity distribution where the dispersion of productivity results from extreme but infrequent productivity levels (extreme deviations) whereas a low kurtosis implies that the dispersion results from frequent modestly sized deviations.

Inserting the equations for different quantiles into these definitions, we obtain a relationship between our explanatory variables and the distributional characteristics. In order to evaluate how changes in human capital and innovation ceteris paribus affect these distributional characteristics, we follow Mata and Wörter (2013) by using the estimated coefficients of these variables at the relevant quantiles. Standard errors of these nonlinear combinations of parameter estimates are calculated using the Delta method (Wooldridge, 2002). ${ }^{8}$

\section{Data description}

Combining firm-, industry-, and country-level perspectives for two countries, our analysis primarily serves the purpose of uncovering heterogeneous returns to human capital and innovation at varying points of the conditional productivity distribution using firm-level data in Germany and the Netherlands. As mentioned above, the selection of the two countries is motivated by (i) differences in the education system in the two countries, (ii) differences in the nature of innovation activities in the two countries, and (iii) the ability to build two highly comparable microdata sets that span the period 1998-2008. The latter ensures that our results reflect underlying economic differences which enables us to perform a reliable international comparative study.

\footnotetext{
${ }^{8}$ Calculations are done in STATA using the nlcom-command.
} 
Enterprises in manufacturing (European industry classification system NACE [Rev. 1.1] 15-37) and services (NACE 50-90) are included in the analysis. The population of interest consists of enterprises with at least 10 employees. This section examines the German and Dutch microdata sets, respectively. For both countries, price deflators for output, value added, intermediate inputs, and capital are drawn from the EUKLEMS database (November 2009 release, March 2011 update), and unit labor costs are taken from the OECD database.

\subsection{Germany}

We use the Mannheim Innovation Panel (MIP). The MIP is made up by representative innovation surveys which are collected by the Centre for European Economic Research (ZEW) in cooperation with the Fraunhofer Institute for Systems and Innovation Research (ISI) and the Institute for Applied Social Science (infas) on behalf of the German Federal Ministry of Education and Research (BMBF). Every fourth (before 2005)/second (after 2005) year, the MIP is the German contribution to the European-wide harmonized Community Innovation Surveys (CIS). In contrast to other European countries, the MIP is an annual panel that started in 1993 in manufacturing and was extended to services in 1995. It is based on a random stratified sample-industry, size, and region serving as stratification criteria-that is refreshed every second year for dead and newly established firms, respectively (see Rammer and Peters, 2013). In addition to the common harmonized innovation indicators, the German innovation surveys additionally ask firms about a host of other general firm characteristics such as sales, number of employees, the share of high-skilled employees, intermediate input costs (including energy costs and intermediate services), and the stock of tangible assets (physical capital).

\subsection{The Netherlands}

We use data that are sourced from different surveys collected by Statistics Netherlands, or "Centraal Bureau voor de Statistiek". The innovation variables stem from five waves of the Dutch CIS: CIS3 (1998-2000), CIS3.5 (2000-2002), CIS4 (2002-2004), CIS4.5 (2004-2006), and CIS5 (2006-2008). CIS enterprises are merged with data from the Production Surveys (PS). ${ }^{9}$ The latter contains data on production value, factor inputs, and factor costs.

The CIS and PS data are collected at the enterprise level. A combination of census and stratified random sampling is used for each wave of the CIS and PS. A census is used for the population of enterprises with at least 50 employees, and a stratified random sampling is used for enterprises with fewer than 50 employees. The

\footnotetext{
${ }^{9}$ Approximately $26 \%$ of the CIS enterprises are matched with the corresponding PS enterprises in manufacturing. For services, the match increases to 33\%.
} 
stratification variables are the industry and the number of employees of an enterprise. The same cutoff point of 50 employees is applied to each wave of the CIS and the PS.

The Social Statistics Database (SSB) forms the backbone to retrieve information

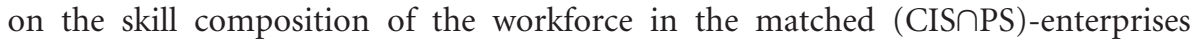
(Bakker, 2002). The SSB links administrative data for the entire population registered as living in the Netherlands with detailed demographic and socioeconomic data from business and household surveys. The data are primarily obtained from the population register, tax registers, social security registers, education registers, and various other registers and administrations. The SSB contains all the relevant information on persons, families, households, jobs, benefits, and living quarters which can be matched with enterprise data through a unique personal identification number. Details on the measurement of the human capital variables are found in Section A.1 of Appendix A.

\subsection{Main estimation samples}

For estimation purposes, we use information from the aforementioned five waves of the CIS (Germany) and matched CIS samples (The Netherlands) in both countries. After some cleaning and trimming on nominal labor productivity levels and growth rates to eliminate outliers and anomalies, we end up with an unbalanced panel of 11,699 observations corresponding to 6634 enterprises (61.4\% in manufacturing and $38.6 \%$ in services) over the period 2000-2008 in Germany (DE) and an unbalanced panel of 24,586 observations corresponding to 14,841 enterprises (38.5\% in manufacturing and $61.5 \%$ in services) over the period $2000-2008$ in the Netherlands $(N L) .{ }^{10}$ The estimation samples are further broken down into five industries according to the OECD (2001) classification: High-technology manufacturing (HT), Medium-technology manufacturing $(M T)$, Low-technology manufacturing $(L T)$, Knowledge-intensive services (KIS), and Other services (OS). ${ }^{11}$ Table A6 in Appendix A provides details on the industry breakdown of manufacturing and services depending on their technological intensity.

Table 1 reports the number of observations and firms in the estimation sample by country, industry, size, and year. Unsurprisingly, the German sample includes more larger enterprises (10.9\% with more than 500 employees) than the Dutch sample

\footnotetext{
${ }^{10}$ In $D E(N L), 2506$ (4452) enterprises take part in at least two consecutive waves, 956 (1860) in at least three consecutive waves, 390 (785) in at least four consecutive waves, and 152 (348) in all five waves.

${ }^{11}$ The OECD classification of manufacturing industries according to their technology intensity is based both on direct R\&D intensity ( $\& \& D$ expenditures divided by production and R\&D expenditures divided by value added) and $\mathrm{R} \& \mathrm{D}$ embodied in intermediate and investment goods (see Hatzichronoglou, 1997). For service industries, the classification is based on skill intensity and indirect R\&D measures such as technology embodied in investment or investment in ICT goods.
} 
Table 1 Estimation sample by country, industry, size, and year

\begin{tabular}{|c|c|c|c|c|c|c|c|c|}
\hline \multirow[t]{2}{*}{ Sample } & \multicolumn{4}{|l|}{ Germany } & \multicolumn{4}{|c|}{ The Netherlands } \\
\hline & $\begin{array}{l}\text { Number of } \\
\text { observations }\end{array}$ & $\%$ & $\begin{array}{l}\text { Number } \\
\text { of firms }\end{array}$ & $\%$ & $\begin{array}{l}\text { Number of } \\
\text { observations }\end{array}$ & $\%$ & $\begin{array}{l}\text { Number } \\
\text { of firms }\end{array}$ & $\%$ \\
\hline \multicolumn{9}{|l|}{ Industry } \\
\hline HT & 1063 & 9.1 & 609 & 9.2 & 716 & 2.9 & 409 & 2.7 \\
\hline MT & 4213 & 36.0 & 2336 & 35.2 & 6091 & 24.8 & 3362 & 22.6 \\
\hline LT & 1910 & 16.3 & 1103 & 16.6 & 2665 & 10.8 & 1555 & 10.5 \\
\hline KIS & 2737 & 23.4 & 1599 & 24.1 & 6624 & 26.9 & 4415 & 29.7 \\
\hline OS & 1776 & 15.2 & 987 & 14.9 & 8490 & 34.5 & 5167 & 34.8 \\
\hline \multicolumn{9}{|l|}{ Industry ${ }^{a}$} \\
\hline HT & 734 & 9.0 & 280 & 9.2 & 486 & 3.1 & 179 & 3.2 \\
\hline $\mathrm{MT}$ & 2977 & 36.7 & 1100 & 36.0 & 4275 & 27.7 & 1543 & 27.2 \\
\hline LT & 1287 & 15.9 & 480 & 15.7 & 1753 & 11.4 & 635 & 11.2 \\
\hline KIS & 1860 & 22.9 & 722 & 23.7 & 3664 & 23.7 & 1383 & 24.4 \\
\hline OS & 1259 & 15.5 & 470 & 15.4 & 5249 & 34.1 & 1924 & 34.0 \\
\hline \multicolumn{9}{|l|}{ Firm size } \\
\hline 10-19 & 2580 & 22.1 & 1482 & 22.3 & 3086 & 12.5 & 2726 & 18.4 \\
\hline $20-49$ & 2659 & 22.7 & 1487 & 22.4 & 6333 & 25.7 & 4797 & 19.5 \\
\hline 50-99 & 1969 & 16.8 & 1151 & 17.4 & 6384 & 25.9 & 3567 & 24.0 \\
\hline $100-249$ & 2075 & 17.7 & 1170 & 17.6 & 5910 & 24.0 & 2482 & 16.7 \\
\hline $250-500$ & 1080 & 9.2 & 618 & 9.3 & 1692 & 6.9 & 736 & 4.9 \\
\hline 500-999 & 652 & 5.6 & 360 & 5.4 & 726 & 2.9 & 314 & 2.1 \\
\hline $1000+$ & 684 & 5.8 & 366 & 5.5 & 455 & 1.8 & 219 & 1.5 \\
\hline \multicolumn{9}{|l|}{ Year } \\
\hline 2000 & 1543 & 13.2 & - & & 4519 & 18.4 & - & \\
\hline 2002 & 2246 & 19.2 & - & & 5365 & 21.8 & - & \\
\hline 2004 & 2404 & 20.5 & - & & 5063 & 20.6 & - & \\
\hline 2006 & 2486 & 21.2 & - & & 4533 & 18.4 & - & \\
\hline 2008 & 3020 & 25.8 & - & & 5106 & 20.8 & - & \\
\hline Total & 11,699 & 100.0 & 6634 & 100.0 & 24,586 & 100.0 & 14,841 & 100.0 \\
\hline
\end{tabular}

Notes: a Sample constrained to firms with at least two observations (DE: 3052 firms, 8117 observations; NL: 5664 firms, 15,427 observations).

(3.6\%). With respect to industry composition, we find that the German sample includes more HT firms but less OS firms. That is, in DE (NL), 9.2\% (2.7\%) of the firms belong to HT, $35.2 \%$ (22.6\%) to MT, $16.6 \%$ (10.5\%) to LT, $24.1 \%(29.7 \%)$ to KIS, and $14.9 \%(34.8 \%)$ to OS. In some robustness checks and to measure some 
variables (see Section 4.4), we use a more detailed industry classification (21 industries: 11 in manufacturing and 10 in services). Table B1 in Appendix B presents the number of observations and the number of firms in the estimation sample by country and by 21 -industry. Table B2 in Appendix B gives the panel structure of the estimation sample. In $D E(N L), 46 \%(38.2 \%)$ of the enterprises have at least two observations. For about $8 \%$ of the enterprises, we have at least four observations in the two countries.

\subsection{Dependent and explanatory variables}

Our main dependent variable is the logarithm of real labor productivity $(R L P)$. Nominal labor productivity is measured by sales per employee $\left(\frac{Q}{L}\right)$ where $L$ is the number of employees in head counts. ${ }^{12}$ EUKLEMS output price indicators (base year 2006) are used for deflation.

We explain the logarithm of RLP by firm size $\left(\ln L_{i t}=S I Z E_{i t}\right)$ and the traditional input factors physical capital and material. Capital is measured as the logarithm of real physical capital per employee $\left(\ln \left(\frac{K}{L}\right)_{i t}=C A P_{i t}\right)$, where $K$ is proxied by tangible assets in the German microdata set and by depreciation of fixed assets in the Dutch microdata set. It is deflated by using the industry-level gross fixed capital formation price index for all assets. Material is defined as the logarithm of real material costs per employee $\left(\ln \left(\frac{M}{L}\right)_{i t}=M A T_{i t}\right)$, where $M$ is intermediate input costs including energy costs and intermediate services, deflated by the industry-level intermediate inputs price index. In order to investigate the role of human capital, we include the share of high-skilled labor $\left(H C_{i t}\right)$, where high-skilled employees are defined as having a college or university degree. Innovation is captured by two innovation outcome variables: product and process innovation. Product innovation is measured by the logarithm of real innovative sales per employee $\left(\ln \left(\frac{S S P D \times S A L E S}{L}\right)_{i t}=P D_{i t}\right) \cdot S S P D_{i t}$ refers to the share of total sales in year $t$ accounted for by new or improved products and services introduced in $(t-2),(t-1)$ and $t$. In addition, we make a corresponding distinction based on the share of sales due to products new to the firm only (firm novelties, $S S F N_{i t}$ ) and the share of sales due to products new to the market (market novelties, $S S M N_{i t}$ ). In contrast to product innovation, process innovation is measured by a binary indicator equaling one if an enterprise introduced any new or significantly improved production technology during the period under review, i.e. between $(t-2)$ and $t\left(P C_{i t}\right)$. In order to investigate whether distance to the technological frontier matters for firm-level productivity, we include the 1-year lagged value of closeness to the technological frontier $\left(C T F_{i t-1}=L 1 . C T F\right)$. Closeness to the

${ }^{12} L$ refers to the average number of employees in the German data set and to the number of employees in September of a given year in the Dutch data set. 
technological frontier is measured as $C T F_{i t}=1-D T F_{i t}=1-\left(\frac{R L P_{F t}-R L P_{i t}}{R L P_{F t}}\right)=\frac{R L P_{i t}}{R L P_{F t}}$, where $R L P$ of the technological frontier firm $F$ is proxied by the $95 \%$ percentile value of RLP at the NACE three-digit industry level in both countries. ${ }^{13}$ The definition of L1.CTF implies that we capture persistence effects. Finally, our productivity estimates control for being part of a group $\left(G P_{i t}\right)$, being located in East Germany for $D E$ $\left(E A S T_{i t}\right)$ and time dummies $\left(D_{t}\right)$. In the estimations, our main focus is on the effect of the human capital and the innovation variables.

Despite the same definitions, one important difference between the German and Dutch variables stems from the measurement of the human capital variable. For $D E$, the skill variable is directly taken from the survey information. For $N L$, this variable is mainly estimated using a matched employer-employee data set (see Section A.1 in Appendix A). In addition to this measurement issue, there are inherent institutional differences between the two countries. In particular, the education system in $D E$ is characterized by a dual system — integrating work-based and school-based learningsupportive for providing high-quality technical skills and for creating a high degree of specialization of skilled employees.

In addition to the main model specification, we perform various robustness checks in Section 6.3. The sensitivity analyses particularly refer to the measurement of the dependent variable and of human capital. We examine two alternative dependent variables. The first is total factor productivity (TFP) which is calculated as the residual of a panel estimation of a standard Cobb-Douglas production function at the industry level. We adopt the system generalized method of moments estimator and use appropriate lags of the input factors as instruments. More specifically, we estimate a production function for each of the 35 NACE two-digit industries in DE and each of the 149 NACE three-digit industries in NL and calculate TFP as $T F P_{i t}=\ln (R L P)_{i t}-\hat{\gamma}_{K} \ln \left(\frac{K}{L}\right)_{i t}-\hat{\gamma}_{M} \ln \left(\frac{M}{L}\right)_{i t}-\hat{\gamma}_{L} \ln L_{i t}-\sum_{t} \hat{\gamma}_{D} D_{t}{ }^{14}$ The second is the 1-year lead of RLP growth (RLPGR), defined as labor productivity growth between year $t$ and $(t+1)$.

Regarding human capital, $H C_{i t}$ is either replaced by (i) a binary variable equaling one if $H C_{i t}$ exceeds the median value of the share of high-skilled labor in industry $j$ (21-industry classification) at time $t$ or (ii) a more detailed decomposition of the workforce. This detailed decomposition is only feasible for $N L$ and splits $L$ into the number of low-skilled, low-medium-skilled, high-medium-skilled, and high-skilled

\footnotetext{
${ }^{13}$ In $D E$, we consider the largest possible population of enterprises included in the MIP. In addition to the response sample, this also includes information from the non-response sample. In total, 84,454 observations from 19,351 enterprises were used for calculating annual CTF during the period 1998-2008. For details on the measurement of CTF in NL, we refer to Section A.2 of Appendix A.

${ }^{14}$ The number of observations for several three-digit industries is insufficient to allow for estimations at a more detailed disaggregation level in $D E$.
} 
employees. ${ }^{15}$ We furthermore investigate whether RLP can be explained by different moments of the industry distribution of human capital intensity (where industries are defined according to the 21-industry classification). In particular, we consider the mean $\left(\right.$ HCmean $\left._{J t}\right)$, the standard deviation $\left(H C s d_{J t}\right)$, the skewness $\left(\right.$ HCskew $\left._{J t}\right)$, and the kurtosis $\left(\right.$ HCkurt $\left._{J t}\right)$ of industry-year distributions of human capital intensity.

Table 2 shows descriptive statistics in the estimation samples for our key variables by country and by industry. Focusing on our dependent and primary explanatory variables, we observe considerable heterogeneity across countries and-within a country-across industries. Except for OS, average $R L P$ is higher for all industries in NL. In manufacturing, RLP (both in levels and growth rates) varies much more across industries in $N L$, while the opposite is true for services. In both countries, average $R L P$ decreases with the level of technological intensity in manufacturing. The same is true for services in $D E$ whereas average $R L P$ is the same in both service industries in NL. Over the period 2000-2008, RLP grows at an average annual rate of $3.6 \%$ in $D E$ and $5.3 \%$ in NL. Except for LT, average RLPGR is significantly higher for all industries in $N L$. The relationship between average $R L P G R$ and technological intensity appears to be hump-shaped in German manufacturing whilst average $R L P G R$ increases with the level of technological intensity in Dutch manufacturing. Average RLPGR is observed to be higher in KIS compared to OS in DE whereas no difference can be detected in $N L$.

The average share of high-skilled labor is 0.19 in $D E$ and 0.26 in NL. A comparable difference in the average proportion of individuals (aged 15-64) with tertiary educational attainment over the period 2000-2008 is reported by Eurostat (2013), i.e. 0.20 in $D E$ and 0.24 in $N L$, which suggests that measurement differences in our human capital variable between the two countries (see supra) do not give any obvious cause for concerns. ${ }^{16}$ We observe considerable heterogeneity across industries. In both countries, high-technology enterprises in both manufacturing and services possess a significantly higher fraction of high-skilled labor compared to their lowtechnology counterparts.

In contrast to human capital, we find that the proportion of innovators, either defined in terms of product innovators or process innovators, and the share of innovative sales (SSPD) are on average higher in DE than in NL. A total of $64 \%$ and $42 \%$ of the enterprises in the German and Dutch sample, respectively, report having process or product innovation. In $D E(N L)$, the proportion of innovators ranges from $38 \%(29 \%)$ in OS to $88 \%(66 \%)$ in HT. The average share of sales due to products new to the market (SSMN) is slightly higher in $N L$, whereas the average share of sales due to products new to the firm only (SSFN) is much higher in DE.

\footnotetext{
${ }^{15}$ Details on the definition of the four skill types are provided in Section A.1 of Appendix A.

${ }^{16}$ Corroborative evidence on $N L$ outperforming $D E$ in terms of skill levels based on international test scores is given in Minne et al. (2007).
} 


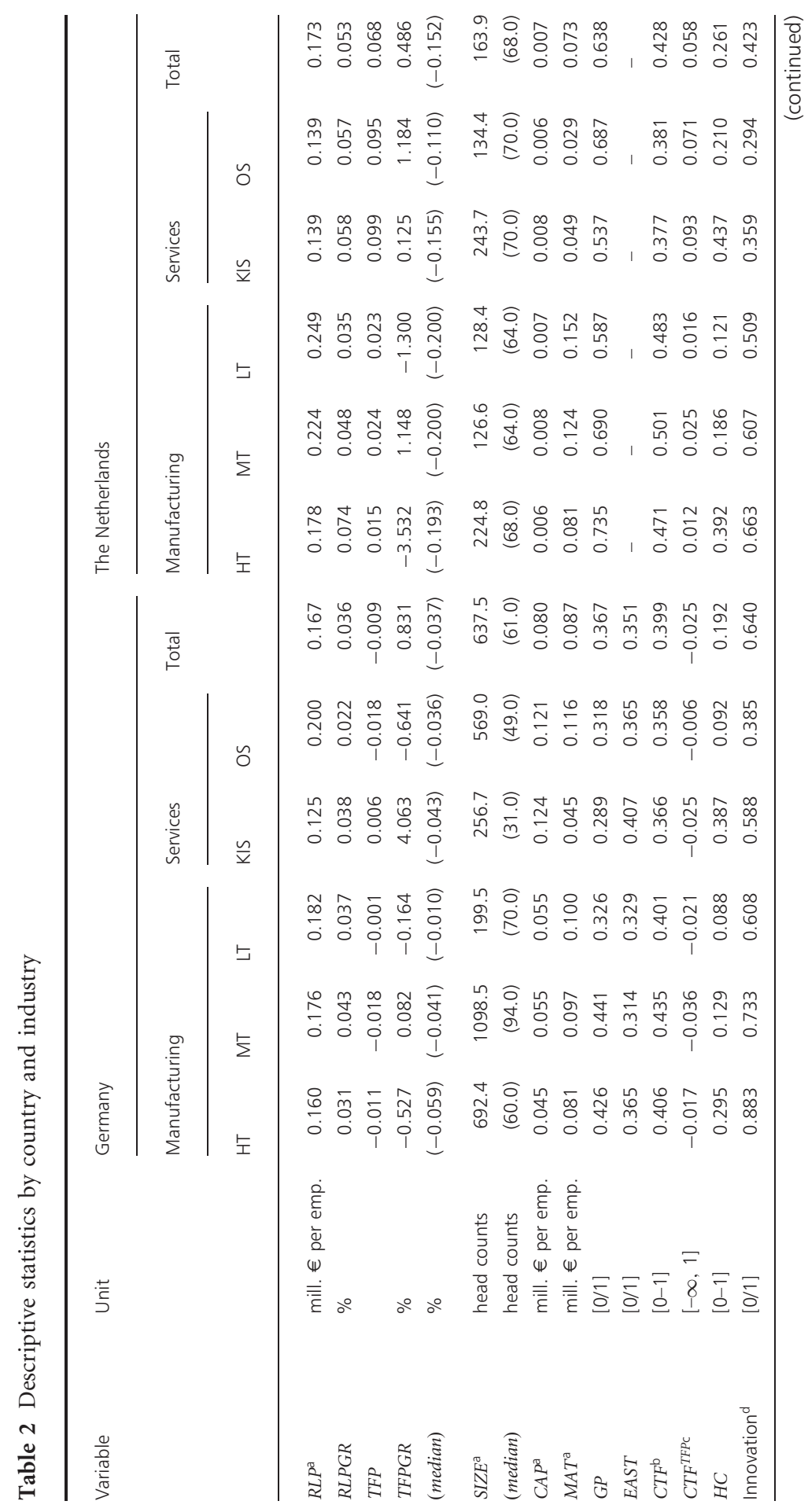




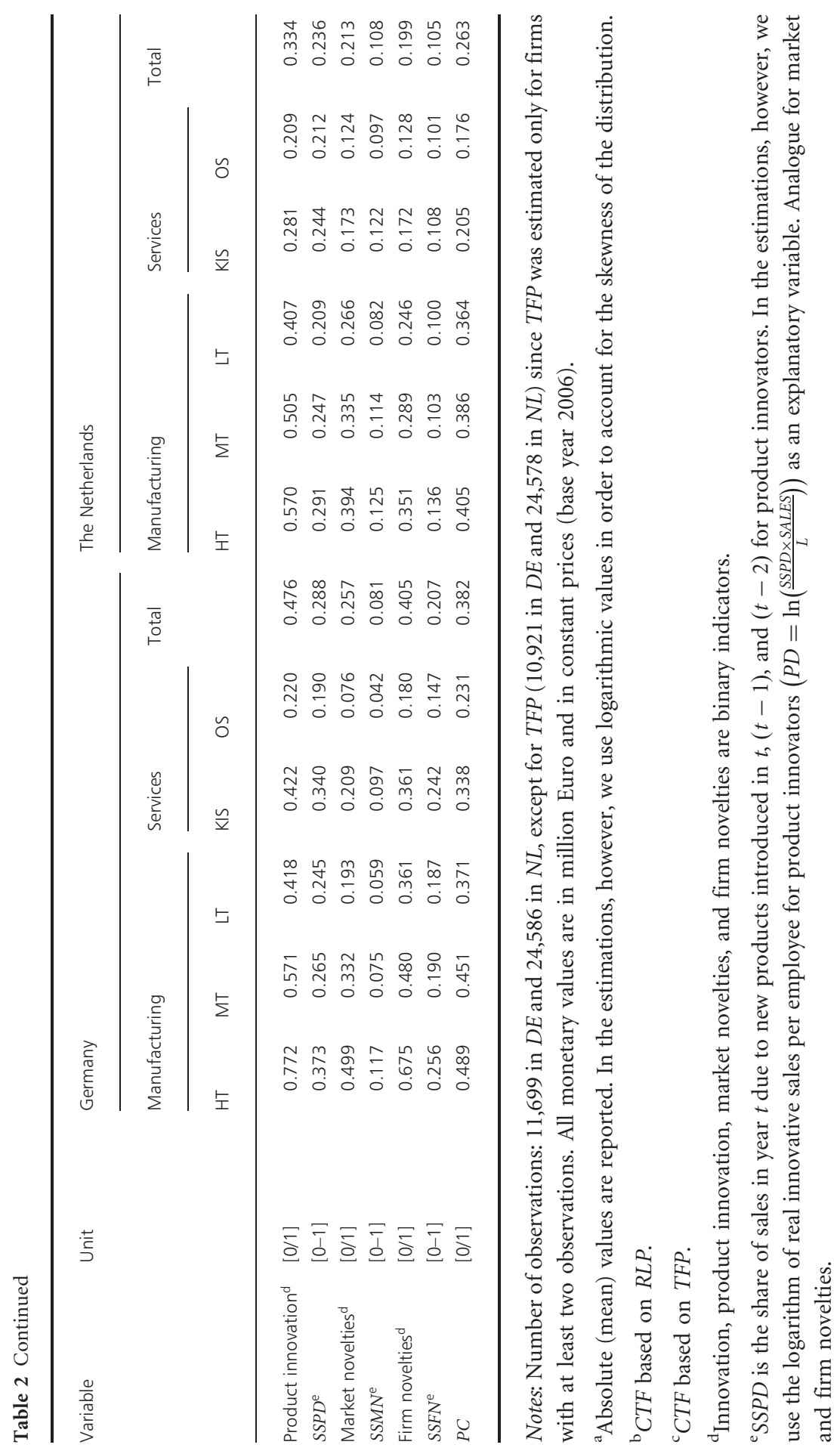


Comparing the different industries across countries reveals a clear pattern: the proportion of product and process innovators is higher in all German industries whilst the opposite is true for the proportion of enterprises having introduced market novelties in LT and OS. Focusing on innovation performance, the share of innovative sales is higher in all German industries. Looking at the different types of product innovation, however, the numbers reveal that the share of sales due to market novelties is considerably higher in all Dutch industries, suggesting that innovations are more radical in $N L$.

\section{Distributions of human capital intensity, innovation, and productivity: some stylized facts}

The productivity literature provides ample evidence that performance in terms of productivity is highly skewed across firms and that this heterogeneity is persistent over time (see Bartelsman and Doms, 2000 for a survey). This observation implies that persistent market dominance of firms is a pervasive fact in technologically advanced countries (e.g. Clements and Ohashi, 2005). The ubiquity of firm-level productivity variation and persistence in itself has spurred research into the underlying factors shaping the firm productivity distribution (see Syverson, 2011 for a survey). In this study, we are particularly interested in the role of human capital and innovation in boosting productivity, both across countries and across industries.

This section presents some stylized facts on human capital intensity, innovation, and productivity in both countries which serve as the backbone of the econometric analysis. More specifically, we provide a detailed comparison of the distributions of human capital intensity, innovation, and productivity across the two countries and across industries. When discussing the moments of these distributions, we take the standard normal distribution as the benchmark.

\subsection{Human capital intensity distribution}

Graph 1 presents the kernel density estimates of the distributions of human capital intensity by country and by industry. Table 3 reports the moments (mean, variance, skewness, and kurtosis) of the corresponding distributions. ${ }^{17}$ Focusing on crosscountry differences, the average share of high-skilled employees is significantly higher in all Dutch industries. The difference varies between 4.6 and 10.1 percentage points in HT and LT, respectively. This result is in line with OECD statistics on

\footnotetext{
${ }^{17}$ When interpreting Graph 1 and Table 3, one should keep in mind that if all firms used human capital at the same intensity, the distribution of human capital intensity would degenerate at one mass point.
} 

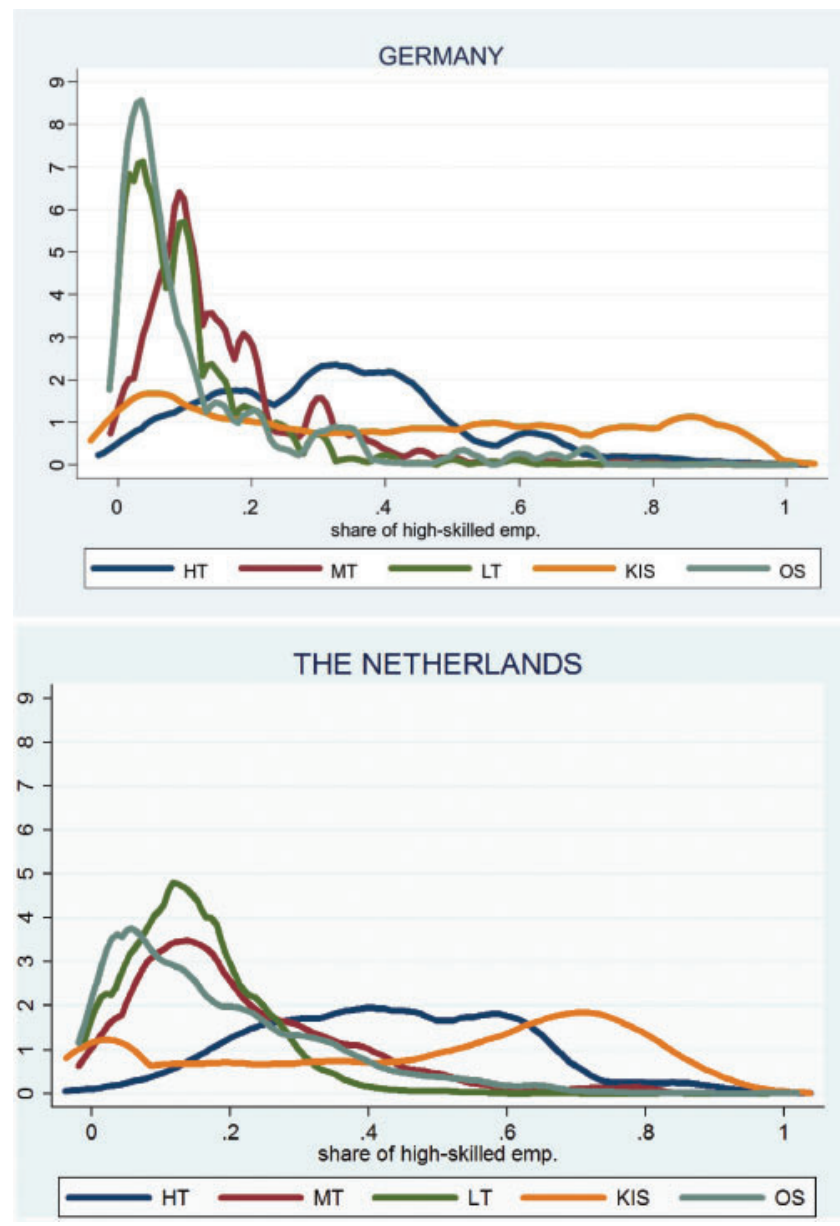

Graph 1 Distribution of human capital intensity, by country and industry

tertiary educational attainment levels in both countries. During the period 20002006 about $23 \%-24 \%$ of the German population aged between 25 and 64 attained a tertiary degree. In $N L$, this proportion rose from $23.4 \%$ to $30.2 \%$ in the same period (OECD, 2009). We observe considerably higher dispersion in all German industries, suggesting more inequality in the distribution of human capital intensity in $D E$, as indicated by the coefficient of variation. In $D E$, the distribution of human capital intensity shows a right-skewed shape in all industries. In $N L$, we observe the same pattern, except for KIS where the mass of the distribution of human capital intensity is concentrated on the right. The positive skewness is significantly larger in all German industries. In both countries, the distribution of human capital intensity appears to be heavy-tailed in MT and LT and OS, as indicated by the positive excess 
Table 3 Distribution of human capital intensity 2000-2008, by country and industry

\begin{tabular}{|c|c|c|c|c|c|c|c|c|c|c|c|c|}
\hline \multirow[t]{2}{*}{$\mathrm{HC}$} & \multicolumn{6}{|c|}{ Germany } & \multicolumn{6}{|c|}{ The Netherlands } \\
\hline & $\mathrm{HT}$ & MT & LT & KIS & OS & Total & HT & MT & LT & KIS & OS & Total \\
\hline Mean & 0.328 & 0.157 & 0.101 & 0.425 & 0.119 & 0.216 & 0.429 & 0.214 & 0.147 & 0.481 & 0.182 & 0.290 \\
\hline SD & 0.186 & 0.129 & 0.109 & 0.306 & 0.154 & 0.220 & 0.182 & 0.155 & 0.093 & 0.282 & 0.154 & 0.240 \\
\hline Skewness & 0.545 & 2.045 & 2.836 & 0.153 & 2.291 & 1.518 & 0.142 & 1.234 & 0.974 & -0.409 & 1.156 & 0.854 \\
\hline Kurtosis & 3.225 & 9.226 & 15.224 & 1.647 & 8.270 & 4.670 & 2.653 & 4.802 & 5.841 & 1.861 & 4.192 & 2.641 \\
\hline CV & 0.567 & 0.819 & 1.075 & 0.720 & 1.293 & 1.018 & 0.425 & 0.726 & 0.633 & 0.587 & 0.850 & 0.828 \\
\hline p10 & 0.100 & 0.040 & 0.010 & 0.030 & 0.010 & 0.020 & 0.198 & 0.052 & 0.034 & 0.0001 & 0.022 & 0.038 \\
\hline p25 & 0.190 & 0.080 & 0.030 & 0.140 & 0.028 & 0.060 & 0.289 & 0.103 & 0.081 & 0.230 & 0.060 & 0.105 \\
\hline p50 & 0.320 & 0.120 & 0.071 & 0.410 & 0.060 & 0.133 & 0.421 & 0.175 & 0.135 & 0.558 & 0.140 & 0.210 \\
\hline p75 & 0.430 & 0.200 & 0.130 & 0.700 & 0.150 & 0.300 & 0.570 & 0.296 & 0.197 & 0.714 & 0.268 & 0.436 \\
\hline p90 & 0.600 & 0.320 & 0.220 & 0.880 & 0.313 & 0.560 & 0.648 & 0.419 & 0.267 & 0.800 & 0.396 & 0.689 \\
\hline
\end{tabular}

Notes: Human capital is measured as the share of high-skilled employees, defined as employees having a college or university degree.

kurtosis. ${ }^{18}$ In those German industries, the positive excess kurtosis is much higher than in the Dutch counterparts, implying that more of the variance is due to extreme deviations. In line with expectations, HT and KIS are characterized by light-tailed distributions of human capital intensity.

Focusing on industry differences, the average share of high-skilled employees is the lowest in LT and the highest in KIS followed by HT. The coefficient of variation, however, shows that human capital intensity is less dispersed in HT than in KIS. The highest dispersion of human capital intensity among firms is observed in OS. This industry distribution pattern holds for both countries. As already mentioned, the human capital intensity distribution is right-skewed in all industries, except for the Dutch KIS. It is characterized by the highest positive skewness in LT in both countries whereas the distribution of human capital intensity in KIS shows a light right-skewed shape in $D E$ and even a left-skewed shape in $N L$. The distribution of human capital intensity is light-tailed in KIS whilst most heavily tailed in LT in both countries.

\subsection{Innovation performance distribution}

While human capital intensity is consistently higher in $N L$ compared to $D E$, we observe the opposite pattern with respect to innovation performance. Graph 2

\footnotetext{
${ }^{18}$ In order to compare the distribution with a standard normal distribution which has a kurtosis $(k)$ of $k=3$, the excess kurtosis $\left(k^{e}\right)$ is defined as $k^{e}=k-3$.
} 

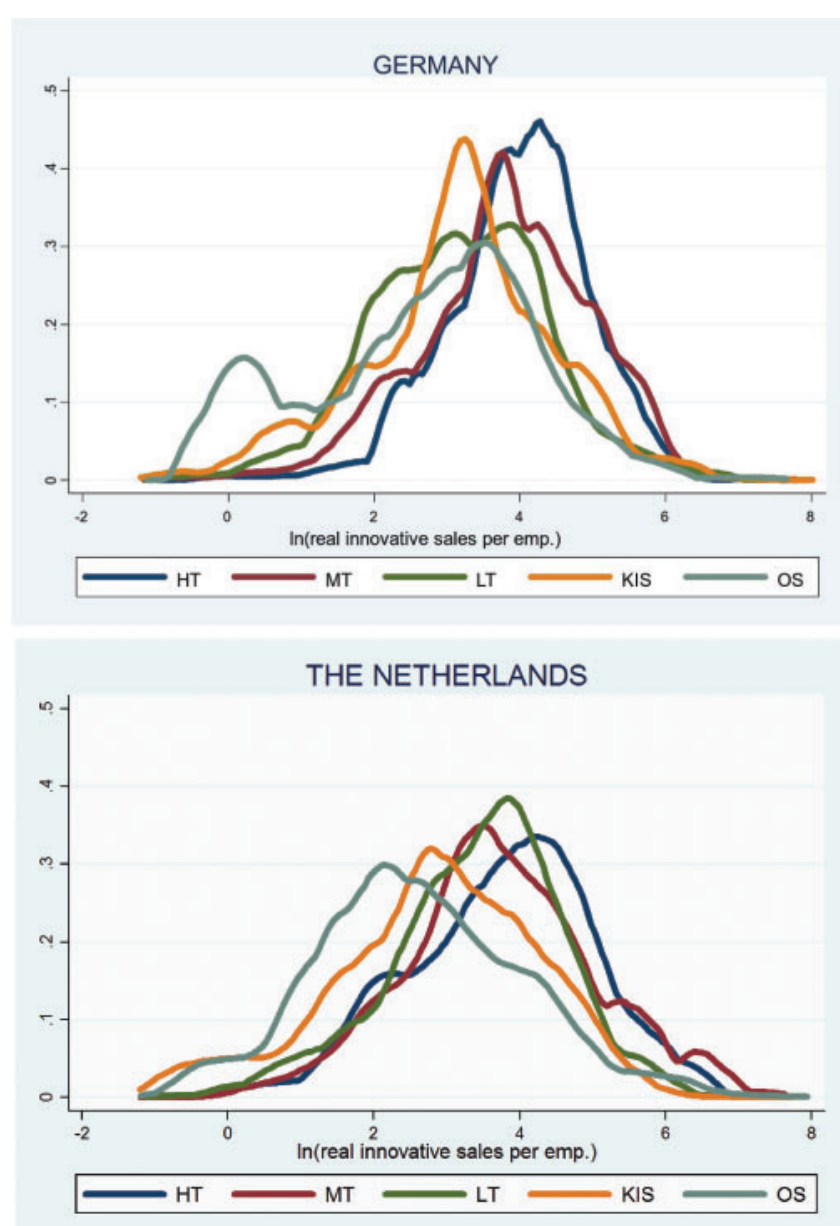

Graph 2 Innovation performance distribution, by country and industry

presents the kernel density estimates of the innovation performance distributions for product innovators by country and by industry. Table 4 completes this picture by reporting the related moments of the distributions. As mentioned above, innovation performance is measured by the logarithm of real innovative sales per employee for product innovators.

Interesting cross-country and cross-industry differences show up. Innovation performance is on average higher and at the same time less dispersed in all German industries, except for LT. The mass of the distribution is concentrated on the right in all German industries (left-skewed). The same holds for the Dutch counterparts, except for MT. The left-skewness is more pronounced in HT and OS in DE and in LT and KIS in NL. In contrast to the mean and dispersion, we find mixed results 
Table 4 Innovation performance distribution 2000-2008, by country and industry

\begin{tabular}{|c|c|c|c|c|c|c|c|c|c|c|c|c|}
\hline \multirow[t]{2}{*}{ PD } & \multicolumn{6}{|c|}{ Germany } & \multicolumn{6}{|c|}{ The Netherlands } \\
\hline & $\mathrm{HT}$ & MT & LT & KIS & OS & Total & HT & MT & LT & KIS & OS & Total \\
\hline Mean & 3.976 & 3.803 & 3.181 & 3.166 & 2.668 & 3.578 & 3.757 & 3.755 & 3.412 & 2.807 & 2.522 & 3.394 \\
\hline SD & 0.970 & 1.168 & 1.175 & 1.296 & 1.531 & 1.231 & 1.232 & 1.334 & 1.164 & 1.451 & 1.571 & 1.416 \\
\hline Skewness & -0.529 & -0.421 & -0.038 & -0.266 & -0.257 & -0.444 & -0.307 & 0.182 & -0.458 & -0.573 & -0.107 & -0.264 \\
\hline Kurtosis & 3.978 & 3.338 & 3.188 & 3.314 & 2.420 & 3.356 & 2.797 & 3.251 & 3.308 & 3.457 & 3.559 & 3.732 \\
\hline CV & 0.244 & 0.307 & 0.369 & 0.409 & 0.574 & 0.344 & 0.328 & 0.355 & 0.341 & 0.517 & 0.623 & 0.417 \\
\hline p10 & 2.742 & 2.190 & 1.684 & 1.471 & 0.136 & 1.975 & 2.041 & 2.075 & 1.832 & 0.962 & 0.720 & 1.615 \\
\hline p25 & 3.443 & 3.119 & 2.266 & 2.495 & 1.522 & 2.856 & 2.972 & 2.925 & 2.714 & 1.966 & 1.602 & 2.570 \\
\hline p50 & 4.047 & 3.818 & 3.197 & 3.239 & 2.961 & 3.668 & 3.865 & 3.681 & 3.540 & 2.923 & 2.466 & 3.455 \\
\hline p75 & 4.571 & 4.566 & 3.972 & 4.021 & 3.727 & 4.399 & 4.608 & 4.569 & 4.159 & 3.808 & 3.522 & 4.287 \\
\hline p90 & 5.147 & 5.298 & 4.561 & 4.849 & 4.489 & 5.054 & 5.334 & 5.593 & 4.751 & 4.619 & 4.483 & 5.056 \\
\hline
\end{tabular}

Notes: Innovation performance is measured as $\ln$ (real innovative sales per employee) for product innovators where real innovative sales are measured in thousand Euro (in constant prices of 2006).

with respect to the kurtosis. Compared to a standard normal distribution, the innovation performance distribution is more peaked and has longer heavier tails in all German industries, except for OS where we observe a platykurtic distribution. In NL, the distribution is likewise more peaked compared to a standard normal distribution in MT and LT and KIS. This peakedness is less pronounced in MT in NL but it is stronger than in $D E$ in the latter two industries. In contrast, the excess kurtosis is negative in HT in $N L$, indicating a relatively flat distribution.

Focusing on industry differences, we observe the same industry ranking in terms of average innovation performance in both countries. That is, average innovation performance is the highest in HT and the lowest in OS. At the same time, innovation performance is less dispersed in HT and most widely dispersed in OS in both countries. As already mentioned, the distribution is left-skewed in all German industries. The negative skewness is the highest in HT and the lowest-almost symmetric-in LT. In $N L$, the innovation performance distribution is most skewed to the left in KIS, followed by LT. In contrast, we observe a right-skewed shape in MT. The kurtosis is the highest in HT and the lowest in OS in DE whilst the opposite holds in $N L$.

\subsection{Labor productivity distribution}

Table 5 reports the moments of the labor productivity distribution by country and by industry. The first part of the table presents the distributional characteristics for all 


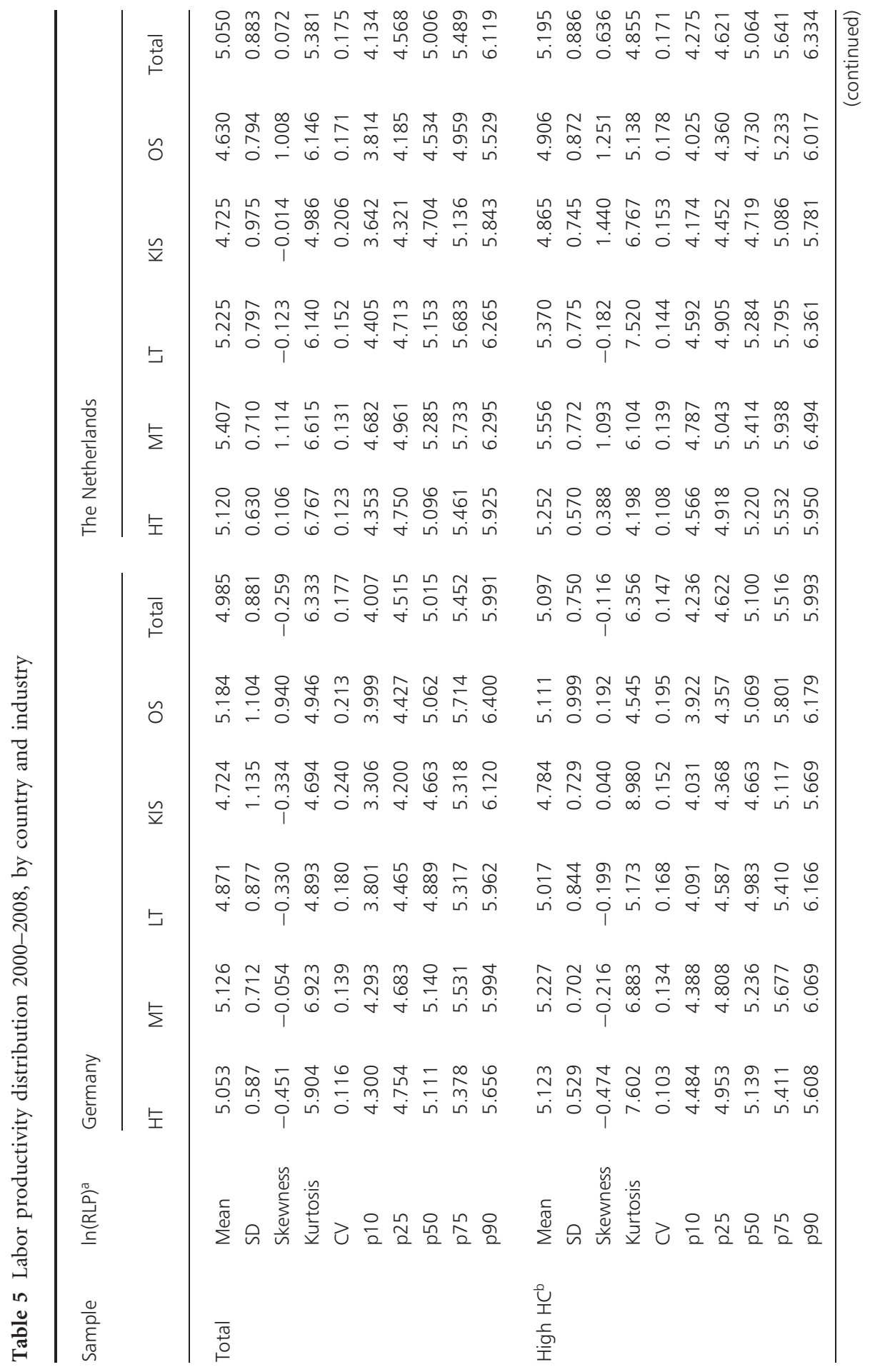




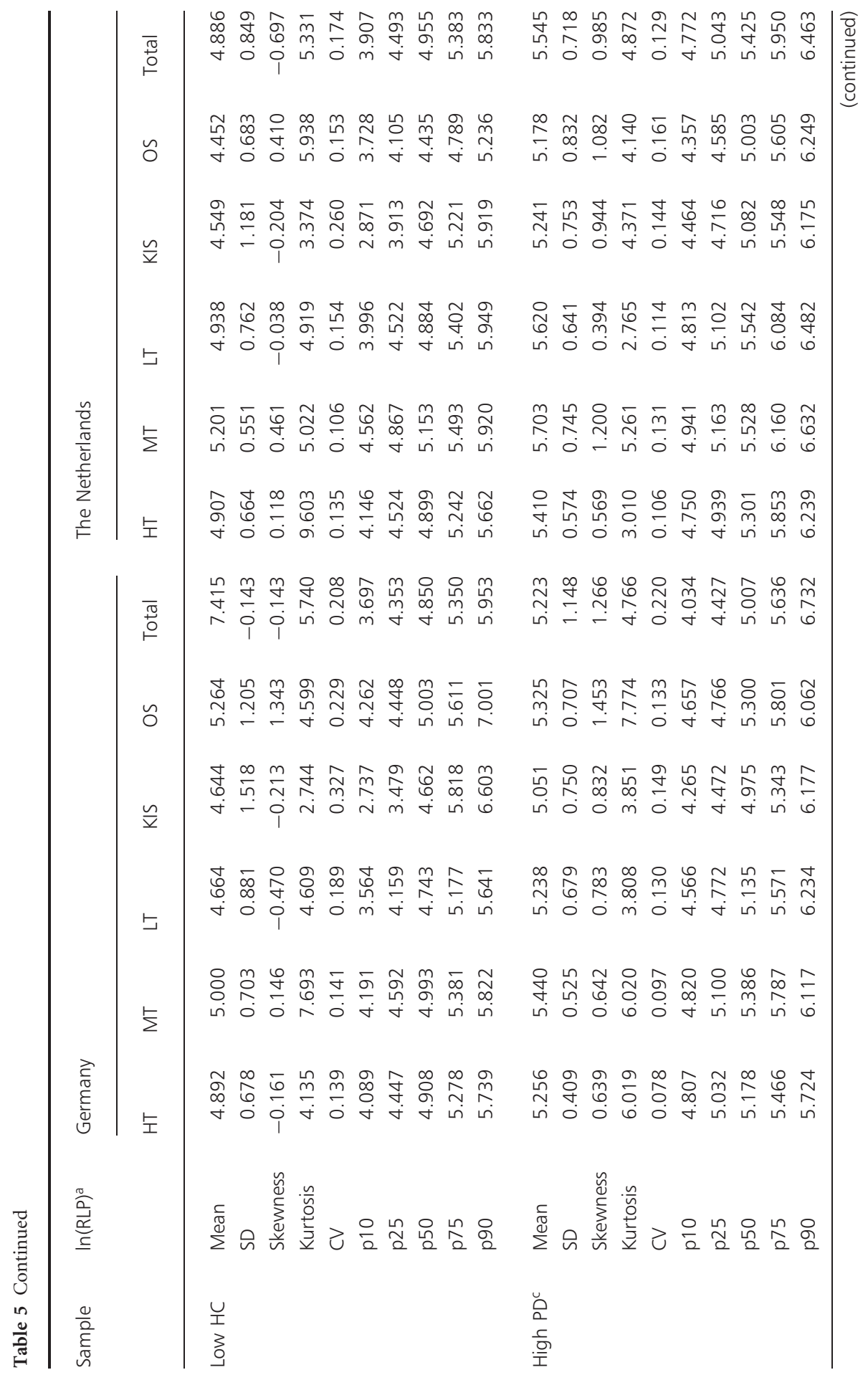




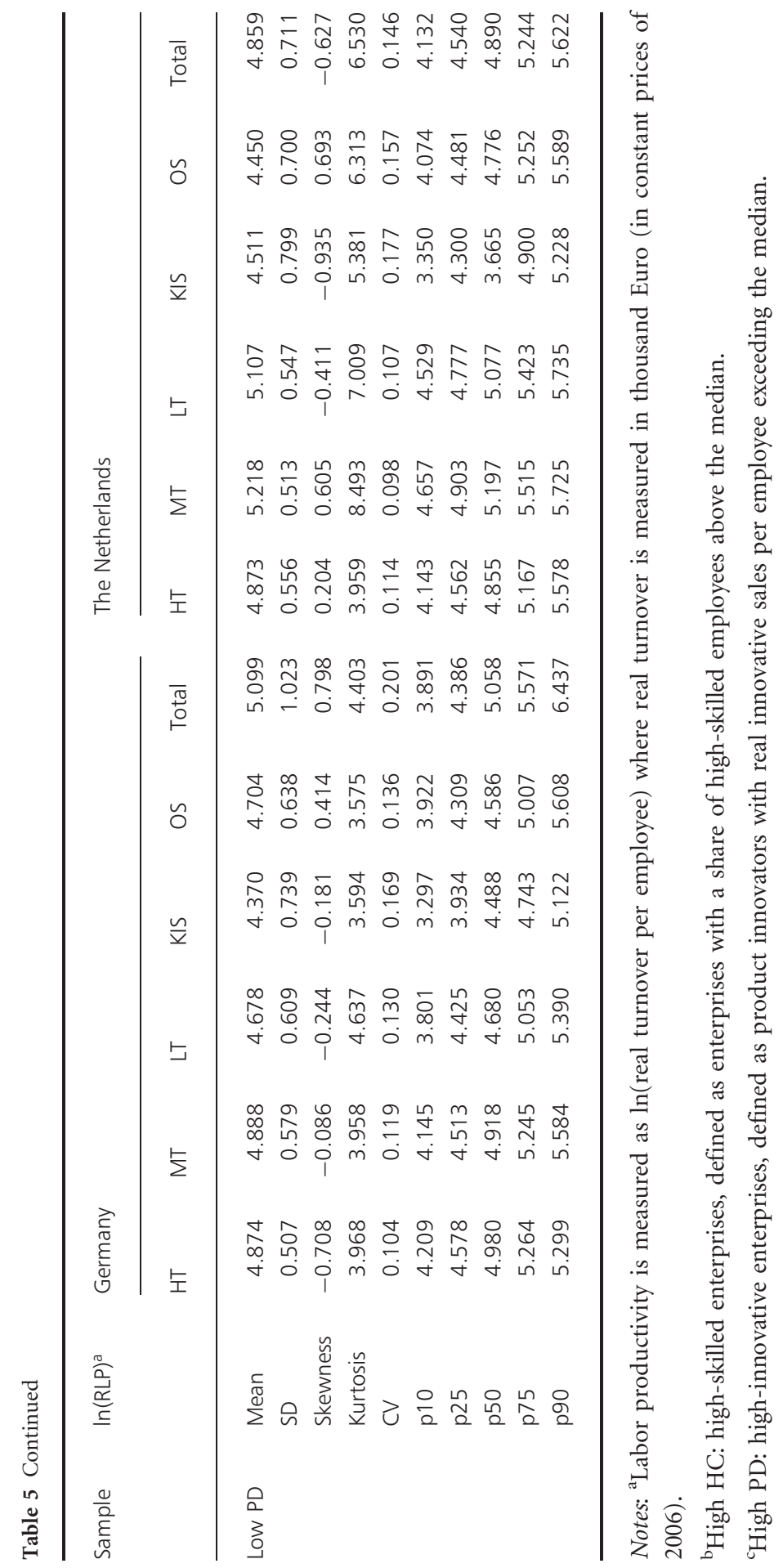


enterprises, the second part distinguishes between high-skilled and low-skilled enterprises, and the third part between enterprises with a high and low innovation performance. ${ }^{19}$ The corresponding labor productivity differences are visualized in Graph 3.

Focusing on cross-country differences, average labor productivity is higher in all manufacturing industries in $N L$ whilst the opposite is true for OS. Labor productivity is less dispersed in all Dutch industries, except for HT. We do not observe a clear pattern with respect to the skewness of the labor productivity distributions across countries. In LT and KIS, the distribution is left-skewed in both countries and more pronounced so in DE. In HT and MT, we likewise observe a left-skewed distribution in $D E$ whilst it is skewed to the right in $N L$. In contrast, we find a right-skewed distribution in OS in both countries, which is even more pronounced in $N L$. The figures further reveal that the labor productivity distributions consistently have sharper peaks and heavier tails than a standard normal distribution in all industries in both countries. Except for MT, this positive excess kurtosis is higher in all Dutch industries.

Focusing on industry differences, we observe the lowest average labor productivity in KIS in $D E$ and in OS in NL. In contrast, the highest average labor productivity is recorded in OS in DE and in MT in NL. While we do not observe a unified ranking of industries in terms of average productivity in both countries, we find one in terms of dispersion. The lowest dispersion is detected in HT and the highest dispersion in KIS in both countries. Both the coefficient of variation and the difference between the 0.90 and 0.10 quantiles lead to this conclusion. The latter indicates e.g. that the $10 \%$ most productive firms in HT are at least about $3.8(D E)$ to $4.8(N L)$ times more productive than the $10 \%$ least productive firms. The labor productivity distribution is most skewed to the left in HT in DE. Among the left-skewed (right-skewed) distributions in $N L$, we observe the highest negative (positive) skewness in Lowtechnology (Medium-technology) manufacturing. The distribution is leptokurtic in all industries. The lowest positive excess kurtosis is detected in KIS in both countries whilst the highest positive excess kurtosis is recorded in MT in DE and HT in NL.

How can these differences in labor productivity distributions across countries and industries be explained? As already pointed out, we are particularly interested in the role of human capital and innovation in shaping productivity. We therefore also differentiate between low- versus high-skilled and low- versus high-innovative enterprises.

Focusing on the first two moments of the labor productivity distribution in the low- and high-skilled groups, we confirm that average labor productivity is consistently higher in high-skilled enterprises, except for OS in DE. Labor productivity is

\footnotetext{
${ }^{19}$ Enterprises with a share of high-skilled employees above the median are defined as high-skilled enterprises. Likewise, product innovators with real-innovative sales per employee exceeding the median are defined as enterprises with a high innovation performance.
} 

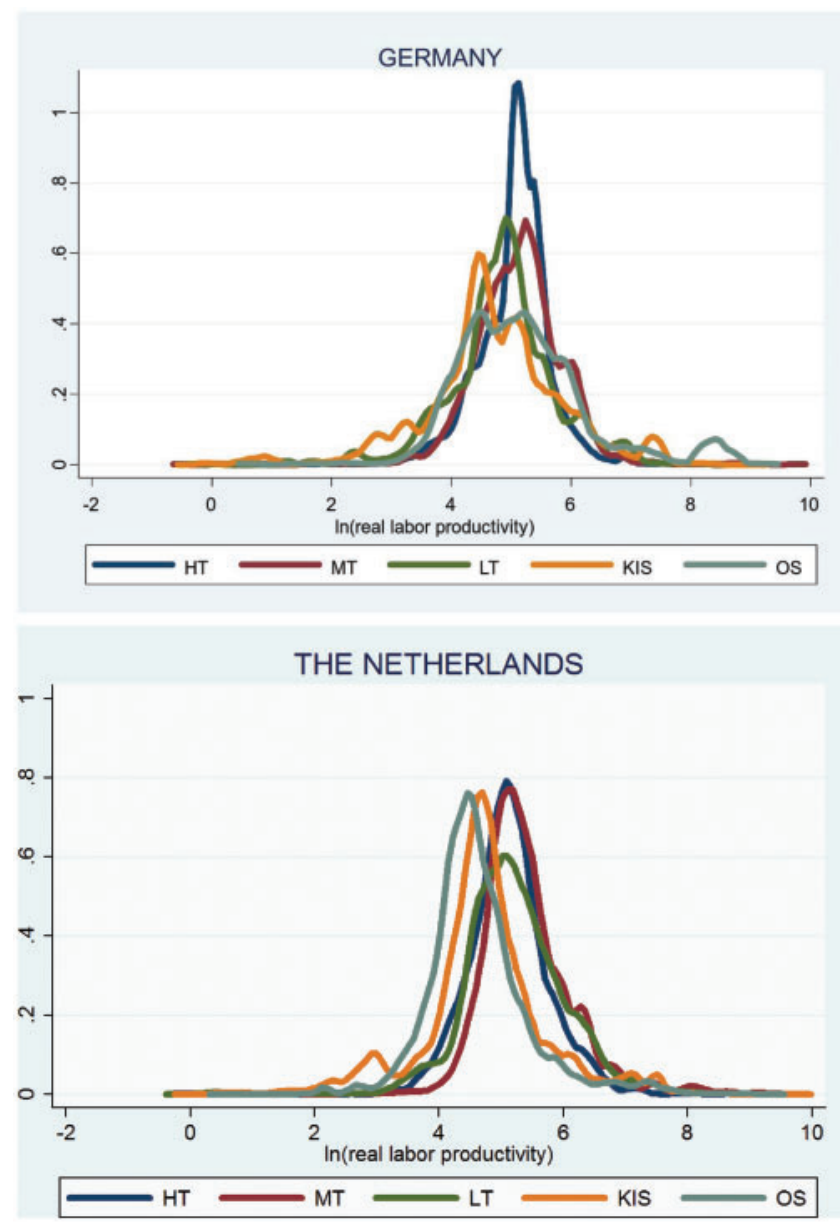

Graph 3 Productivity distribution, by country and industry

less dispersed in high-skilled enterprises in all German industries whilst this does not hold for MT and OS in NL.

Distinguishing enterprises on the basis of their innovation performance, average labor productivity is consistently higher in all high-innovative enterprises in both countries. This is accompanied by a lower dispersion in these enterprises in $D E$, except for LT where no difference in dispersion can be detected. In $N L$, the pattern is more heterogeneous. Labor productivity is less dispersed in high-innovative enterprises in HT and KIS whilst the opposite is true in the other three industries.

Summing up, this section illustrates considerable heterogeneity in productivity across the two countries, between different industries but also between enterprises within an industry. In the following section, we use econometric tools to investigate the role of human capital and innovation in shaping productivity distributions. 


\section{Results}

As a benchmark, we first present average returns to human capital and innovation in Section 6.1. Our main results are reported in Section 6.2, where we first examine firm-level heterogeneity in these returns and then exploit this degree of firm-level heterogeneity in order to describe how differences in human capital and innovation returns shape industry-specific productivity distributions. Section 6.3 presents the results of various robustness checks. We conclude with a discussion of the main results in Section 6.4.

\subsection{Average returns to human capital and innovation}

As a benchmark, we estimate average returns to human capital and innovation using equation (1). Tables 6 and 7 present OLS and FE results, respectively. From Table 6, it follows that the average return to $H C$ is significantly positive in both countries. However, an increase in the share of high-skilled employees, e.g. by 10 percentage points, raises productivity more strongly in $N L(+4.9 \%)$ than in $D E(+1.2 \%)$. One potential explanation for these differential average human capital returns could be that because of the well-developed dual education system in Germany, human capital differences between low- and high-skilled employees are narrower than in the Netherlands. Table 6 also reveals substantial heterogeneity in average HC returns across industries. In $D E$, we observe significantly positive average $H C$ returns in MT and LT and OS but surprisingly not in HT and KIS. Average $H C$ returns are likewise significantly positive in all Dutch industries, except for HT. In both countries, the average $H C$ return decreases with the level of technological intensity of an industry. Except for LT, average $H C$ returns are much higher in all Dutch industries. However, Table 7 shows that average $H C$ returns become insignificant, except for MT in NL when we account for unobserved firm-specific effects. A relatively low withinvariation in the human capital variable might explain this finding.

The OLS estimates also point to significantly positive average returns to product innovation in all industries in both countries. The returns of a $1 \%$ increase in the product innovation performance range from $1.7 \%(\mathrm{MT})$ to $7.7 \%(\mathrm{OS})$ in $D E$ and from $0.6 \%(\mathrm{MT})$ to $5.5 \%$ (OS) in NL. Except for KIS, average returns to product innovation are higher in all German industries. Moreover, service enterprises yield on average a higher return in both countries. These significantly positive average returns to product innovation survive in all industries when we additionally account for firm-specific effects, except for HT in DE. They shrink, however, to a range of about $0.7 \%$ to $2.9 \%$ in both countries.

From Table 6, it follows that average returns to process innovation are significantly negative in both countries and larger in absolute terms in services. ${ }^{20}$ When

\footnotetext{
${ }^{20}$ Admittedly, identifying the effect of process innovation is more difficult in empirical analyses. This is more likely to be the case in service industries since services are more often customized to
} 


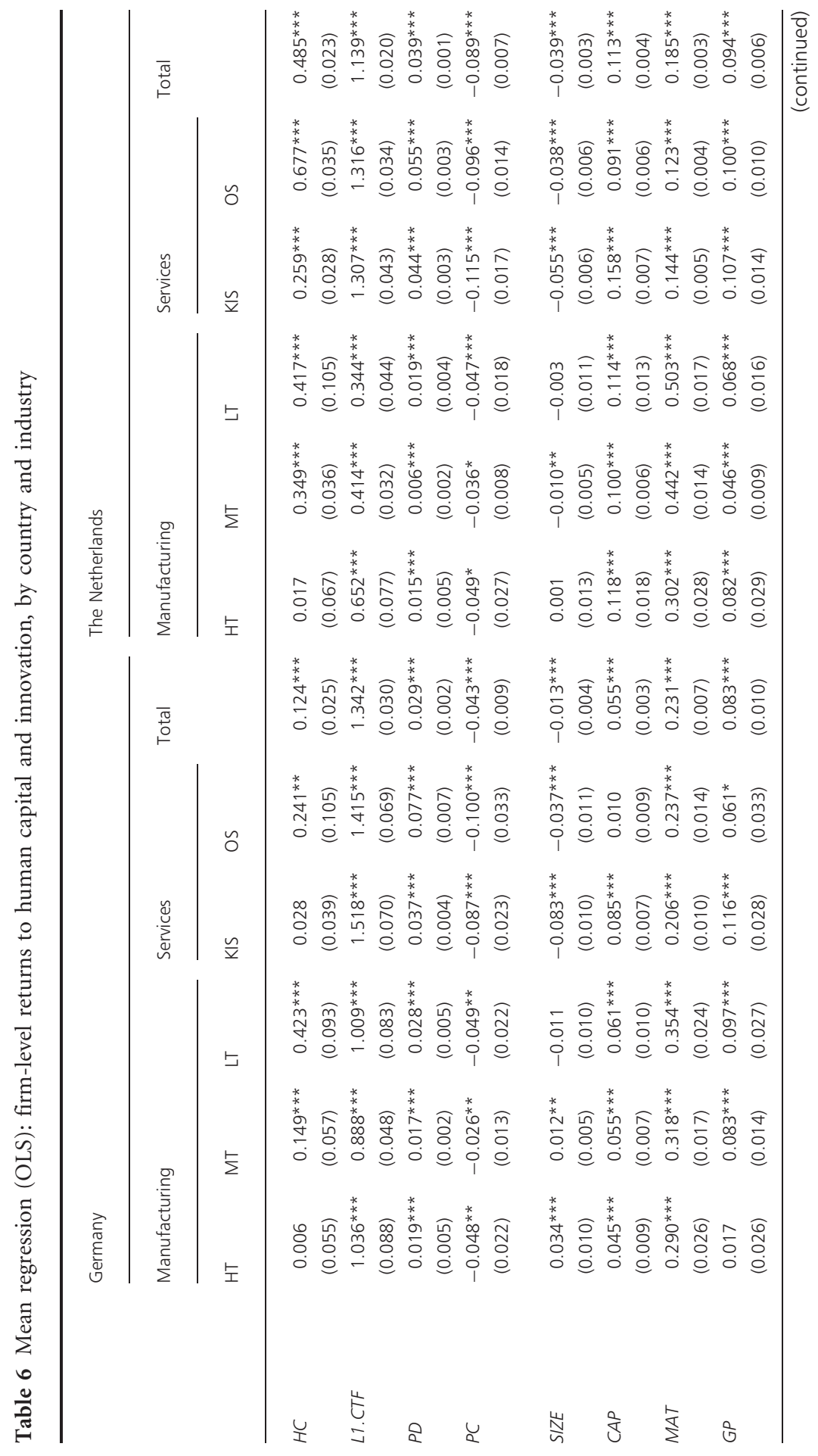




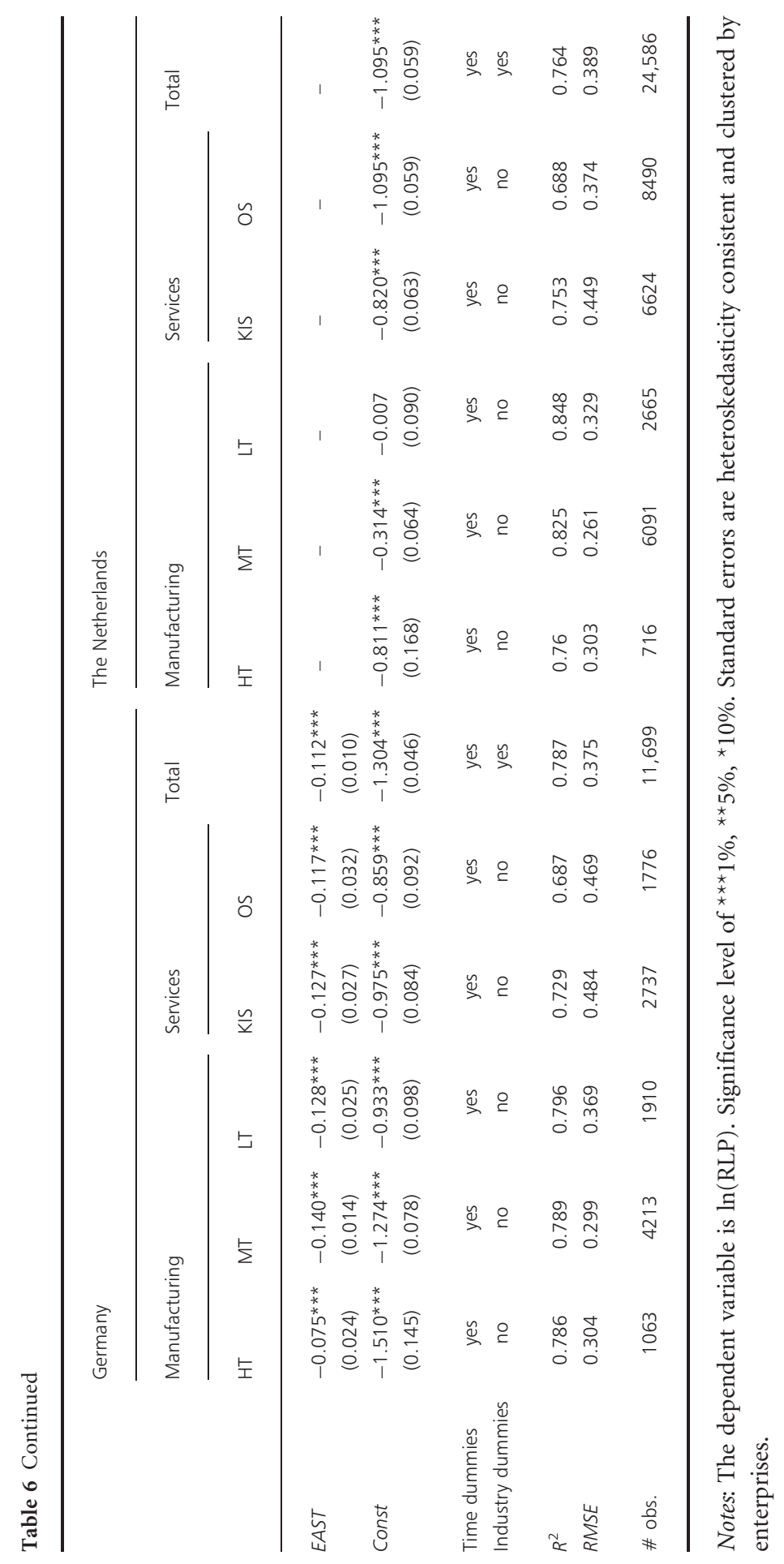




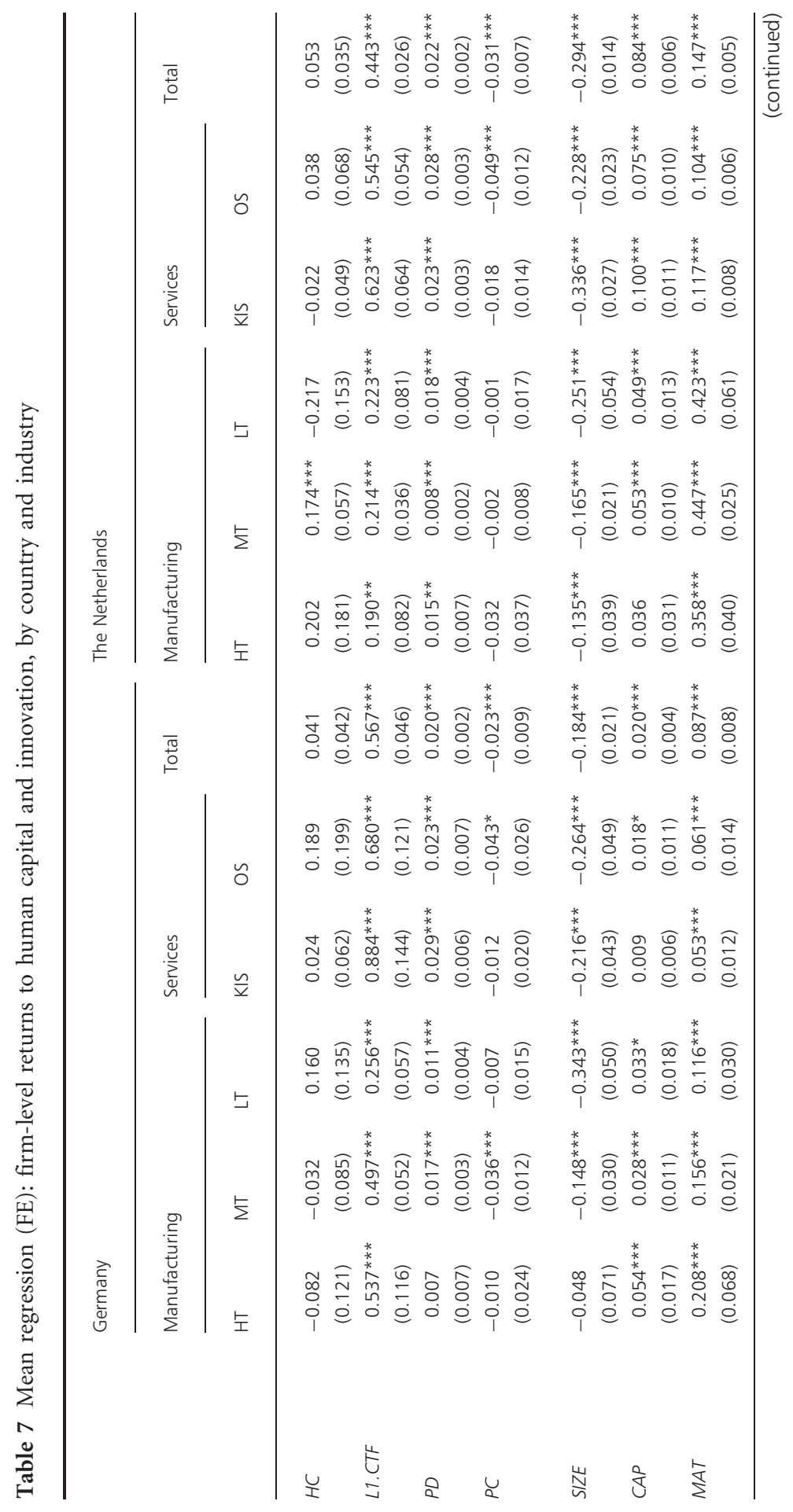




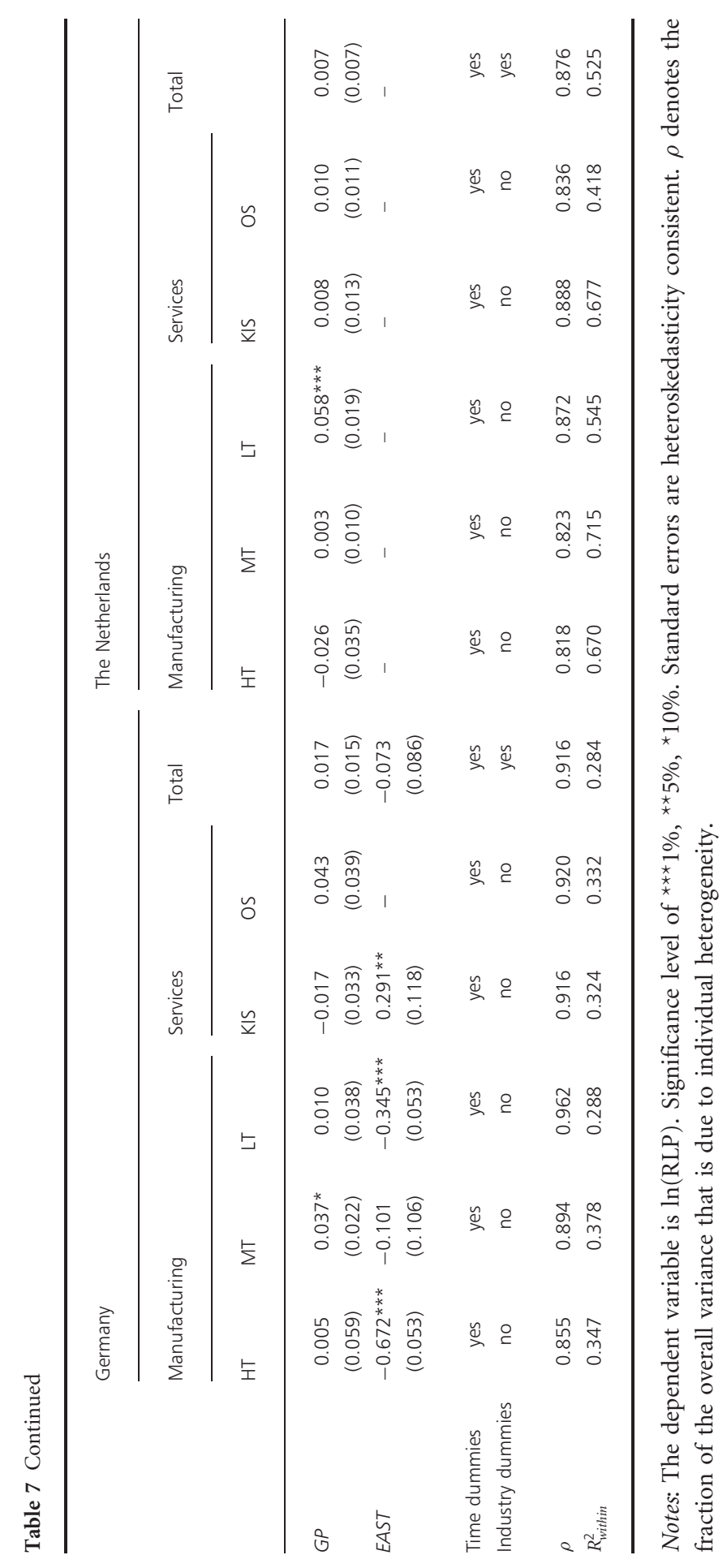


accounting for unobserved firm-specific effects, the negative average returns to $P C$ become generally smaller and they only survive in OS in both countries and in MT in $D E$.

\subsection{Firm-level heterogeneity in returns to human capital and innovation and its impact on industry productivity distributions}

To what extent do firm-level returns to human capital and innovation vary at different points of the conditional productivity distribution and how does this affect the characteristics of industry productivity distributions? We answer these two questions by first neglecting firm-FE and using pooled QRs (Section 6.2.1). In Section 6.2.2, we additionally account for firm-FE in the QRs.

\subsubsection{Not accounting for firm FE}

A. Firm-level heterogeneity in returns to human capital and innovation

Table 8 reports the results of pooled simultaneous-QRs for the 10th, 25th, 50th, 75th, and 90th percentiles of the productivity distribution. ${ }^{21}$ Graphs 4,5 , and 6 display the estimated coefficients for our variables of interest ( $H C, P D$, and $P C$ ) across all quantiles, together with the $95 \%$ confidence intervals. For comparison, the OLS estimates and their 95\% confidence intervals are presented as dashed horizontal lines. Clearly, OLS estimates-calculating "the average effect for the average enterprise"-do not accurately describe the relationship between our main variables and productivity. Let us focus the discussion on our three main variables.

The upper part of Table 8 and Graph 4 reveal a heterogeneous pattern for the effect of human capital upon productivity at different quantiles. We observe heterogeneous productivity effects within an industry, and also discern cross-country and cross-industry differences. In $D E$, the estimates point to an inverted U-shaped influence of human capital along the conditional productivity distribution in HT and LT and OS. This is particularly intriguing for HT where we did not detect any significant average return. This can be explained by the fact that the $10 \%$ least-performing enterprises experience a significantly negative return to $H C$ whereas enterprises along the 40th and 80th percentile of the distribution yield significantly positive returns. In LT and OS, we observe a different pattern: enterprises yield positive but first increasing and than decreasing returns along the full conditional distribution. In MT, we observe increasing marginal returns to human capital as we

specific demands and clearly structured production processes are lacking in many cases. Moreover, many enterprises perform product and process innovation simultaneously. But while the $P D$ variable is continuous, our $P C$ variable is a binary indicator and hence less informative than $P D$. These two reasons may partly explain the finding of a negative $P C$ return.

21 We estimate pooled simultaneous-quantile regressions for $\theta \in\{0.05,0.10,0.20,0.25,0.30$, $0.40,0.50,0.60,0.70,0.75,0.80,0.90,0.95\}$. Table 8 shows results for some selected quantiles. 


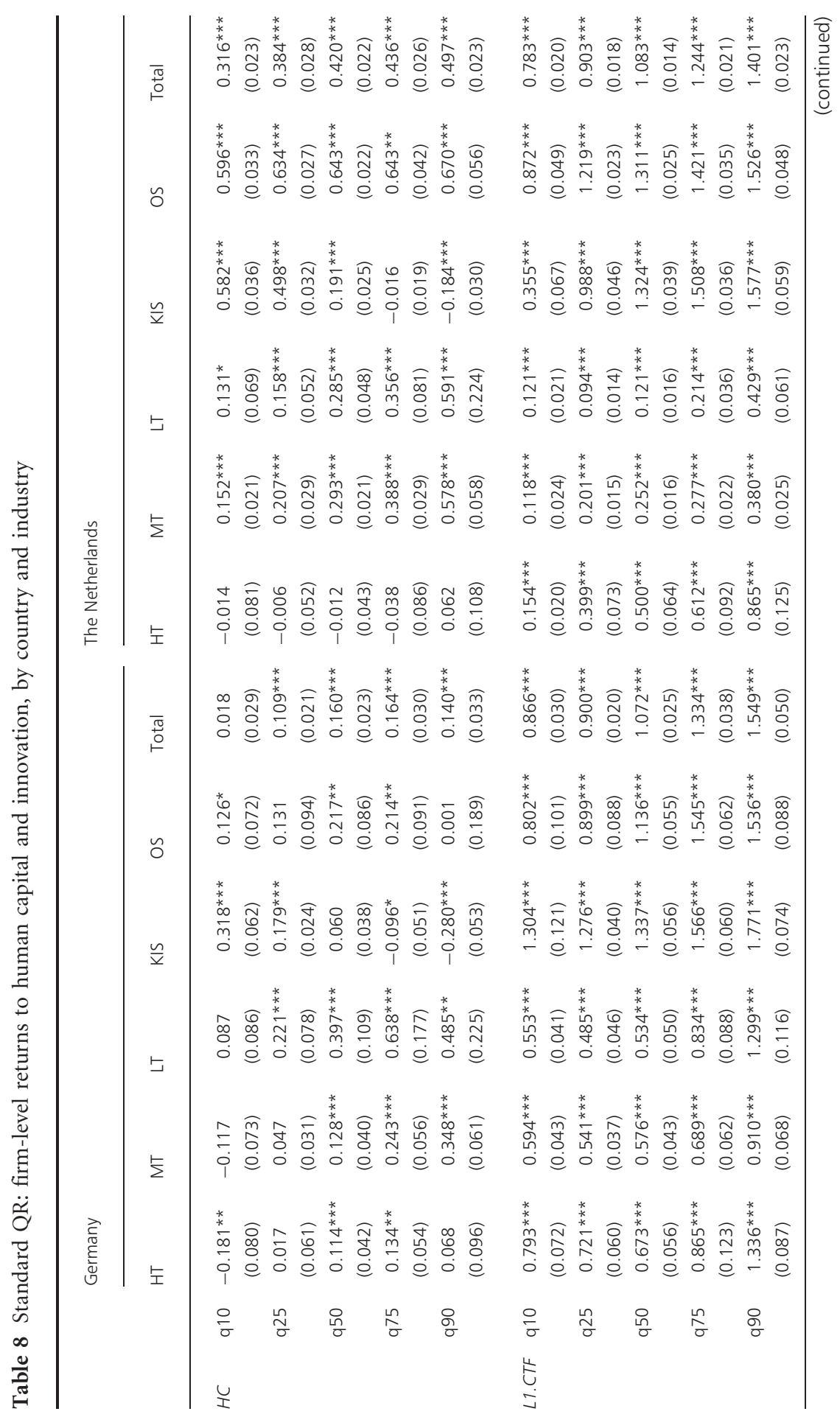




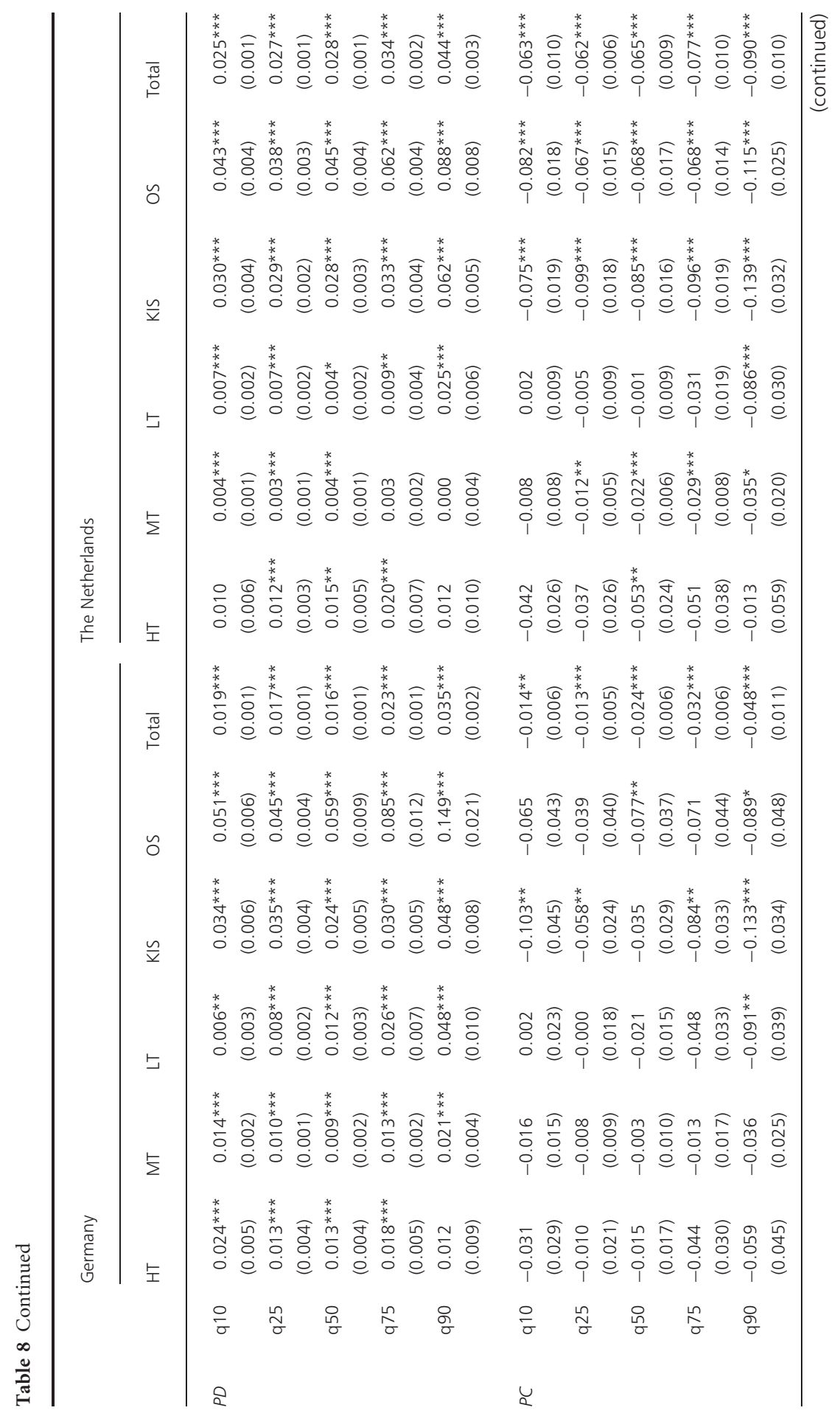




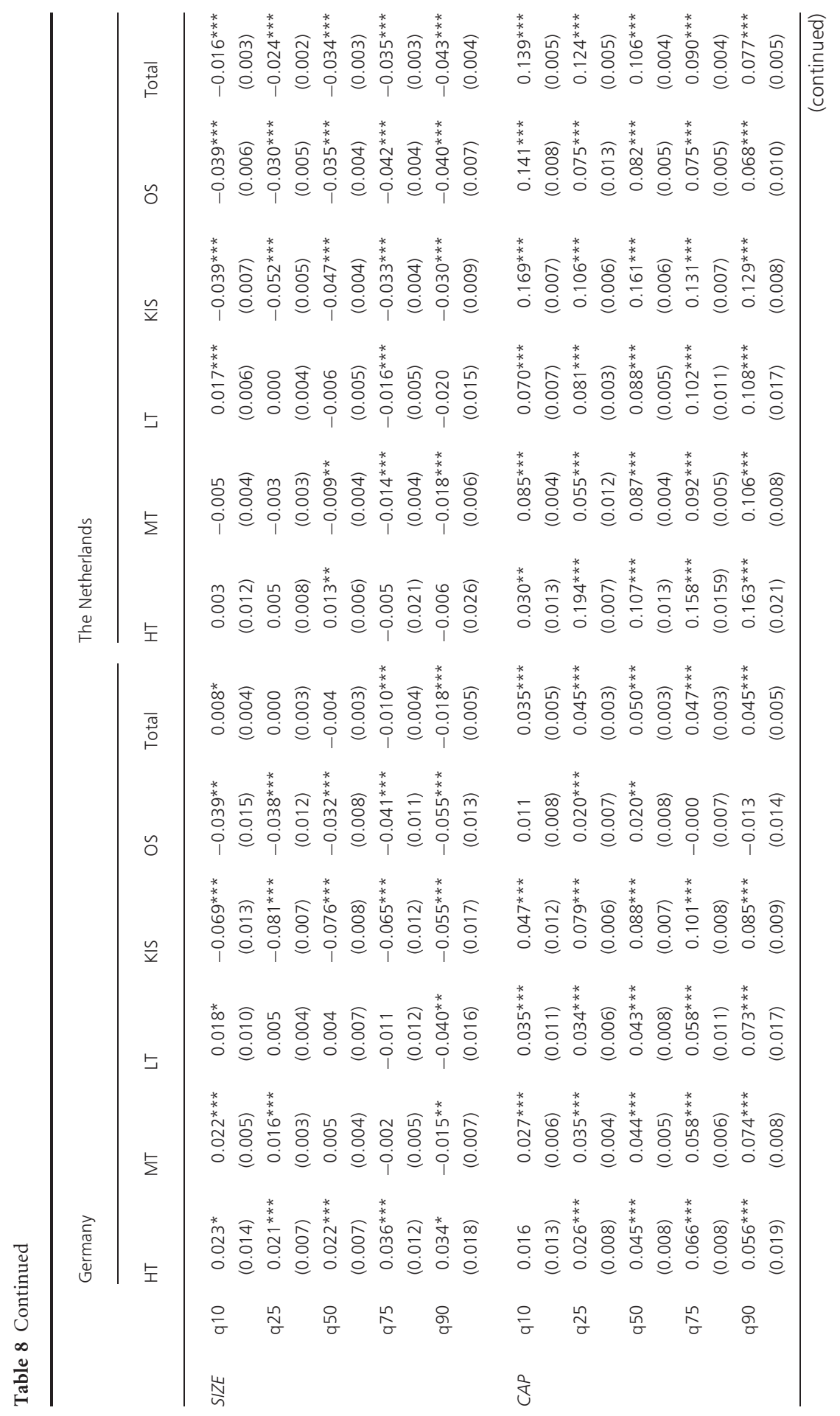




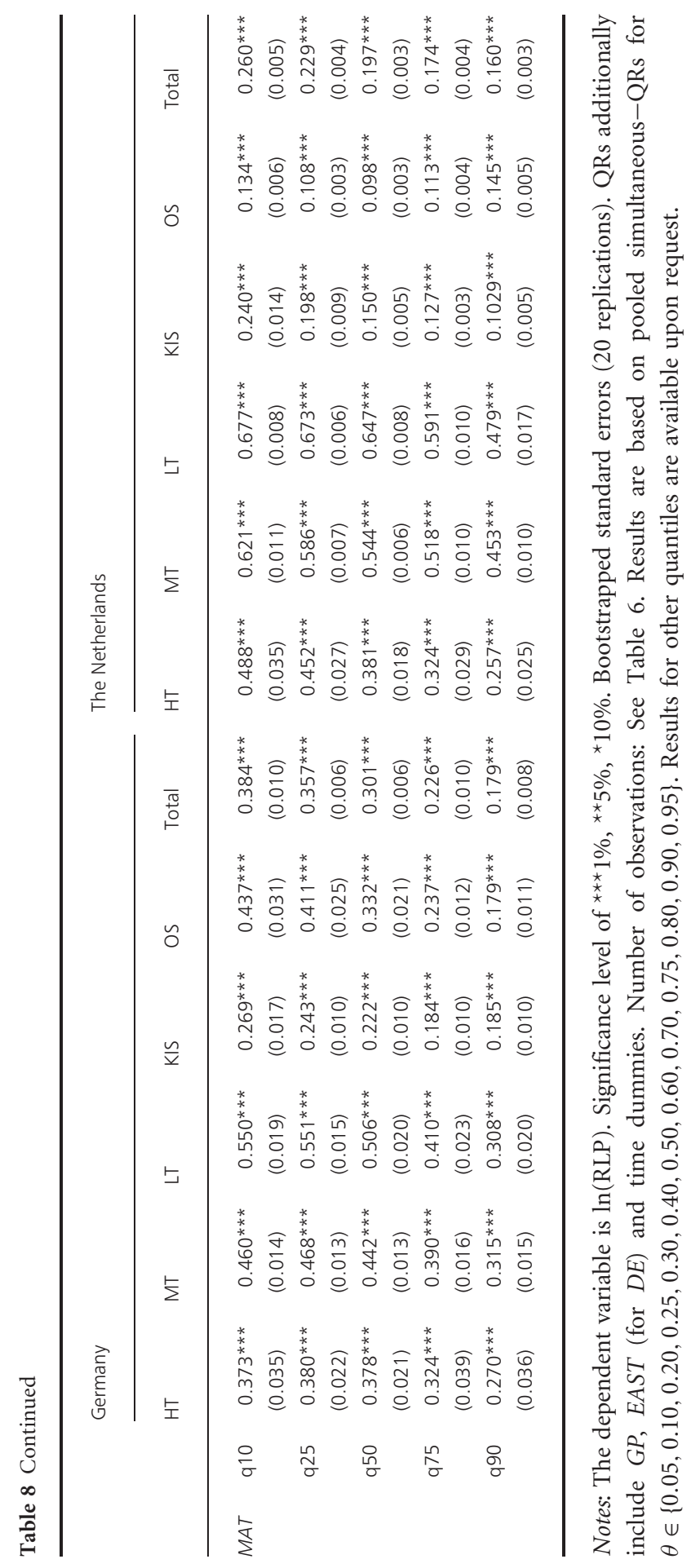



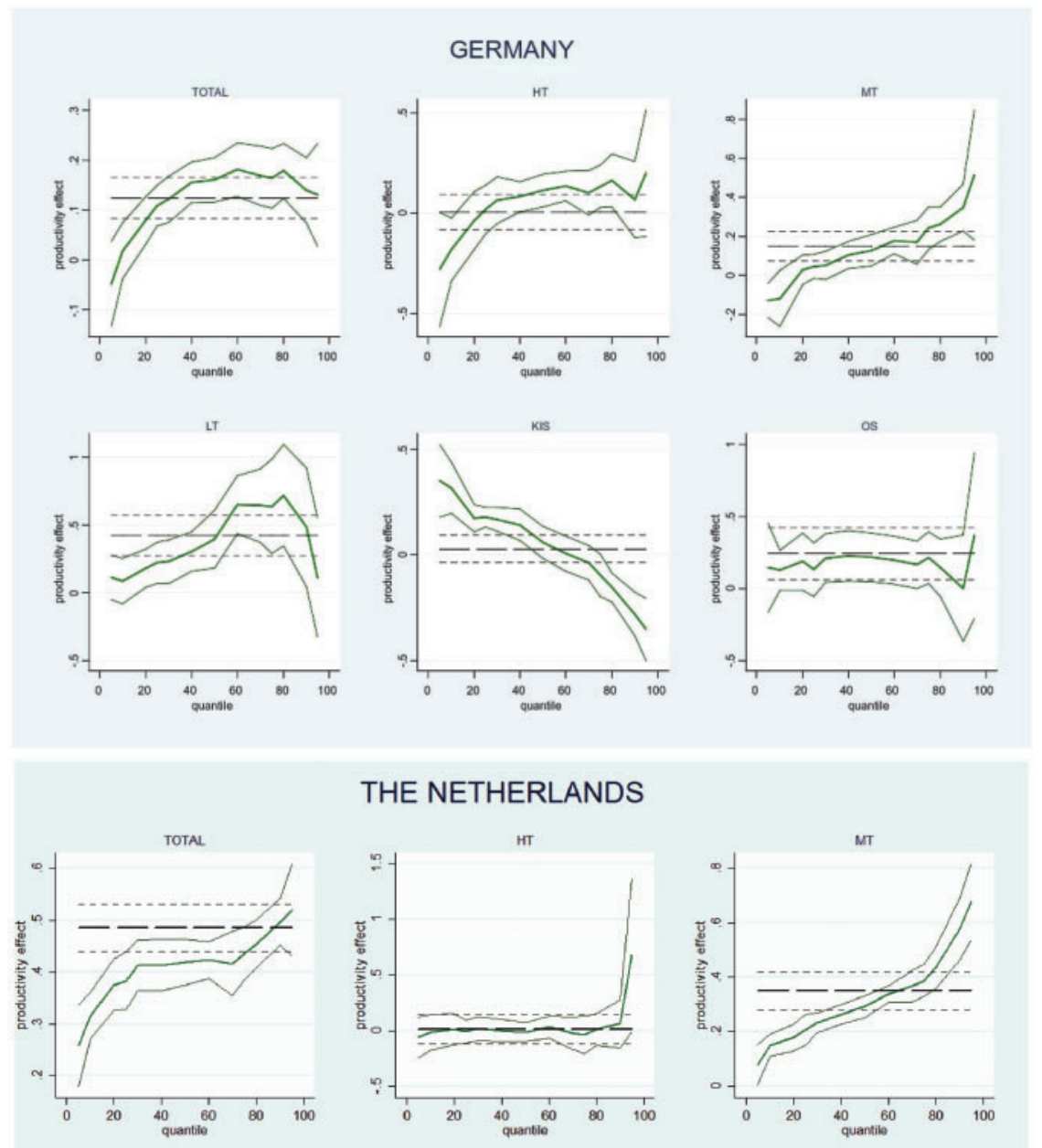

\section{THE NETHERLANDS}
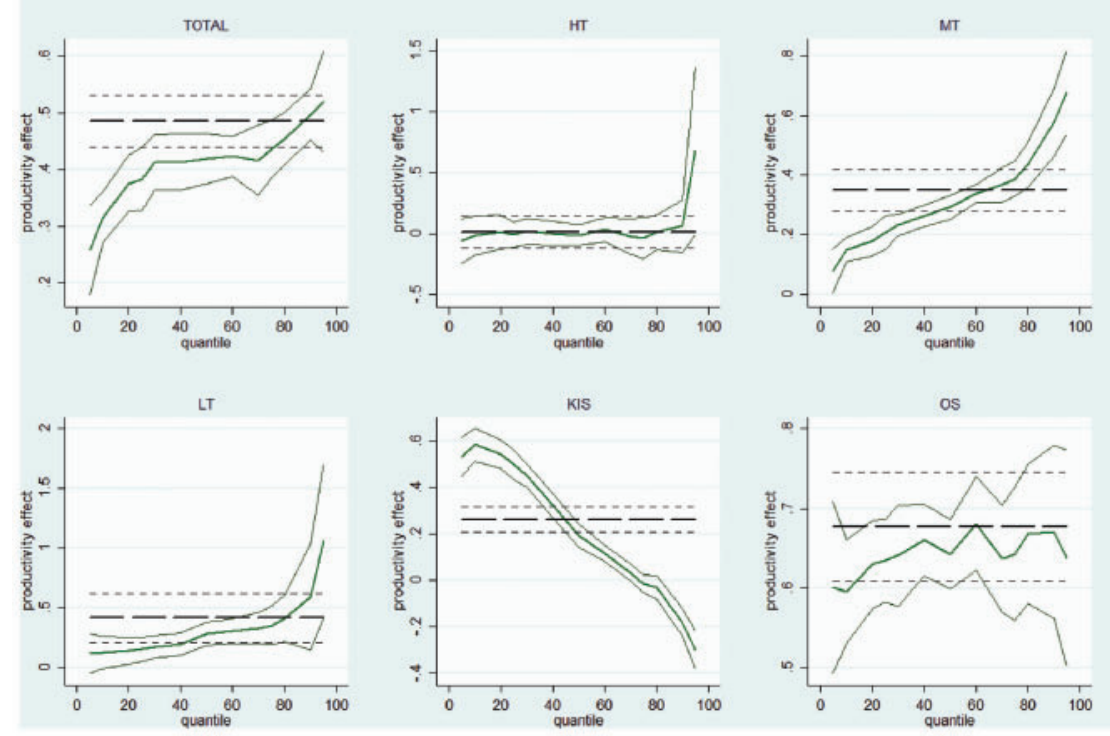

Graph 4 Average and quantile impact of human capital on productivity, by country and industry

Note: Solid lines present coefficient estimates and 95\% confidence intervals of QRs. For comparison, dashed lines mark coefficient estimates and $95 \%$ confidence intervals of the OLS regression. 


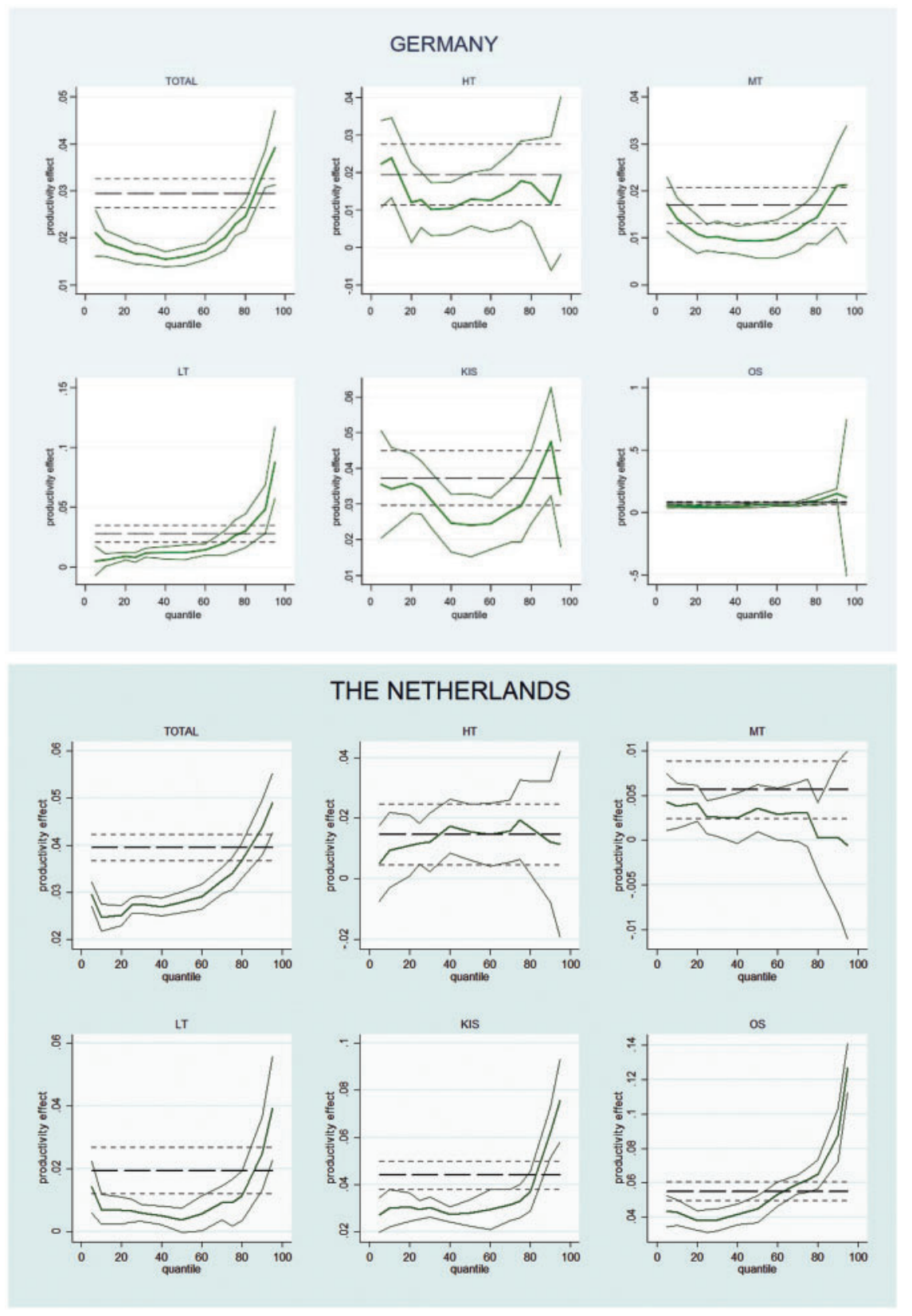

Graph 5 Average and quantile impact of product innovation on productivity, by country and industry

Note: Solid lines present coefficient estimates and 95\% confidence intervals of QRs. For comparison, dashed lines mark coefficient estimates and $95 \%$ confidence intervals of the OLS regression. 


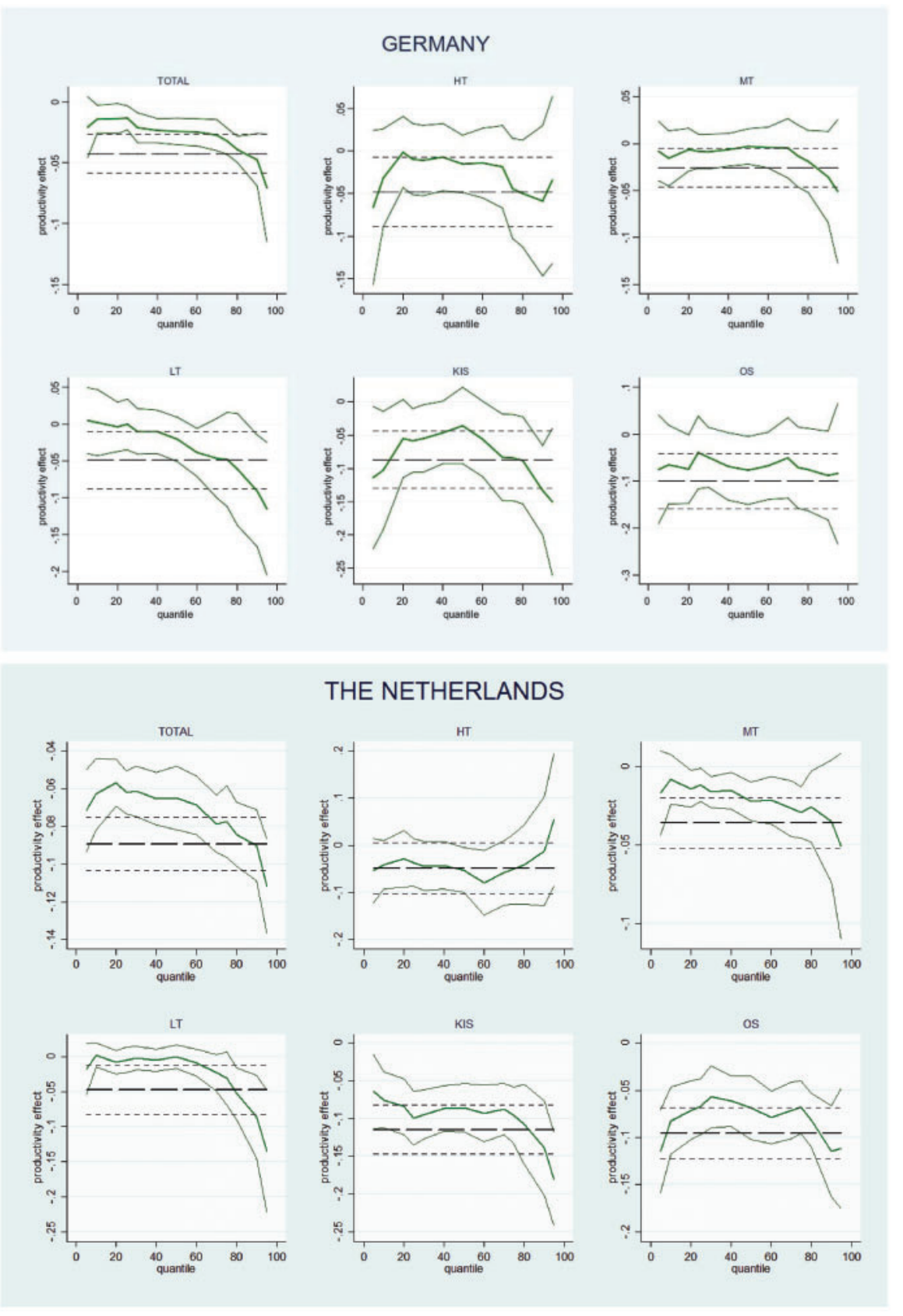

Graph 6 Average and quantile impact of process innovation on productivity, by country and industry

Note: Solid lines present coefficient estimates and 95\% confidence intervals of QRs. For comparison, dashed lines mark coefficient estimates and $95 \%$ confidence intervals of the OLS regression. 
move from lower to upper quantiles. The coefficient for $H C$ starts negative (but insignificant) at the bottom of the distribution and becomes significantly positive from the 40th percentile onward. On the contrary, we surprisingly observe diminishing rates of returns to human capital in KIS. Productivity effects of human capital are significantly positive up to the 40th percentile, become insignificantly positive between the 40th and the 70th percentiles and are significantly negative from the 70th percentile onward.

In contrast to $D E$, we do not find any such nonlinearities in human capital returns in $N L$. We observe increasing rates of returns to human capital as we move up the productivity distribution in MT, LT and OS. In the former two industries, the increase tends to be steep whilst it is modest in the latter. Consistent with the German results, highly diminishing rates of returns to human capital are found in KIS. From the 80th percentile onward, the estimated coefficient for human capital is significantly negative.

In a nutshell, the best-performing enterprises enjoy the highest rates of return to human capital in MT in DE and in MT, LT and OS in NL. This finding provides microeconomic support for the positive complementarity effect between human capital and proximity to the technological frontier as postulated by Vandenbussche et al. (2006). In sharp contrast, the top firms in KIS seem to have the lowest (even negative) human capital returns in both countries, suggesting a negative aforementioned complementarity effect.

The middle part of Table 8 and Graph 5 highlight nonlinearities in the returns to product innovation along the conditional productivity distribution in the majority of industries in both countries. In $D E$, we observe an increase in the rate of returns to product innovation as we move from the lower to the upper quantiles in LT. In all other industries, marginal returns to product innovation follow a $U$-shaped curve.

In $N L$, the $U$-shaped pattern is likewise observed in LT and both service industries. In contrast, a hump-shaped relationship is found in HT with positive but insignificant returns below the 20th and above the 80th percentile. Product innovation returns appear to be very stable in MT, although the estimated coefficient is not significantly different from zero from the 75th percentile onward.

Summing up, the best-performing enterprises enjoy the highest rates of return to product innovation in all industries in DE and in all but HT and MT in NL, suggesting strong positive complementarity effects between product innovation and proximity to the frontier.

The main finding that follows from the lower part of Table 8 and Graph 6 is that the top firms in the majority of industries experience the most negative rates of returns to process innovation. This holds for LT and both service industries in DE and for all industries, except for HT, in NL. In addition, the results shed some light on the negative average returns to process innovation reported in Section 6.1. In all manufacturing industries in $D E$ and in LT in $N L$, they are caused by (extreme) 
outliers whilst the productivity effect of investing in process innovation is insignificant for most enterprises along the productivity distribution.

\section{B. Impact on industry productivity distribution}

To gain insight into the importance of human capital and product and process innovation in shaping the characteristics of industry productivity distributions, we combine firm-level results from regressions at different quantiles of the productivity distribution to evaluate how changes in these three variables ceteris paribus affect the moments of industry productivity distributions.

The impact of human capital and both types of innovation upon the 2nd through 4th moment of the industry productivity distributions are reported in Table 9. In both countries, human capital is found to exert a significantly positive effect on the dispersion and the kurtosis of the productivity distribution in MT and LT whilst it leaves the skewness unchanged. Put differently, strategies to invest in human capital do not only increase the median return in these industries (see Table 8) but also widen the productivity distribution. This increased dispersion results from more extreme productivity outcomes at both right and left tails. In $D E$, we identify the same qualitative impact of product innovation on the productivity distribution in MT and OS. This means that (i) productivity is significantly more dispersed for firms in these industries that invest in product innovation and (ii) this increased variability results from an increased mass at both tails of the productivity distribution. The latter effect is much stronger for product innovation than for human capital. In $N L$, the same qualitative impact of process innovation on the productivity distributioni.e. a positive influence on the dispersion and the kurtosis - is found in MT and LT. ${ }^{22}$

In addition, product innovation positively affects all three moments of the productivity distribution in LT in DE and OS in NL. The finding that product innovation additionally alters the skewness of the distribution means that the increased dispersion results from more extreme productivity outcomes at both tails but that we observe an increase in the concentration of mass on the left.

On the contrary, human capital is found to exert a negative effect on the dispersion, skewness, and kurtosis of the productivity distribution in Dutch KIS.

\subsubsection{Accounting for firm FE}

A. Restriction of estimation sample

To additionally account for unobserved firm heterogeneity in estimating human capital and innovation returns, we perform FEQRs. For that purpose, we restrict the sample and only select firms with at least two observations. We end up with an unbalanced panel of 8117 observations corresponding to 3052 enterprises $(61 \%$ in

\footnotetext{
${ }^{22}$ Mata and Wörter (2013) report a similar pattern for the impact of external innovation strategies on profits.
} 


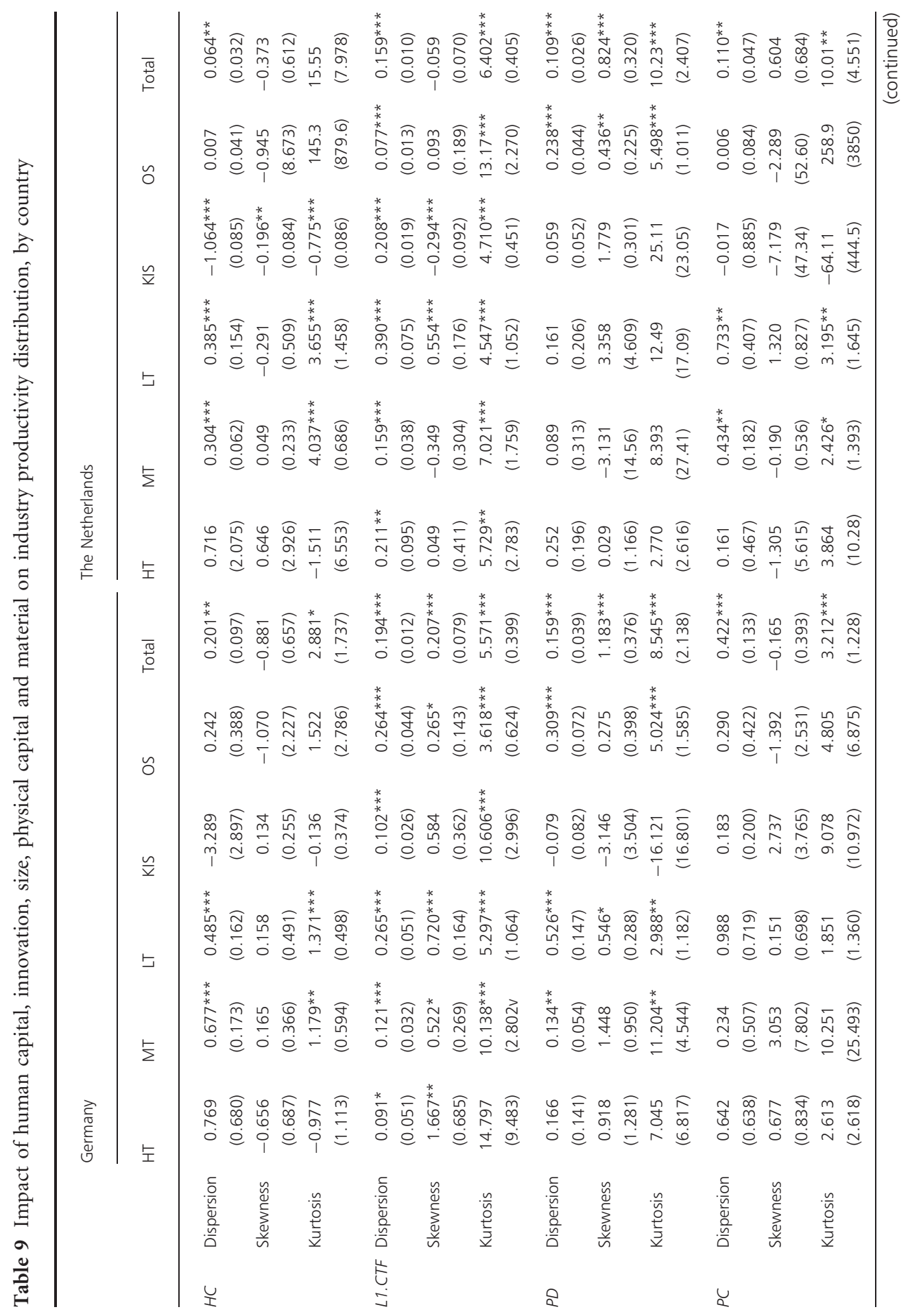




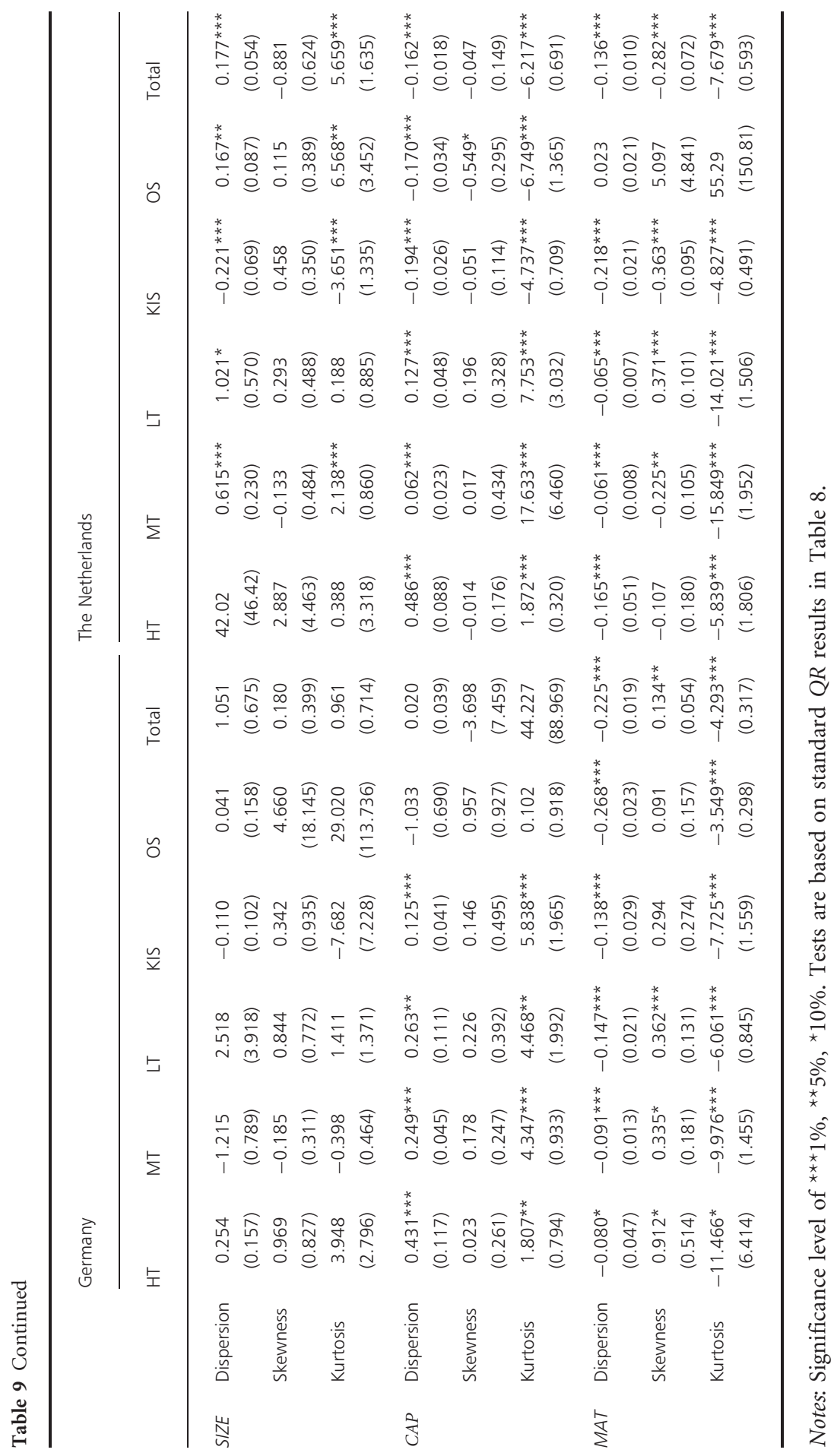


manufacturing and 39\% in services) over the period 2000-2008 in DE and an unbalanced panel of 15,427 observations corresponding to 5664 enterprises (42\% in manufacturing and 58\% in services) over the period 2000-2008 in NL.

To investigate the selectivity impact of this restricted estimation sample, we performed the same analysis as for the main estimation sample. The results of the first part, examining the average and quantile productivity effects of human capital and innovation at the firm level, are largely confirmed when moving to the restricted sample. Likewise, the results of the second part, evaluating the impact of human capital and innovation on the distributional characteristics of industry productivity, are mostly confirmed. ${ }^{23}$ The only discrepancy between the main estimation sample and the restricted one is that we do not find any distributional impact of process innovation anymore. This may be explained by the fact that the influence of process innovation was largely driven by some extreme outliers which may be dropped from the restricted sample.

\section{B. Firm-level heterogeneity in returns to human capital and innovation}

Table 10 reports the results of estimating FE QRs for the 10th, 25th, 50th, 75th, and 90th percentiles of the productivity distribution. For the sake of parsimony, we only report the estimated coefficients for $H C, L 1 . C T F, P D$, and PC. A visual representation is given in Graphs 7-9. For comparison, the standard FE estimates and their $95 \%$ confidence intervals are presented as dashed horizontal lines. Similar to the OLS estimates, it appears that standard FE estimates—-making inferences about "the average enterprise" - mask important aspects of the relationship between human capital and innovativeness on the one hand and productivity on the other hand. In general, taking into account unobserved firm heterogeneity does not exert a profound impact on the shape of human capital, process innovation, and product innovation returns. In the following three paragraphs, we limit the discussion to those cases where the $F E Q R$ estimates deviate significantly from the standard $Q R$ estimates.

The upper part of Table 10 and Graph 7 focus on the heterogeneous productivity effects of human capital. Contrary to the standard $Q R$ estimates, we find that accounting for firm FE leads to $(i)$ strongly increasing rates of returns to human capital as we move up through the productivity distribution in KIS in DE, implying that the best-performing enterprises in that industry seem to enjoy the highest rates of return to human capital and (ii) positive but diminishing rates of returns to human capital in HT in NL.

From the middle part of Table 10 and Graph 8, it follows that controlling for unobserved firm heterogeneity influences the shape of returns to product innovation in LT in DE and in HT in NL. More specifically, we observe (i) hump-shaped returns to product innovation rather than an increasing effect of product innovation along

\footnotetext{
${ }^{23}$ Detailed OLS, FE, and standard $Q R$ estimation results are provided in our Online Statistical Appendix.
} 


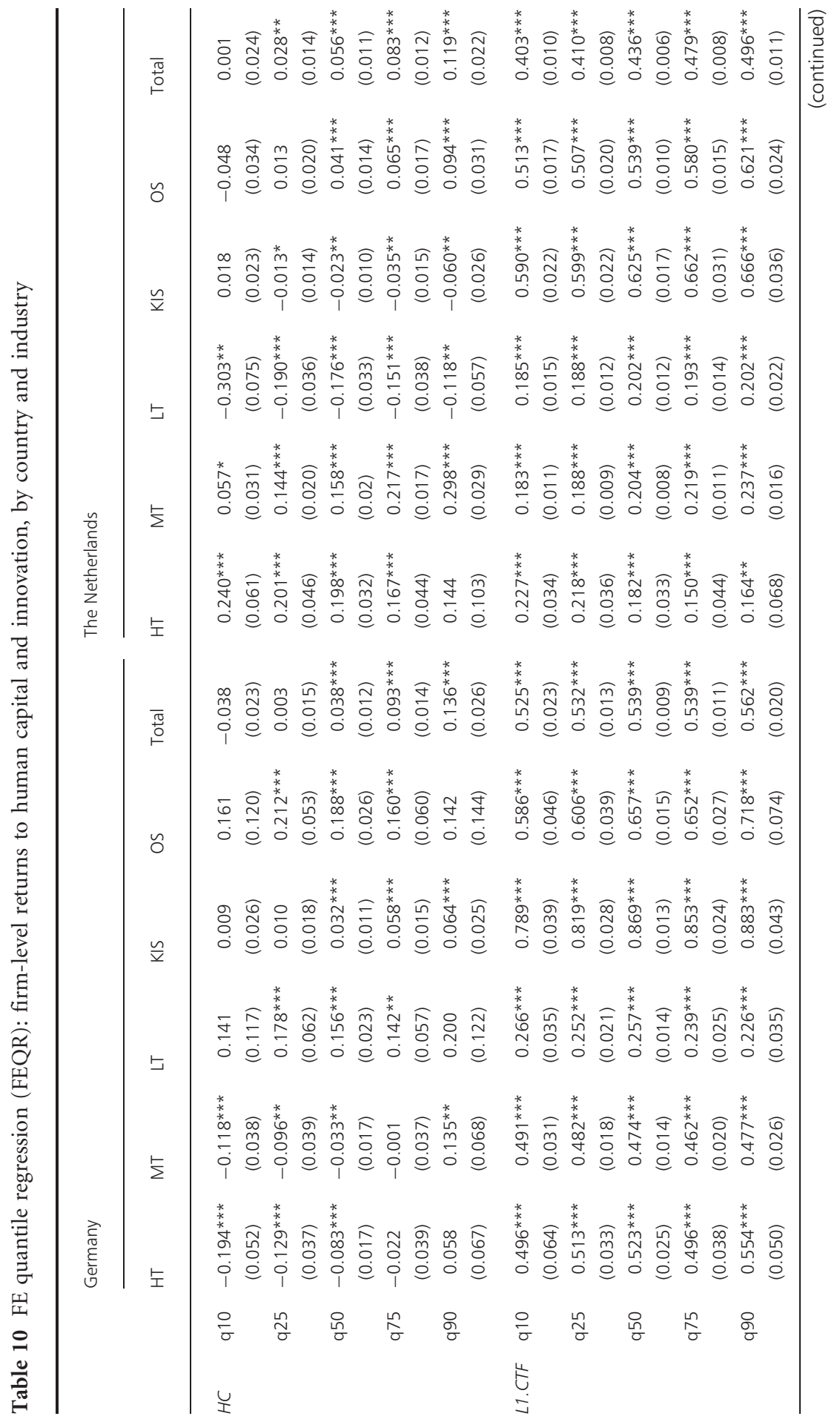




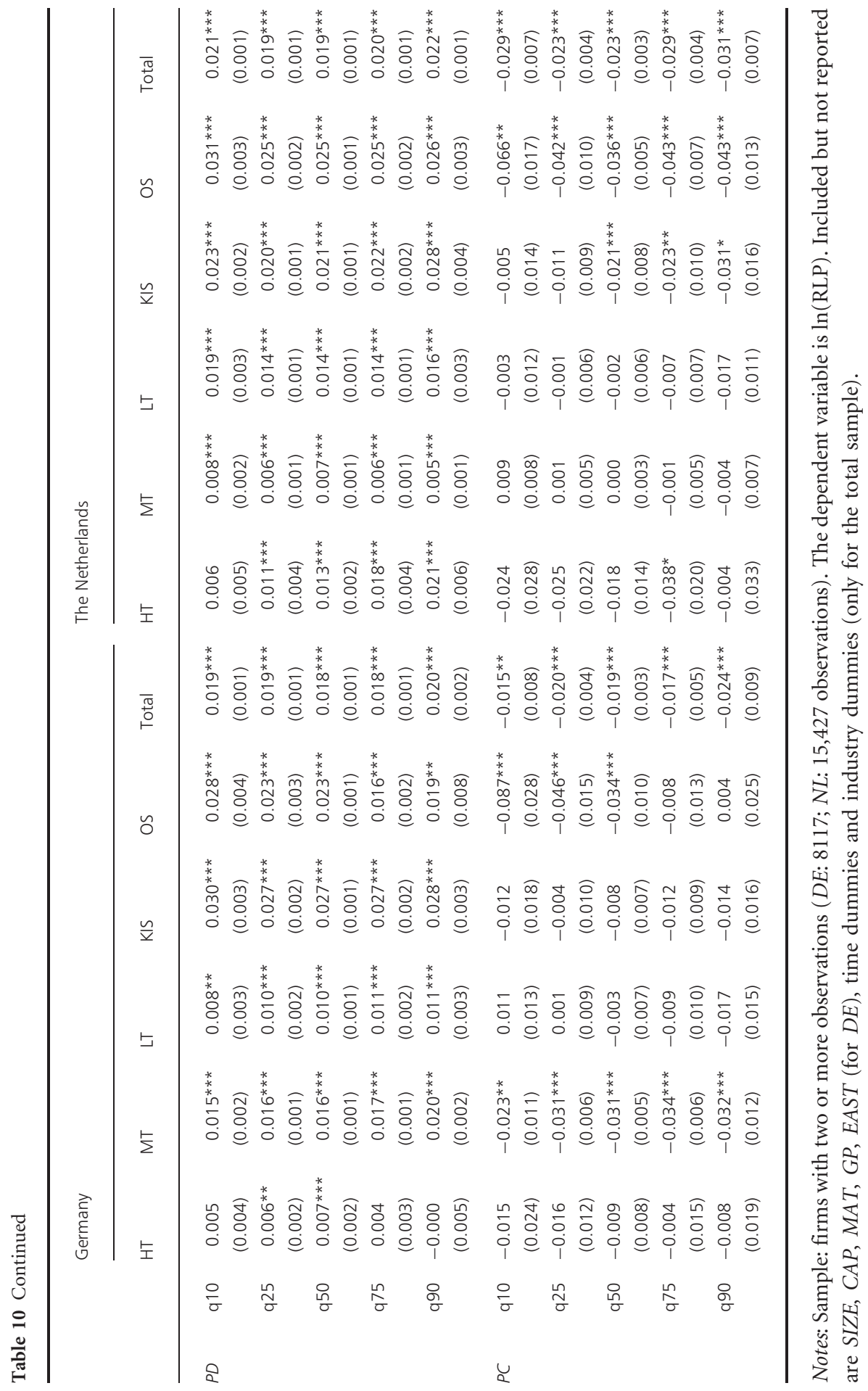




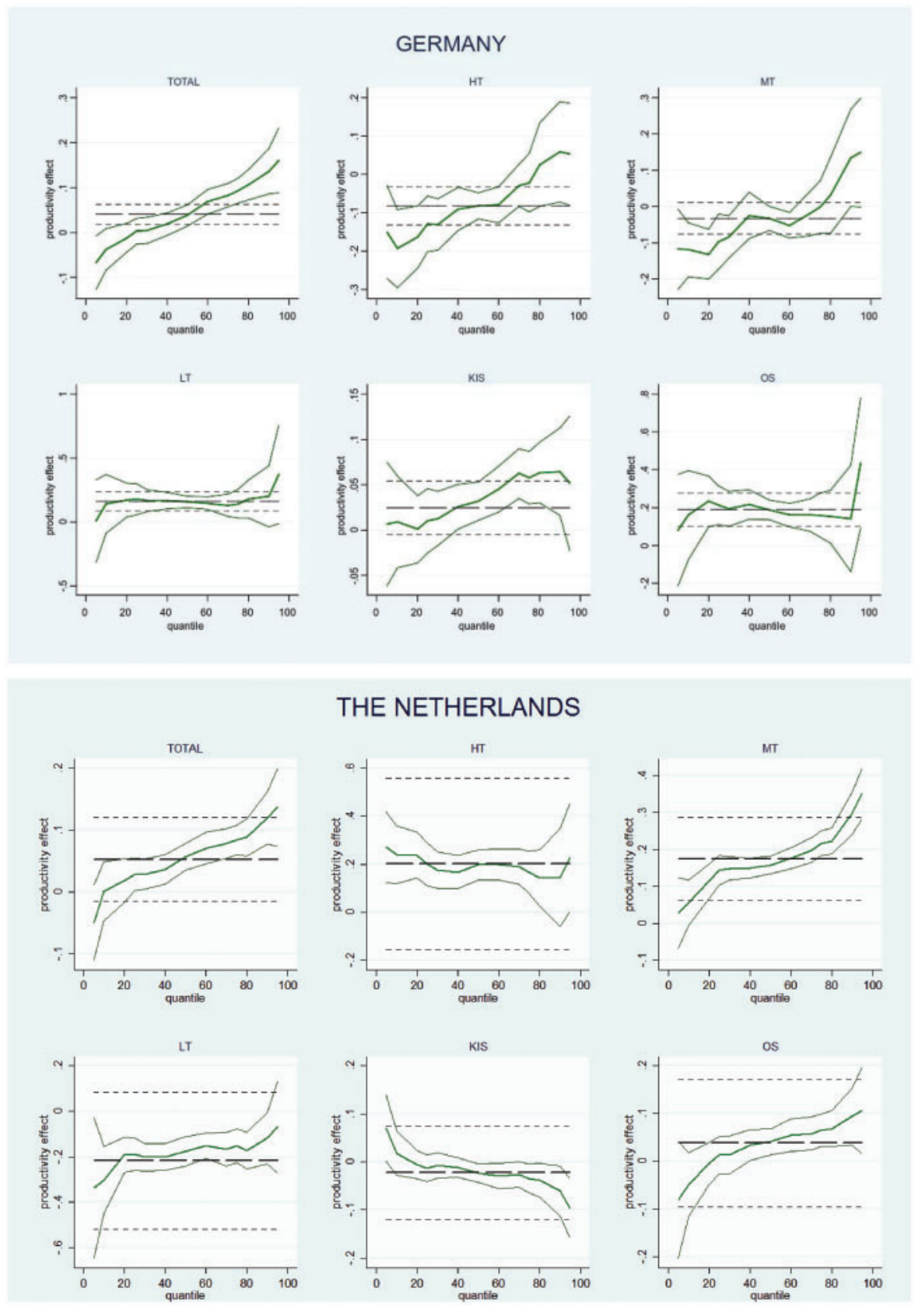

Graph 7 FE: Average and quantile impact of human capital on productivity, by country and industry

Note: Solid lines present coefficient estimates and 95\% confidence intervals of QRs. For comparison, dashed lines mark coefficient estimates and $95 \%$ confidence intervals of the FE regression. 

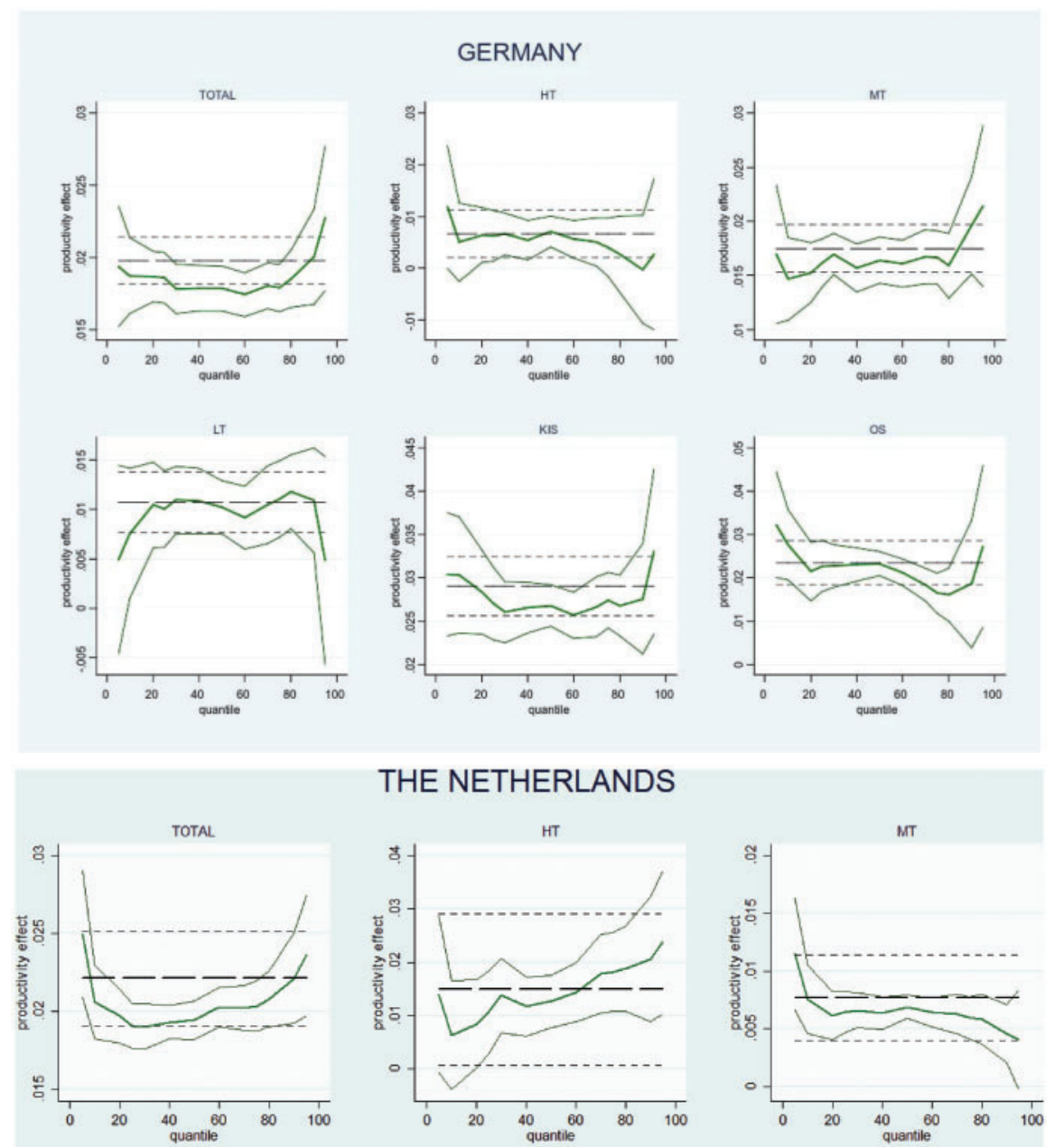

THE NETHERLANDS
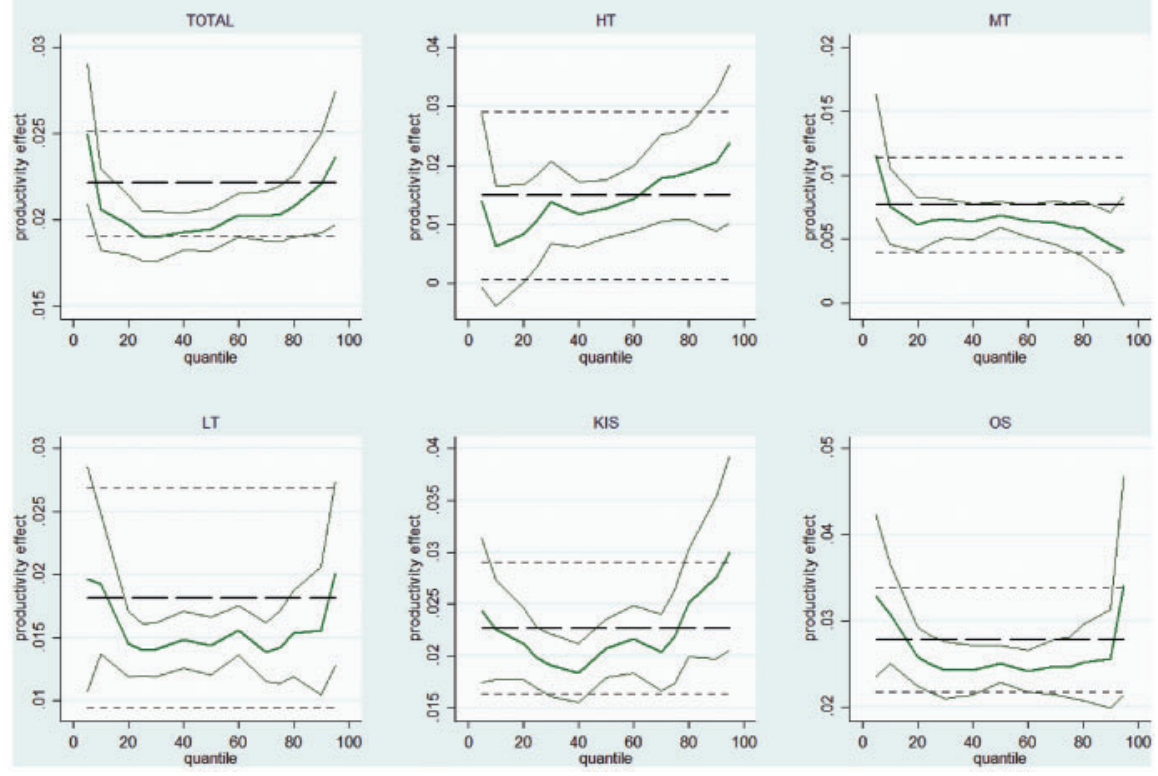

Graph 8 FE: Average and quantile impact of product innovation on productivity, by country and industry

Note: Solid lines present coefficient estimates and 95\% confidence intervals of QRs. For comparison, dashed lines mark coefficient estimates and $95 \%$ confidence intervals of the $F E$ regression. 


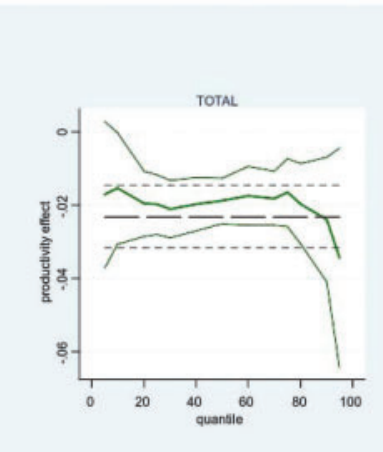

\section{GERMANY}
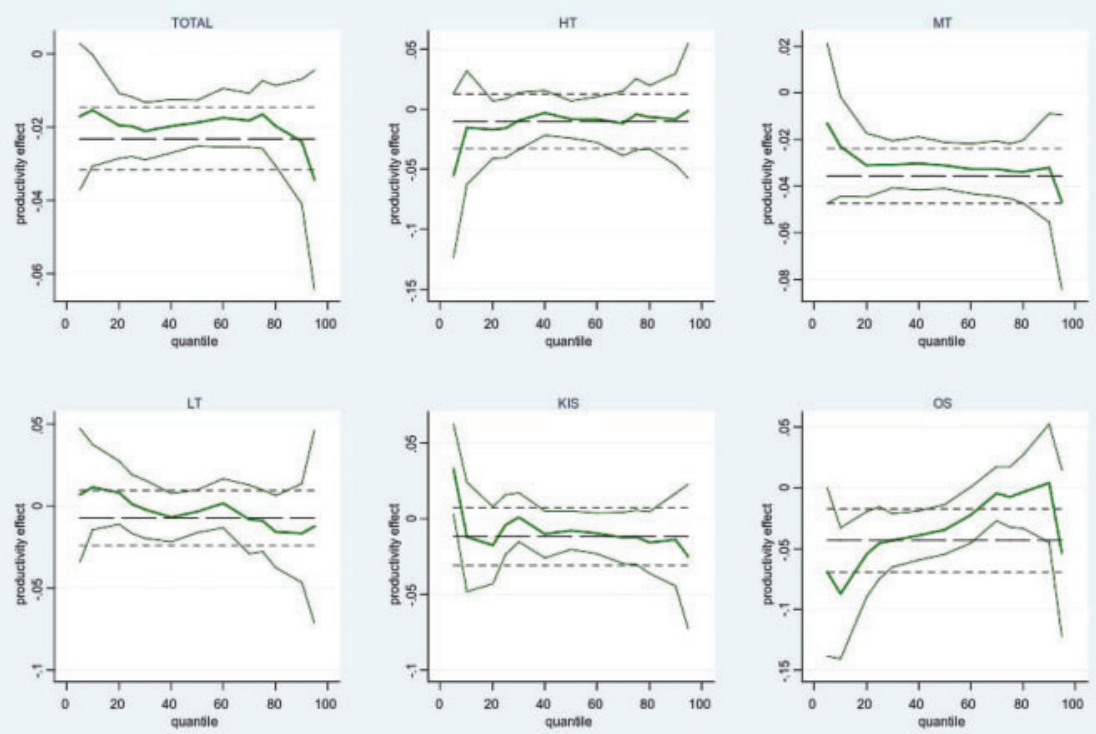

\section{THE NETHERLANDS}
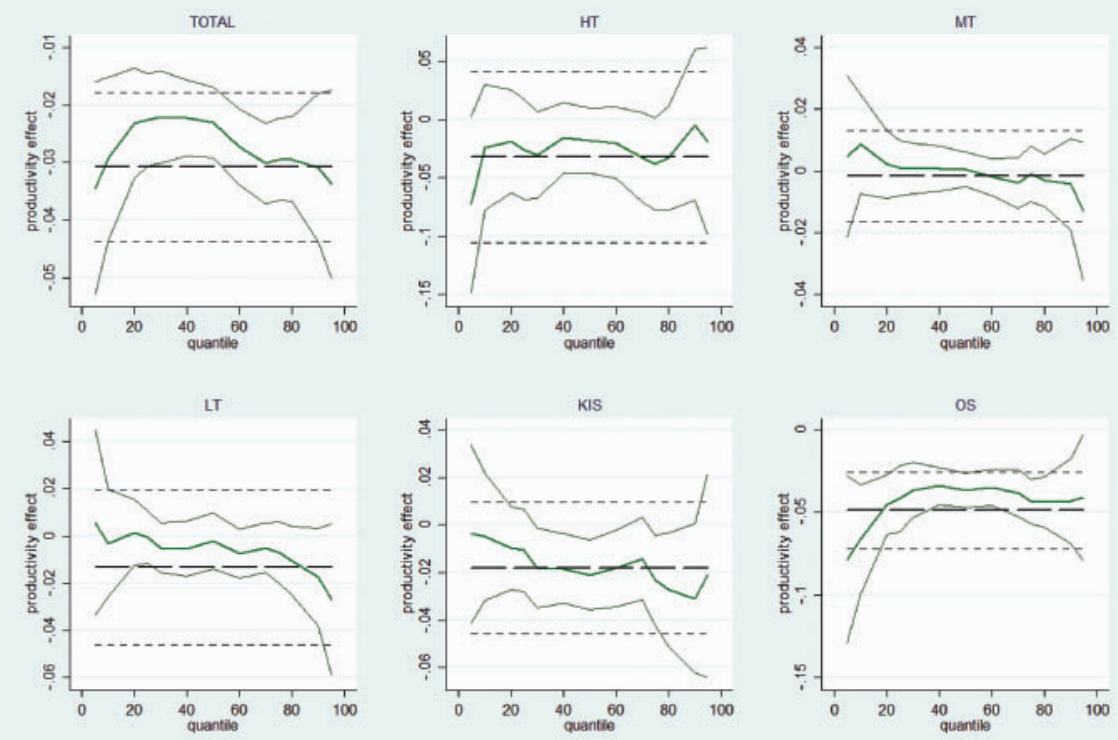

Graph 9 FE: Average and quantile impact of process innovation on productivity, by country and industry.

Note: Solid lines present coefficient estimates and 95\% confidence intervals of QRs. For comparison, dashed lines mark coefficient estimates and 95\% confidence intervals of the FE regression. 
quantiles in LT in DE and (ii) gradually increasing returns to product innovation in HT in NL. Hence, the positive complementarity effect between product innovation and proximity to the frontier vanishes in LT in DE but shows now up in HT in NL. Note that although we corroborate a $U$-shaped influence along the quantiles of the productivity distribution in all German industries, except for LT, this $U$-shape has become wider and the returns to product innovation have become very stable for a broader range of quantiles.

The lower part of Table 10 and Graph 9 show that taking into account unobserved firm heterogeneity mainly affects the shape of returns to process innovation in $D E$. Contrary to the standard $Q R$ estimates, the negative decreasing rates of returns to process innovation in LT and both service industries no longer hold. Instead, we find (i) negative decreasing rates of returns in MT suggesting a negative complementarity effect between process innovation and proximity to the frontier whilst (ii) an increasing shape is detected in OS. For the latter, the estimated returns are significantly negative up to the 60th percentile.

\section{Impact on industry productivity distribution}

The relatively minor differences between the FEQR and the standard $Q R$ estimates appear to result in relatively large differences in the impact of our main variables on the distributional characteristics of productivity in both countries (see Table 11). In $D E$, we no longer find that human capital increases the productivity dispersion and kurtosis in MT and LT. Instead, human capital even narrows the distribution in HT. We already pointed out that the impact of product innovation has become very similar along different quantiles once we account for unobserved firm heterogeneity. As a result, any significant influence on the characteristics of industry productivity distributions disappears, except for OS. Both product and process innovation affect the dispersion and the kurtosis in OS negatively. In $N L$, we no longer observe a significant impact of human capital on the dispersion and the kurtosis in LT. Instead, human capital is found to widen the industry productivity distribution in OS. Contrary to the standard $Q R$ results, the positive influence of product innovation on the dispersion and the kurtosis in OS has disappeared but is now observed in HT. Contrary to the standard $Q R$ results, any significant impact of process innovation on the distributional characteristics of productivity vanishes when controlling for unobserved firm heterogeneity.

\subsection{Robustness checks}

To check the robustness of our results using the main estimation sample, we performed a large number of sensitivity checks. ${ }^{24}$ The first set of robustness checks relates to our explanatory variables. Employing the logarithm of RLP as the

${ }^{24}$ Details on the results of these checks are available upon request. 


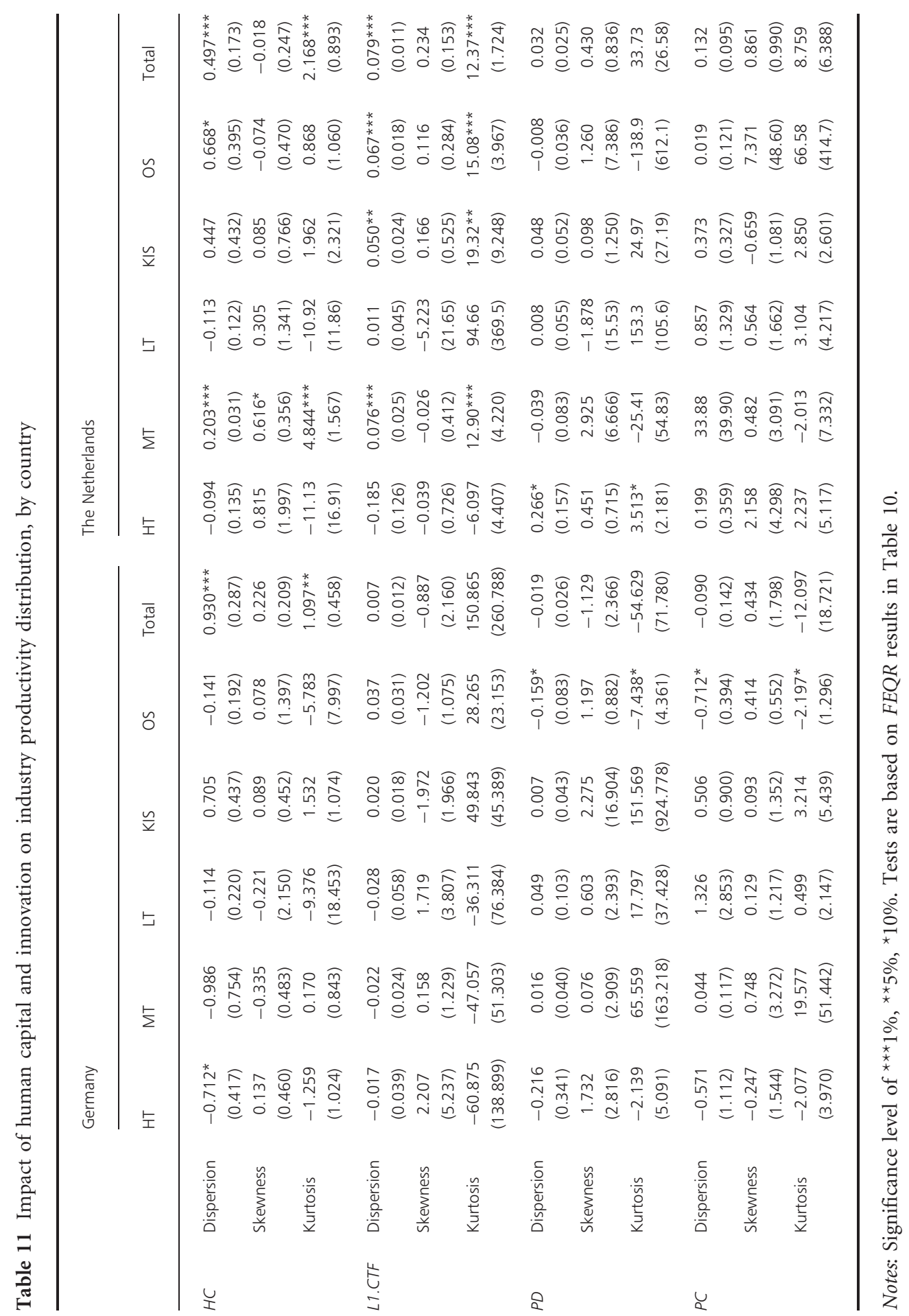


dependent variable, we examined in both countries the productivity effects of (i) different types of product innovation (i.e. market novelties versus firm novelties), (ii) human capital where human capital is measured by a binary variable equaling one if $H C_{i t}$ exceeds the median value of the share of high-skilled labor in industry $j$ (21-industry classification), (iii) human capital when additionally controlling for different moments of industry-year distributions of human capital intensity (where industries are defined according to the 21-industry classification). In addition, we replaced the human capital variable and firm size in $N L$ by a more detailed decomposition of the workforce, splitting the number of employees into the number of low-skilled, low-medium-skilled, high-medium-skilled, and high-skilled employees.

In $D E$, our main results show a $U$-shaped pattern for product innovation returns along the conditional productivity distribution in all industries, except for LT where increasing returns are found. It turns out that these results are to a large extent driven by market novelties. In particular, we corroborate the results for this type of product innovation in all industries, except for HT where the returns are steadily increasing when we move up through the productivity distribution. With respect to firm novelties, we still find evidence of $U$-shaped returns in MT and KIS. In contrast, decreasing returns to firm novelties are observed in HT and OS. In addition, the returns to market novelties are higher than the ones to firm novelties at nearly all quantiles in all industries in $D E$. In all industries, our results support evidence of positive complementarity effects between market novelties and proximity to the technological frontier. For firm novelties, this complementary effect only holds for MT, LT and KIS. Firm-level heterogeneity in the returns to market novelties also significantly changes the distributional characteristics of productivity. We find a larger productivity dispersion in all industries-except for OS-that primarily stems from more infrequent productivity levels at both tails.

In $N L$, we find increasing returns to market novelties in HT, MT and in KIS. Nonlinearities in the productivity effects of investing in products new to the market are observed in LT and OS. Consistent with DE, the best-performing enterprises enjoy the highest rates of returns to market novelties in all industries. Except for HT, innovation of products new to the market appears to have a significantly positive impact on the dispersion and the kurtosis of the productivity distribution in all industries. We detect increasing returns to firm novelties in all industries, except for HT. In the latter, the productivity effects of investing in products new to the firm follow a $U$-shaped pattern. In contrast to market novelties, we only find a positive complementarity effect between firm novelties and proximity to the technological frontier in MT and LT. Innovation of products new to the firm seems to exert a positive influence on the dispersion and skewness of the productivity distribution in all industries, except for HT and MT.

In $N L$, the productivity effects of human capital are robust to the measurement of human capital and to the inclusion of additional covariates. In $D E$, we likewise confirm our main results with one exception. When measuring human capital by 
a binary variable, we no longer find decreasing returns to human capital in KIS. Firms that are characterized by a human capital intensity above the industry-median consistently enjoy positive $\mathrm{HC}$ returns along all quantiles of the productivity distribution. These returns are increasing up to the median and then start to decrease.

The second set of robustness checks examines the sensitivity of our main results to using two alternative dependent variables in both countries: (i) TFP and (ii) the 1-year lead of RLPGR. In DE, we fully confirm the results for the returns to product and process innovation when using TFP as the dependent variable. For human capital, however, evidence is mixed. We find increasing returns to human capital in HT and MT but in none of the other industries. In NL, the results using TFP as the dependent variable are qualitatively similar to the main results.

In $D E$, the results for human capital are qualitatively confirmed in HT, MT and OS but not for the other two industries when using the 1-year lead of RLPGR as the dependent variable. Estimates for the returns to product innovation become insignificant for most quantiles in all German industries. In $N L$, the productivity effects of human capital are qualitatively confirmed in MT and KIS. In contrast, human capital returns lose significance in LT and OS and become significantly negative from the 75th percentile onward in HT. In contrast to the main results for $N L$, returns to product innovation only appear to be significant (and negative) from the 50th percentile onward in LT and returns to process innovation are significantly positive in the lower quantiles in all industries, except for MT and LT.

\subsection{Discussion}

Focusing on the productivity effects of human capital, two main findings stand out. First, we observe increasing marginal human capital returns to the best-performing enterprises in industries with a low level of technological intensity in both countries. Having high-skilled employees makes it easier for frontier firms in these industries to excel. Put differently, we find a significantly positive complementarity between human capital and proximity to the frontier in these industries. Second, we observe diminishing (even negative) marginal human capital returns for the "stars" in KIS, suggesting a significantly negative complementarity between human capital and proximity to the frontier. ${ }^{25}$ Becoming a "superstar" seems to be extremely difficult if one is already quite successful. We put forward two interpretations. Firstly, the results simply reflect a misallocation of high-skilled employees. Secondly, winner-take-all behavior underlies this finding. Investment in intangibles in frontier firms of KIS, using human capital intensely, might create a profitable breakthrough for one firm which could compensate the losses of many competitors. Suggestive evidence indicates that this interpretation might be more valid in $N L$ as (i) more experimentation and radical

\footnotetext{
${ }^{25}$ This finding is less consistent across different estimates in $D E$, though (see FEQR estimates and standard $Q R$ estimates using TFP as the dependent variable).
} 
innovation takes place in frontier firms in KIS, (ii) the distribution of human capital intensity is more left-skewed in KIS, and (iii) the sharply decreasing human capital returns appear to be even stronger in the high-technology KIS to which the telecommunication, computer, and R\&D services industries belong.

Focusing on the productivity effects of innovation, the main finding is that there are increasing marginal product innovation returns but negative marginal process innovation returns for the best-performing enterprises in the majority of industries in both countries. Hence, the best strategy for frontier enterprises is to focus on product rather than on process innovation. In addition, our results suggest that product innovation strategies are risky in OS in both countries implying that these strategies might lead to a large number of successful projects but also to a large number of unsuccessful ones in that particular industry. In $D E$, the same result holds for MT and LT.

\section{Conclusion}

This study reconsiders the relationship between human capital and innovation on the one hand and productivity on the other hand. We examine firm-level heterogeneity in returns to human capital and product and process innovation across industries that differ in the level of technological intensity and across countries. In addition, we exploit the degree in this firm-level heterogeneity to evaluate the impact of human capital and product and process innovation upon the attributes of industry productivity distributions.

Irrespective of their level of technological intensity, industries in the Netherlands are characterized by a larger average proportion of employees possessing a college or university degree and industries in Germany by a more unequal distribution of human capital intensity. In contrast, average innovation performance-measured by the logarithm of real innovative sales per employee for product innovators-is higher in all industries in Germany, except for LT. The distribution of innovation performance appears to be wider in the Netherlands. Average productivity turns out to be higher in all manufacturing industries in the Netherlands. Productivity is more unequally distributed in all German industries, except for HT.

In both countries, nonlinearities in the productivity effects of investing in product innovation are found in the majority of industries. Frontier firms enjoy the highest returns to product innovation in most industries. Investing in product innovation significantly increases the spread of the productivity distribution and the probability of observations at both the right and left tails of the productivity distribution in OS in both countries as well as in MT and LT in Germany. In sharp contrast, the most negative returns to process innovation are observed in the best-performing enterprises of most industries in both countries. Clearly, the best strategy for frontier firms is to focus on product rather than on process innovation. 
In Germany, we observe nonlinearities in the productivity effects of investing in human capital in HT, LT and in OS whilst human capital returns follow an increasing linear curve as we move up through the productivity distribution in all industries in the Netherlands, except for KIS. A positive complementarity effect between human capital and proximity to the technological frontier is found in industries with a low level of technological intensity whilst a negative complementarity effect is observed in KIS in both countries. The latter result no longer holds for Germany once unobserved firm heterogeneity is taken into account. Suggestive evidence for the Netherlands suggests an interpretation of a winner-takes-all market in KIS. Productivity is significantly more dispersed for enterprises that invest in human capital in MT and LT, which is caused by an increased mass of extreme (positive and negative) productivity outcomes in these industries.

Our analysis can be pursued in several directions, either to explain some of our findings or to examine some new developments. First, numerous studies have followed the Crépon et al. (1998) approach to investigate the interrelations between $R \& D$, innovation, and productivity at the firm level. One natural extension of our productivity framework is to endogenize the innovation or knowledge production function following Crépon et al. (1998) and use an instrumental variables estimator for QR in panel data with FE which is consistent for small periods (Powell, 2014). This would allow us to investigate (i) whether heterogeneous returns to R\&D expenditures feed through in heterogeneous returns to innovation and (ii) the role of firm-level innovation persistence in explaining firm-level persistence in productivity. Second, given that our study provides evidence of large heterogeneity in the returns of human capital across countries and across industries, another potential research avenue is to exploit our rich matched employeremployee data and build on the Hellerstein et al. (1999) methodology to examine the divergence between productivity premiums associated with worker characteristics (such as education, age, and gender) and the corresponding wage premiums. Such issues are naturally investigated within a QR framework. A final promising direction of research is to apply the moment-based approach developed by Lochner and Shin (2014) to our production function framework to disentangle sorting effects from effects due to labor market frictions in the context of TFP dispersion.

\section{Acknowledgements}

We are grateful to the Editor and two anonymous referees for helpful comments and suggestions. We also benefitted from useful discussions with and comments by Alex Coad, José-Luis Moraga-Gonzalez, Mark J. Roberts, Reinhilde Veugelers, and other participants at various conferences and seminars. The authors would like to thank Statistics Netherlands for providing the Dutch data. 


\section{Funding}

Financial support from the SEEK (Strenghtening Efficiency and Competitiveness in the European Knowledge Economies) research program is gratefully acknowledged.

\section{References}

Abowd, J. M., F. Kramarz and D.N. Margolis (1999), 'High wage workers and high wage firms,' Econometrica, 67(2), 251-334.

Abrevaya, J. and C. M. Dahl (2008), 'The effects of birth inputs on birthweight evidence from quantile estimation on panel data,' Journal of Business \& Economic Statistics, 26(4), 379-397.

Acemoglu, D., P. Aghion, C. Lelarge, J. Van Reenen and F. Zilibotti (2007), 'Technology, information and the decentralization of the firm,' Quarterly Journal of Economics, 122(4), 1759-1799.

Acemoglu, D., P. Aghion and F. Zilibotti (2003), 'Vertical integration and distance to frontier,' Journal of the European Economic Association, 1(2-3), 630-638.

Acemoglu, D., P. Aghion and F. Zilibotti (2006), 'Distance to frontier, selection and economic growth,' Journal of the European Economic Association, 4(1), 37-74.

Acs, Z. J. (2011), 'High-impact firms: Gazelles revisited,' in M. Fritsch (ed.), Handbook of Research on Entrepreneurship and Regional Development: National and Regional Perspectives. Edward Elgar Publishing: Cheltenham.

Aghion, P., N. Bloom, R. Blundell, R. Griffith and P. Howitt (2005), 'Competition and innovation: an inverted-U relationship,' Quarterly Journal of Economics, 120(2), 701-728.

Aghion, P., R. Blundell, R. Griffith, P. Howitt and S. Prantl (2004), 'Entry and productivity growth: evidence from micro-level panel data,' Journal of the European Economic Association, 2(2-3), 265-276.

Aghion, P., R. Burgess, S. Redding and F. Zilibotti (2008), 'The unequal effects of liberalization: evidence from dismantling the license Raj in India,' American Economic Review, 98(4), 1397-1412.

Alder, S (2010), Competition and innovation: does the distance to the technology frontier matter?. IEW - Working Papers 493, University of Zurich, Zurich.

Amable, B., L. Demmou and I. Ledezma (2010), 'Product market regulation, innovation, and distance to frontier,' Industrial and Corporate Change, 19(1), 117-159.

Antenbrink, P., K. Burger, M. Cornet, M. Rensman and D. Webbink (2005), 'Nederlands onderwijs en onderzoek in internationaal perspectief,' $C P B$ Document 88. Centraal Planbureau: Den Haag.

Arias, O., K. Hallock and W. Sosa-Escudero (2001), 'Individual heterogeneity in the returns to schooling: instrumental variables quantile regression using twins data,' Empirical Economics, 26(1), 7-40.

Arnold, J.M., G. Nicoletti and S. Scarpetta (2011), 'Does anti-competitive regulation matter for productivity? Evidence from European firms,' IZA Discussion Paper 5511. IZA: Bonn.

Atkinson, A. B. and J. E. Stiglitz (1969), 'A new view of technological change,' Economic Journal, 79(315), 573-578. 
Bakker, B. F. M. (2002), 'Statistics Netherlands' approach to social statistics: the social statistical dataset,' Statistics Newsletter, 11, 4-6.

Barro, R. and J. W. Lee (2010), 'A new data set of educational attainment in the world, 1950-2010,' NBER Working Paper 15902. National Bureau for Economic Research: Cambridge, MA.

Bartelsman, E. J. and M. Doms (2000), 'Understanding productivity: lessons from longitudinal microdata,' Journal of Economic Literature, 38(3), 569-594.

Bartelsman, E. J., J. Haskel and R. Martin (2008), 'Distance to which frontier? Evidence on productivity convergence from international firm-level data,' CEPR Discussion Paper 7032. Centre for Economic Policy Research: London.

Benhabib, J. and M. Spiegel (1994), 'The role of human capital in economic development: evidence from aggregate cross-country data,' Journal of Monetary Economics, 34(2), 143-174.

Ben Yahmed, S. and S. Dougherty (2012), 'Import competition, domestic regulation and firmlevel productivity in the OECD,' OECD Economics Department Working Paper 980. OECD: Paris.

Binder, M. and A. Coad (2014), 'Heterogeneity in the relationship between unemployment and subjective well-being: a quantile approach,' Levy Economics Institute Working Paper 808.

Bourlès, R., G. Cette, J. Lopez, J. Mairesse and G. Nicoletti (2010), 'Do product market regulations in upstream sectors curb productivity growth? Panel data evidence for OECD countries,' OECD Economics Department Working Paper 791. OECD: Paris.

Bournakis, I., S. Mallick, D. Kernohan and D. A. Tsouknidis (2013), 'Measuring firm-level productivity convergence in the UK: the role of taxation and R\&D investment,' CGR Working Paper 45. Queen Mary University of London: London.

Buchinsky, M. (1994), 'Changes in the US wage structure 1963-1987: application of quantile regression,' Econometrica, 62(2), 405-458.

Buchinsky, M. (2001), 'Quantile regression with sample selection: estimating women's return to education in the US,' Empirical Economics, 26(1), 87-113.

Canay, I. A. (2011), 'A simple approach to quantile regression for panel data,' Econometric Journal, 14(3), 368-396.

Cedefop (2008), Initial Vocational Education and Training (IVET) in Europe. European Centre for the Development of Vocational Training, Publications Office of the European Union: Luxembourg.

Chamberlain, G. (1982), 'Multivariate regression models for panel data', Journal of Econometrics, 18(1), 5-46.

Chandra, V., I. Osorio-Rodarte and C. A. P. Braga (2009), 'Korea and the BICs (Brazil, India and China): catching-up experiences,' in V. Chandra, D. Eröcal, P. C. Padoan and C. A. P. Braga (eds), Innovation and Growth - Chasing a Moving Frontier. OECD and the International Bank for Reconstruction and Development/The World Bank: Paris.

Chernozhukov, V., I. Fernández-Val, J. Hahn and W. Newey (2013), 'Average and quantile effects in nonseparable panel models,' Econometrica, 81(2), 535-580. 
Chevalier, A., C. Harmon, I. Walker and Y. Zhu (2004), 'Does education raise productivity, or just reflect it?' Economic Journal, 114(499), F499-F517.

Choi, K. S. and J. Jeong (2007), 'Does unmeasured ability explain the wage premium associated with technological change? Quantile regression analysis,' Applied Economics, 39(7), 1163-1171.

Cingano, F., M. Leonardi, J. Messina and G. Pica (2014), 'Employment protection legislation, capital investment and access to credit: evidence from Italy,' MEF Working Paper 4/2014. Ministry of Economy and Finance: Rome.

Clements, M. and H. Ohashi (2005), 'Indirect network effects and the product cycle: video games in the U.S., 1994-2002,' Journal of Industrial Economics, 53(4), 515-542.

Coad, A. (2011), 'Appropriate business strategy for leaders and laggards,' Industrial and Corporate Change, 20(4), 1049-1079.

Coad, A. and R. Rao (2008), 'Innovation and firm growth in high-tech sectors: a quantile regression approach,' Research Policy, 37(4), 633-648.

Coad, A. and R. Rao (2006), 'Innovation and market value: a quantile regression analysis,' Economics Bulletin, 15(13), 1-10.

Cohen, D. and M. Soto (2007), 'Growth and human capital: good data, good results,' Journal of Economic Growth, 12(1), 51-76.

Coulombe, S., J. F. Tremblay and S. Marchand (2004), Literacy Scores, Human Capital and Growth Across Fourteen OECD Countries. Statistics Canada and Human Resources and Skills Development Canada: Ottawa.

Crépon, B., E. Duguet and J. Mairesse (1998), 'Research, innovation and productivity: An econometric analysis at the firm level,' Economics of Innovation and New Technology, 7(2), $115-158$.

D'Costa, S., E. Garcilazo and J. Oliveira Martins (2013), 'The impact of structural and macroeconomic factors on regional growth,' OECD Regional Development Working Paper 2013/11. OECD: Paris.

de la Fuente, A. (2011), 'Human capital and productivity,' Barcelona Economics Working Paper 530. Barcelona Graduate School of Economics: Barcelona.

de la Fuente, A. and R. Doménech (2001), 'Schooling data, technological diffusion and the neoclassical model,' American Economic Review, 91(2), 323-327.

de la Fuente, A. and R. Doménech (2006), 'Human capital in growth regressions: how much difference does data quality make?' Journal of the European Economic Association, 4(1), 1-36.

Denny, K. and V. O'Sullivan (2007), 'Can education compensate for low ability? Evidence from British data, Applied Economics Letters, 14(7-9), 657-660.

European Commission (2008), Jobs and Growth in the EU, A Roadmap to a Sustainable Tomorrow, Europe on the move, European Commission: Brussels.

European Commission (2010), Europe 2020: A Strategy for Smart, Sustainable and Inclusive Growth: Communication from the Commission, Research report, European Commission: Brussels. 
Eurostat (2013), Regional Education Statistics. Eurostat: Luxemburg.

Flabbi, L., S. Paternostro and E. Tiongson (2008), 'Returns to education in the economic transition: a systematic assessment using comparable data,' Economics of Education Review, 27(6), 724-740.

Foster, L., J. C. Haltiwanger and C. J. Krizan (2001), 'Aggregate productivity growth. Lessons from microeconomic evidence,' in C. R. Hulten, E. R. Dean and M. J. Harper (eds), New Developments in Productivity Analysis. University of Chicago Press: Chicago.

Foster-McGregor, N., I. Isaksson and F. Kaulich (2013), 'Importing, exporting and the productivity of services firms in Sub-Saharan Africa,' Vienna Institute for International Economic Studies Working Paper 98. Vienna Institute for International Economic Studies: Vienna.

Fox, J. and V. Smeets (2011), 'Does input quality drive measured differences in firm productivity?' International Economic Review, 52(4), 961-989.

Galindo-Rueda, F. and J. Haskel (2005), 'Skills, workforce characteristics and firm-level productivity: evidence from the matched ABI/Employer skills survey,' IZA Discussion Paper 1542. IZA: Bonn.

Galvao, A. F. (2011), 'Quantile regression for dynamic panel data with fixed effects,' Journal of Econometrics, 164(1), 142-157.

Gerschenkron, A. (1962), Economic Backwardness in Historical Perspective. Harvard University Press: Cambridge MA.

Goedhuys, M. and L. Sleuwaegen (2010), 'High-growth entrepreneurial firms in Africa: a quantile regression approach,' Small Business Economics, 34(1), 31-51.

Griffith, R., S. Redding and H. Simpson (2003a), 'Productivity convergence and foreign ownership at the establishment level,' CEP Discussion Paper dp0573. Centre for Economic Performance: London.

Griffith, R., S. Redding and J. van Reenen (2003b), 'R\&D and absorptive capacity: theory and empirical evidence,' Scandinavian Journal of Economics, 105(1), 99-118.

Griffith, R., S. Redding and J. van Reenen (2004), 'Mapping the two faces of R\&D: productivity growth in a panel of OECD industries,' Review of Economics and Statistics, 86(4), 883-895.

Hall, B., J. Mairesse and P. Mohnen (2010), 'Measuring the returns to R\&D,' in B. Hall and N. Rosenberg (eds), Handbook of the Economics of Innovation, Vol. 2, North-Holland: Amsterdam.

Hall, B. (2011), 'Innovation and productivity,' NBER Working Paper 17178. National Bureau for Economic Research: Cambridge, MA.

Haltiwanger, J., J. Lane and J. Spletzer (1999), 'Productivity differences across employers: the roles of employer size, age and human capital,' American Economic Review, 89(2), 94-98.

Haltiwanger, J., J. Lane and J. Spletzer (2007), 'Wages, productivity, and the dynamic interaction of businesses and workers,' Labour Economics, 14(3), 575-602.

Hanushek, E. and D. Kimko (2000), 'Schooling, labor-force quality and the growth of nations,' American Economic Review, 90(5), 1184-1208. 
Hanushek, E. and L. Wößmann (2008), 'The role of cognitive skills in economic development,' Journal of Economic Literature, 46(3), 607-668.

Hanushek, E. and L. Wößmann (2012), 'Do better schools lead to more growth? Cognitive skills, economic outcomes and causation,' Journal of Economic Growth, 17(4), 267-321.

Harmon, C., H. Oosterbeek and I. Walker (2003), 'The returns to education: microeconomics,' Journal of Economic Surveys, 17(2), 115-155.

Hartog, J., P. T. Pereira and J. A. C. Vieira (2001), 'Changing returns to education in Portugal during the 1980s and early 1990s: OLS and quantile regression estimators,' Applied Economics, 33(8), 1021-1137.

Haskel, J., D. Hawkes and S. Pereira (2005), 'Skills, human capital and the plant productivity gap: UK evidence from matched plant, worker and workforce data,' CEPR Discussion Paper 5334. Centre for Economic Policy Research: London.

Hatzichronoglou, T. (1997), 'Revision of the high-technology sector and product classification, OECD Science,' Technology and Industry Working Paper 1997/02. OECD: Paris.

Henrekson, M. and D. Johansson (2010), 'Gazelles as job creators: a survey and interpretation of the evidence,' Small Business Economics, 35(2), 227-244.

Heckman, J. J. (2001), 'Micro data, heterogeneity, and the evaluation of public policy: nobel lecture,' Journal of Political Economy, 109(4), 673-748.

Hellerstein, J. K., D. Neumark and K. Troske (1999), 'Wages, productivity and worker characteristics: evidence from plant-level production functions and wage equations,' Journal of Labor Economics, 17(3), 409-446.

Hölzl, W. (2014), 'Persistence, survival, and growth: a closer look at 20 years of fast-growing firms in Austria,' Industrial and Corporate Change, 23(1), 199-231.

Hölzl, W. and K. Friesenbichler (2010), 'High-growth firms, innovation and the distance to the frontier,' Economic Bulletin, 30(2), 1016-1024.

Inklaar, R., M. Timmer and B. van Ark (2008), 'Market services productivity across Europe and the US,' Economic Policy, 23(53), 139-194.

Kneller, R. and P. A. Stevens (2006), 'Frontier technology and absorptive capacity: evidence from OECD manufacturing industries,' Oxford Bulletin of Economics and Statistics, 68(1), $1-21$.

Koenker, R. W. (2004), 'Quantile regression for longitudinal data,' Journal of Multivariate Analysis, 91(1), 74-89.

Koenker, R. W. and G. J. Bassett (1978), 'Regression quantiles,' Econometrica, 46(1), 33-50.

Kok, W. (2004), Facing the Challenge: The Lisbon Strategy for Growth and Employment, Report for a high-level group, European Communities: Luxembourg.

Krueger, A. and M. Lindahl (2001), 'Education for growth: why and for whom?' Journal of Economic Literature, 39(4), 1101-1136.

Lamarche, C. (2010), 'Robust penalized quantile regression estimation for panel data,' Journal of Econometrics, 157(2), 396-408. 
Lebedinski, L. and V. Vandenberghe (2014), 'Assessing education's contribution to productivity using firm-level evidence,' International Journal of Manpower, 35(8).

Lochner, L. and Y. Shin (2014), 'Understanding earnings dynamics: identifying and estimating the changing roles of unobserved ability, permanent and transitory shocks,' NBER Working Paper 20068. National Bureau for Economic Research: Cambridge, MA.

Machado, J. A. F. and J. Mata (2000), 'Box-Cox quantile regression and the distribution of firm sizes,' Journal of Applied Econometrics, 15(3), 253-274.

Machado, J. A. F. and J. Mata (2001), 'Earning functions in Portugal 1982-1994: evidence from quantile regressions,' Empirical Economics, 26(1), 115-134.

Machado, J. A. F. and J. Mata (2005), 'Counterfactual decomposition of changes in wage distributions using quantile regression,' Journal of Applied Econometrics, 20(4), 445-465.

Madsen, J., R. Islam and J. Ang (2010), 'Catching up to the technology frontier: the dichotomy between innovation and imitation,' Canadian Journal of Economics, 43(4), 1389-1411.

Madsen, J. (2014), 'Human capital and the world technology frontier,' Review of Economics and Statistics, 96, 676-692.

Mairesse, J. and M. Sassenou (1991), 'R\&D productivity: a survey of econometric studies at the firm level,' Science Technology and Industry Review, 8, 317-348.

Martins, P. and P. Pereira (2004), 'Does education reduce wage inequality? Quantile regression evidence from 16 countries,' Labour Economics, 11(3), 355-371.

Mason, G., B. O'Leary and M. Vecchi (2012), 'Certified and uncertified skills and productivity growth performance: cross-country evidence at industry level,' Labour Economics, 19(3), 351-360.

Mata, J. and M. Wörter (2013), 'Risky innovation: the impact of internal and external R\&D strategies upon the distribution of returns,' Research Policy, 42(2), 495-501.

Minne, B., M. Rensman, B. Vroomen and D. Webbink (2007), Excellence for Productivity? Centraal Planbureau: The Hague.

Moretti, E. (2004), 'Workers' education, spillovers and productivity: evidence from plant-level production functions,' American Economic Review, 94(3), 656-690.

Mundlak, Y. (1978), 'On the pooling of time series and cross section data,' Econometrica, 46(1), 69-85.

Mwabu, G. and T. P. Schultz (1996), 'Education returns across quantiles of the wage function: alternative explanations for returns to education by race in South Africa,' American Economic Review, 86(2), 335-339.

Nelson, R. and E. Phelps (1966), 'Investment in humans, technological diffusion and economic growth,' American Economic Review, 56(1-2), 69-75.

Nicoletta, G. and S. Scarpetta (2003), 'Regulation, productivity and growth: OECD evidence,' Economic Policy, 18(36), 9-72.

Nishimura, K.G., T. Nakajima and K. Kiyota (2005), 'Productivity convergence at the firm level,' mimeo. Available at SSRN: http://ssrn.com/abstract=721423. 
OECD (2001), Science, Technology and Industry Outlook 2001. OECD: Paris.

OECD (2009), OECD Factbook 2009. OECD: Paris.

OECD (2010), Innovation Strategy. OECD: Paris.

Ohinata, A. and J. C. van Ours (2013), 'Spillover effects of studying with immigrant students: a quantile regression approach,' IZA Discussion Paper 7720. IZA: Bonn.

Oja, H. (1981), 'On location, scale, skewness and kurtosis of univariate distributions,' Scandinavian Journal of Statistics, 8, 154-168.

O'Mahony, M., C. Robinson and M. Vecchi (2008), 'The impact of ICT on the demand for skilled labour: a cross-country comparison,' Labour Economics, 15(6), 1435-1450.

Pereira, P. and P. S. Martins (2002), 'Is there a return-risk relationship in education?' Economics Letters, 75(2), 31-37.

Peters, B., M. J. Roberts, V. A. Vuong and H. Fryges (2013), 'Estimating dynamic R\&D demand: an analysis of costs and long-run benefits,' NBER Working Paper 19374. National Bureau for Economic Research: Cambridge, MA.

Powell, D. (2014), 'Did the economic stimulus payments of 2008 reduce labor supply?' RAND Labor \& Population Working Paper WR-710-3. Rand Corporation: Santa Monica, CA.

Rammer, C. and B. Peters (2013), 'Innovation Panel Surveys in Germany,' in F. Gault (ed.), Handbook of Innovation Indicators and Measurement. Edward Elgar: Cheltenham, UK and Northampton, MA, USA, pp. 135-177.

Roeger, W., J. Varga and J. in 't Veld (2010), 'How to close the productivity gap between the US and Europe. A quantitative assessment using a semi-endogenous growth model,' Economic Papers 399. European Commission: Brussels.

Ruppert, D. (1987), 'What is kurtosis? An influence function approach,' The American Statistician, 41, 1-5.

Sabirianova Peter, K., J. Svejnar and K. Terell (2012), 'Foreign investment, corporate ownership and development: are firms in emerging markets catching up to the world standard?' Review of Economics and Statistics, 94(4), 981-999.

Sapir, A., P. Aghion, G. Bertola, M. Hellwig, J. Pisani-Ferry, D. Rosati, J. Viñals and H. Wallace (2004), An Agenda for a Growing Europe: The Sapir Report. Oxford University Press: Oxford.

Segarra, A. and M. Teruel (2011), 'Productivity and R\&D sources: evidence for Catalan firms,' Economics of Innovation and New Technology, 20(8), 727-748.

Sianesi, B. and J. van Reenen (2003), 'The returns to education: macroeconomics,' Journal of Economic Surveys, 17(2), 157-200.

Streeck, W. (1997), 'German capitalism: does it exist? Can it survive?,' in C. Crouch and W. Streeck (eds), The Political Economy of Modern Capitalism. Mapping Convergence and Diversity. Sage Publications Ltd: London.

Syverson, C. (2011), 'What determines productivity?' Journal of Economic Literature, 49(2), 326-365. 
Turcotte, J. and L. W. Rennison (2004), 'The link between technology use, human capital, productivity and wages: firm-level evidence,' International Productivity Monitor, 9(Fall), 25-36.

Van Biesebroeck, J. (2011), 'Wages equal productivity. Fact or fiction? Evidence from Sub Saharan Africa,' World Development, 39(8), 1333-1346.

Vandenberghe, V., M. Rigo and F. Waltenberg (2013), 'Ageing and employability. Evidence from Belgian firm-level data,' Journal of Productivity Analysis, 40(1), 111-136.

Vandenbussche, J., P. Aghion and C. Meghir (2006), 'Growth, distance to frontier and composition of human capital,' Journal of Economic Growth, 11(2), 97-127.

van Ours, J. and L. Stoeldraijer (2011), 'Age, wage and productivity in Dutch manufacturing,' De Economist, 159(2), 113-137.

Wieser, R. (2005), 'Research and development productivity and spillovers: empirical evidence at the firm level,' Journal of Economic Surveys, 19(4), 587-621.

Wooldridge, J. (2002), Econometric Analysis of Cross Sections and Panel Data. MIT Press: Cambridge, MA.

\section{Appendix A : Measurement details}

\section{A.1 Measurement of the human capital variable in the Dutch data}

In order to define the education type of employees in the matched (CIS $\cap P S$ )-enterprises, we built a matched employer-employee microdata set by merging our enterprise data with the Social Statistics Database (SSB). The population of interest consists of individuals aged $15-65$ covering the period $1999-2008 .{ }^{26}$ Table A1 reports the number of employees $(N)$, the number of enterprises, and the median number of employees per enterprise for each year in manufacturing and services in the matched employer-employee data.

The education type of each employee is determined in two stages. In the first stage, the matched employer-employee microdata set is linked to the Education database which provides the highest level of education attained by an individual. The education type is based on a two-digit SOI-code (Dutch education classification: Standaard $\mathbf{O}$ nderwijsindeling) and is converted to the ISCED classification (International Standard Classification of Education). Table A2 provides details on the Dutch education system and on the mapping between the SOI and the ISCED classifications.

On the basis of the ISCED-codes, we characterize two decompositions of the workforce which are reported in the last two columns of Table A2. Following Antenbrink et al. (2005), the first decomposition splits the workforce into three skill types (low-skilled $(L S)$, medium-skilled $(M S)$, and high-skilled $(H S)$ ). In line with O’Mahony et al. (2008), the second decomposition further refines the middle

\footnotetext{
${ }^{26}$ We select the period $1999-2008$ since this period is covered in the Education database (see supra).
} 
Table A1 Panel structure of matched employer-employee microdata set-1999-2008

\begin{tabular}{|c|c|c|c|c|c|c|c|c|}
\hline \multirow[t]{2}{*}{ Year } & \multicolumn{4}{|c|}{ Manufacturing } & \multicolumn{4}{|l|}{ Services } \\
\hline & $\begin{array}{l}\text { Number of } \\
\text { employees }\end{array}$ & $\begin{array}{l}\% \text { employed } \\
\text { in education }\end{array}$ & $\begin{array}{l}\text { Number } \\
\text { of firms }\end{array}$ & $\frac{\text { Number of employees }^{\mathrm{a}}}{\text { firm }}$ & $\begin{array}{l}\text { Number of } \\
\text { employees }\end{array}$ & $\begin{array}{l}\% \text { employed. } \\
\text { in education }\end{array}$ & $\begin{array}{l}\text { Number } \\
\text { of firms }\end{array}$ & $\frac{\text { Number of employees }}{\text { firm }}$ \\
\hline 1999 & 768,844 & 19.2 & 9452 & 30 & $1,749,492$ & 30.5 & 14,320 & 29 \\
\hline 2000 & 759,266 & 20.1 & 9284 & 31 & $1,796,189$ & 32.0 & 14,192 & 31 \\
\hline 2001 & 745,032 & 20.4 & 9244 & 31 & $1,760,933$ & 32.4 & 14,382 & 32 \\
\hline 2002 & 705,867 & 21.1 & 9048 & 30 & $1,729,602$ & 33.3 & 14,417 & 32 \\
\hline 2003 & 677,188 & 22.6 & 8842 & 30 & $1,669,277$ & 34.8 & 14,236 & 31 \\
\hline 2004 & 648,995 & 24.3 & 8675 & 29 & $1,667,713$ & 36.6 & 14,086 & 31 \\
\hline 2005 & 626,966 & 26.2 & 8429 & 29 & $1,664,649$ & 39.3 & 13,766 & 31 \\
\hline 2006 & 623,756 & 29.2 & 8074 & 30 & $1,686,114$ & 42.8 & 13,253 & 32 \\
\hline 2007 & 614,249 & 31.4 & 7875 & 31 & $1,720,888$ & 45.4 & 12,987 & 32 \\
\hline 2008 & 611,725 & 33.8 & 7496 & 31 & $1,722,096$ & 47.5 & 12,194 & 33 \\
\hline
\end{tabular}

Notes: ${ }^{\mathrm{a}}$ Median value.

Table A2 The Dutch education system

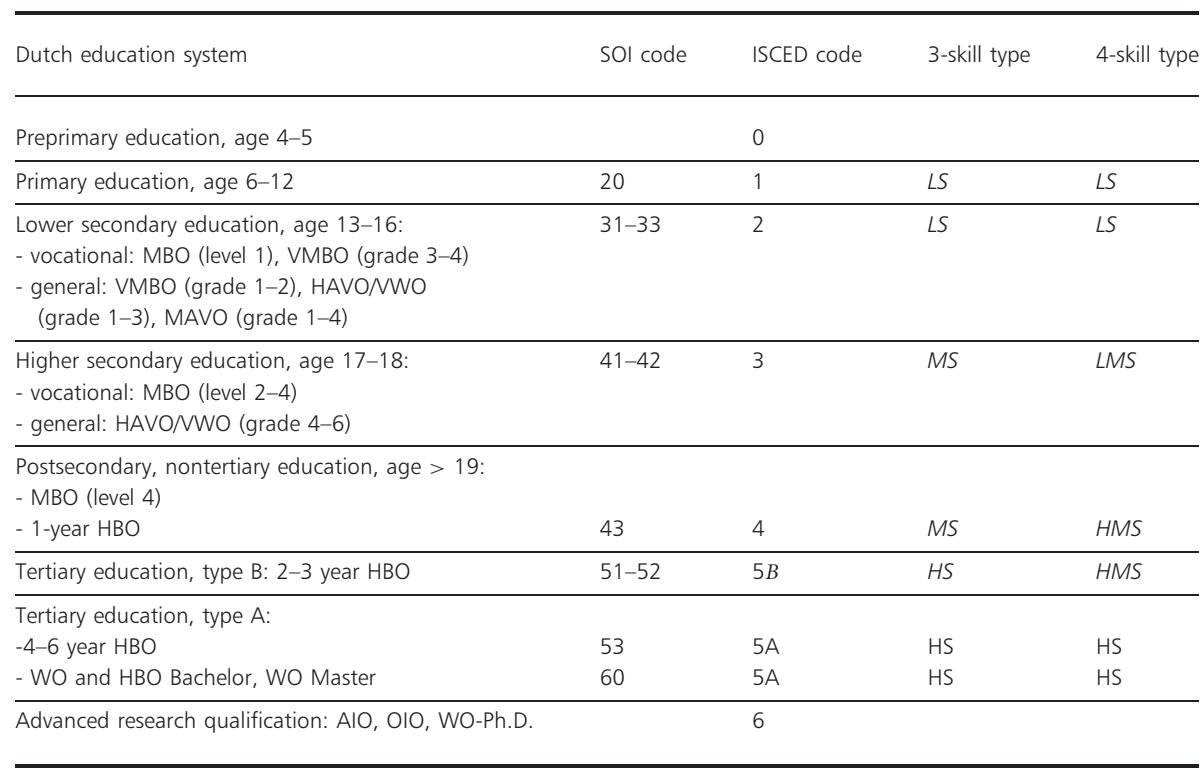

type into low-medium-skilled (LMS) and high-medium-skilled (HMS) types. The third and seventh columns in Table A1 report the fraction of employees that are observed in the Education database in manufacturing and services, respectively. The fraction lies in the $[19.2 \%-33.8 \%]$ range for manufacturing and in the $[30.5 \%-47.5 \%]$ range for services. 
In the second stage, we determine the skill type of employees who are not observed in the Education database. For that purpose, we estimate a reverse Mincer equation. More specifically, we estimate an ordered probit model to predict each individual's skill type ( $L S, M S, H S$ ) based on individual and firm characteristics in the matched employer-employee microdata for each year during the period 1999-2008. The ordered probit model is built around a latent regression equation:

$$
\operatorname{Skill}_{j(i)}^{*}=\mathbf{x}_{j} \alpha+\mathbf{z}_{i} \beta+\epsilon_{j}
$$

where $S_{k i l l}^{*}$ i $i$ is the skill type of individual $i$ working in enterprise $j, \mathbf{x}_{j}$ a vector of the individual's family background and labor market characteristics, $\mathbf{z}_{i}$ a vector of enterprise characteristics and $\epsilon_{j}$ a normally distributed error term. We do not observe the latent variable $S k i l l_{j(i)}^{*}$. However, the observed skill type can be modeled in the following way:

$$
\operatorname{Skill}_{j(i)}=l \quad \text { if } \quad c_{l-1} \leq \operatorname{Skill}_{j(i)}^{*}<c_{l}
$$

where $l=1,2,3$ are the three skill types and $c_{l}$ are the cutoff levels in the ordered probit model. To predict skill outcomes, we use the following explanatory variables: age, age squared, tenure, tenure squared, ln (yearly gross wage), ln (yearly working hours), 11 province dummies capturing the location of the individual, ${ }^{27}$ sex dummy $(0=$ female, $1=$ male $)$, marital status dummy $(0=$ unmarried/widowed/ divorced/registered partnership, $1=$ married $)$, birth country dummy $(0=$ other than the Netherlands $(N L), 1=N L)$, birth country father dummy $(0=$ other than $N L, 1=N L)$, birth country mother dummy $(0=$ other than $N L, 1=N L), 6$ size class dummies $^{28}$ and 20 industry dummies. ${ }^{29}$ The estimation sample is restricted to individuals aged 15-65 with wage and working time values within the [ $p 1-p 99$ ] range.

Table A3 presents the yearly skill composition of the workforce in manufacturing and services. The first percentage in each column refers to the proportion of respectively low-skilled, medium-skilled, and high-skilled employees based on the Education Database, i.e. the education (and hence skill) type for these individuals

\footnotetext{
27 The 12 provinces are Groningen (reference), Friesland, Drenthe, Overijssel, Flevoland, Gelderland, Utrecht, Noord-Holland, Zuid-Holland, Zeeland, Noord-Brabant, and Limburg.

${ }^{28}$ The 7 size classes are defined as follows: size class $=1$ if the number of employees $(L)<10$ (reference), size class $=2$ if $L \in[10,20$ [, size class $=3$ if $L \in[20,50$ [, size class $=4$ if $L \in$ [50, 100[, size class $=5$ if $L \in[100,200$ [, size class $=6$ if $L \in[200,500$ [, and size class $=7$ if $L \geq 500$.

29 The 11 manufacturing industries are food, textiles, wood, chemicals, plastics, glass, metal, machinery, electrical engineering, vehicles, furniture/recycling, and the 10 services industries are wholesale, transport, telecommunication, computer, technical services, consultancy, other business related services, renting, retail, and R\&D services.
} 
Table A3 Skill composition of the workforce in matched employer-employee microdata set1999-2008

\begin{tabular}{|c|c|c|c|c|c|c|}
\hline \multirow[t]{2}{*}{ Year } & \multicolumn{3}{|c|}{ Manufacturing } & \multicolumn{3}{|l|}{ Services } \\
\hline & $\% L S$ & $\% M S$ & $\% H S$ & $\% L S$ & $\% M S$ & $\% H S$ \\
\hline 1999 & $25.0[21.7]$ & $43.1[59.9]$ & $31.8[18.4]$ & 22.0 [16.3] & $46.1[55.8]$ & $32.0[28.1]$ \\
\hline 2000 & $25.4[21.7]$ & $41.7[58.5]$ & $32.9[19.8]$ & $23.4[16.9]$ & $44.5[53.8]$ & $32.1[29.3]$ \\
\hline 2001 & $24.3[21.5]$ & $41.3[58.0]$ & $34.3[20.5]$ & $22.6[16.3]$ & $44.3[53.2]$ & $33.1[30.5]$ \\
\hline 2002 & $24.2[21.7]$ & $40.0[56.1]$ & $35.8[22.2]$ & $22.8[16.7]$ & 42.9 [51.3] & 34.2 [32.0] \\
\hline 2003 & $25.7[23.1]$ & $37.9[52.2]$ & 36.4 [24.7] & $25.4[17.7]$ & $40.5[48.6]$ & $34.1[33.6]$ \\
\hline 2004 & $26.0[25.2]$ & $37.4[49.1]$ & $36.6[25.7]$ & $26.4[18.2]$ & $40.0[47.5]$ & 33.5 [34.3] \\
\hline 2005 & $25.9[24.3]$ & $37.7[49.4]$ & 36.5 [26.3] & $26.2[17.5]$ & $40.6[47.2]$ & $33.2[35.2]$ \\
\hline 2006 & $24.8[23.0]$ & $37.4[48.8]$ & $37.8[28.2]$ & $27.0[18.9]$ & $40.6[46.7]$ & 32.4 [34.4] \\
\hline 2007 & $26.0[24.0]$ & 37.8 [49.1] & 36.2 [26.9] & $27.9[19.8]$ & $40.7[47.0]$ & $31.3[33.1]$ \\
\hline 2008 & $25.9[24.1]$ & $38.2[49.4]$ & $35.8[26.4]$ & $27.9[20.1]$ & $41.2[47.8]$ & $31.0[32.1]$ \\
\hline TOTAL ${ }^{a}$ & $25.5[23.0]$ & $38.0[50.8]$ & $36.0[25.2]$ & $25.8[17.6]$ & 40.9 [48.2] & $32.7[32.6]$ \\
\hline
\end{tabular}

Note: ${ }^{a}$ Median value.

is observed. The second percentage in each column-put in square bracketscorresponds to the skill composition based on predicted skill outcomes. ${ }^{30}$ The match between the observed and the predicted skill type for individuals in the Education Database lies in the [58\%-65\%] range in both manufacturing and services. ${ }^{31}$ Focusing on the skill composition in square brackets, we observe a slight decrease in the proportion of low-skilled employees and a considerable decrease in the proportion of medium-skilled employees over time in both manufacturing and services which translates into a significant increase in the proportion of high-skilled employees over time. The latter appears to be more pronounced in manufacturing.

We applied the same procedure to determine the skill type for each employee in the matched employer-employee microdata set based on the 4-skill type decomposition (see supra). ${ }^{32}$

As noted above, we performed the ordered probit regressions on a yearly basis. To investigate the stability of an individual's (observed or predicted) skill type over the considered period (1999-2008), we compared the skill type of an individual in the

\footnotetext{
${ }^{30}$ Evidently, we take the observed skill type for individuals in the Education Database. The predicted skill type is used for the remaining individuals.

${ }^{31}$ Details on the ordered probit estimates are not reported but available upon request.

${ }^{32}$ Details are not provided but available upon request.
} 
first year of observation to her skill type in the last year of observation. Focusing on manufacturing, our unbalanced panel consists of 1,470,982 individuals over the period 1999-2008. The skill type is observed for $31.1 \%$ of the individuals. Considering the subsample of individuals for which the skill type is observed, $34.8 \%$ of the individuals belong to the low-skilled type, $38.1 \%$ to the medium-skilled type, and $27.1 \%$ to the high-skilled type. Considering the total sample of individuals (for which the skill type is either observed or predicted), the corresponding shares are $24.3 \%, 51.9 \%$, and $23.9 \%$. The number of observations per individual is two for the first quartile of individuals, three for the second quartile, and eight for the third quartile. ${ }^{33}$ Restricting the sample to individuals having at least two observations, we observe that the skill type is unchanged for $69.1 \%$ of the individuals whereas $14.6 \%$ of the individuals experience skill upgrading and $16.4 \%$ skill downgrading. Focusing on services, our unbalanced panel consists of 4,865,343 individuals over the period 1999-2008. The skill type is observed for $42.2 \%$ of the individuals. Considering the subsample of individuals for which the skill type is observed, $41.4 \%$ of the individuals are low-skilled, $38.7 \%$ medium-skilled, and 19.9\% high-skilled. Considering the total sample of individuals, the corresponding shares are $26.1 \%, 49.0 \%$, and $24.9 \%$. The number of observations per individual is one for the first quartile of individuals, three for the second quartile, and five for the third quartile. ${ }^{34}$ Restricting the sample to individuals having at least two observations, we observe that the skill type is unchanged for $66.6 \%$ of the individuals whereas $23.2 \%$ of the individuals experience skill upgrading and $10.2 \%$ skill downgrading. Since no clear pattern can be discerned in the skill type of the skill-downgrading category in both manufacturing and services, we decided to leave the skill type of these individuals unchanged.

Finally, we determine the share of each skill type for each matched (CIS $\cap P S$ )enterprise by aggregating to the enterprise level. ${ }^{35}$ Table A4 reports the means, standard deviations and quartile values of the skill types-defined as shares lying in the $[0,1]$ range-in manufacturing and services. We further break down

\footnotetext{
${ }^{33}$ Putting the number of individuals between brackets and the number of observations between square brackets, the structure of the manufacturing data is given by: $(333,076)[1],(242,420)[2]$, $(163,997)[3],(103,604)[4],(83,037)[5],(71,751)[6],(75,460)[7],(71,246)[8],(86,136)[9]$, $(240,255)[10]$. The total number of observations is $6,845,976$.

${ }^{34}$ Putting the number of individuals between brackets and the number of observations between square brackets, the structure of the services data is given by: $(1,300,050)$ [1], $(1,015,217)$ [2], $(677,490)[3],(476,719)[4],(335,782)[5],(247,174)[6],(205,536)[7],(174,679)[8],(172,800)$ [9], $(259,896)$ [10]. The total number of observations is $17,422,128$.

${ }^{35}$ Information on the skill decomposition of the workforce is missing for about $5 \%$ of the matched

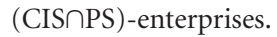


Table A4 Skill composition of the workforce in enterprise data set-1999-2008

\begin{tabular}{|c|c|c|c|c|c|c|}
\hline Variables & Mean & SD & $\mathrm{Q}_{1}$ & $\mathrm{Q}_{2}$ & $\mathrm{Q}_{3}$ & $N$ \\
\hline \multicolumn{7}{|c|}{ Manufacturing } \\
\hline$L S$ & 0.266 & 0.141 & 0.160 & 0.250 & 0.354 & 22614 \\
\hline MS & 0.557 & 0.128 & 0.476 & 0.556 & 0.641 & 22883 \\
\hline$H S$ & 0.180 & 0.153 & 0.069 & 0.140 & 0.254 & 23225 \\
\hline \multicolumn{7}{|l|}{ HT } \\
\hline$L S$ & 0.139 & 0.089 & 0.071 & 0.118 & 0.190 & 1549 \\
\hline MS & 0.480 & 0.158 & 0.387 & 0.489 & 0.583 & 1619 \\
\hline HS & 0.387 & 0.205 & 0.237 & 0.362 & 0.522 & 1644 \\
\hline \multicolumn{7}{|l|}{ MT } \\
\hline$L S$ & 0.258 & 0.135 & 0.156 & 0.241 & 0.344 & 14557 \\
\hline MS & 0.560 & 0.122 & 0.480 & 0.557 & 0.639 & 14738 \\
\hline$H S$ & 0.184 & 0.145 & 0.077 & 0.149 & 0.264 & 14961 \\
\hline \multicolumn{7}{|l|}{ LT } \\
\hline$L S$ & 0.313 & 0.142 & 0.210 & 0.293 & 0.402 & 6508 \\
\hline MS & 0.570 & 0.127 & 0.486 & 0.569 & 0.658 & 6526 \\
\hline HS & 0.119 & 0.099 & 0.044 & 0.100 & 0.170 & 6620 \\
\hline \multicolumn{7}{|l|}{ Services } \\
\hline$L S$ & 0.170 & 0.122 & 0.074 & 0.149 & 0.240 & 30787 \\
\hline MS & 0.518 & 0.186 & 0.385 & 0.545 & 0.656 & 33766 \\
\hline HS & 0.317 & 0.256 & 0.101 & 0.250 & 0.510 & 35417 \\
\hline \multicolumn{7}{|l|}{ KIS } \\
\hline$L S$ & 0.141 & 0.130 & 0.041 & 0.094 & 0.214 & 12319 \\
\hline MS & 0.418 & 0.193 & 0.258 & 0.397 & 0.571 & 14713 \\
\hline HS & 0.439 & 0.290 & 0.152 & 0.493 & 0.692 & 15901 \\
\hline \multicolumn{7}{|l|}{ OS } \\
\hline$L S$ & 0.189 & 0.113 & 0.107 & 0.173 & 0.250 & 18468 \\
\hline MS & 0.596 & 0.137 & 0.506 & 0.602 & 0.692 & 19053 \\
\hline$H S$ & 0.217 & 0.167 & 0.082 & 0.186 & 0.320 & 19516 \\
\hline
\end{tabular}

manufacturing and services into five industries according to the OECD (2001) classification: High-technology manufacturing (HT), Medium-technology manufacturing (MT), Low-technology manufacturing (LT), Knowledge-intensive services (KIS), and Other services (OS).

From Table A4, it follows that the median proportion of high-skilled employees (HS) is about $14 \%$ in manufacturing. We observe considerable heterogeneity across 
Table A5 Panel structure of PS sample-1998-2008

\begin{tabular}{ll}
\hline Number of consecutive years & Number of firms \\
\hline$\geq 2$ & 74,378 \\
$\geq 3$ & 32,114 \\
$\geq 4$ & 22,714 \\
$\geq 5$ & 17,310 \\
$\geq 6$ & 12,990 \\
\hline
\end{tabular}

industries: the median HS ranges from $10 \%$ in LT industries to $36.2 \%$ in HT. The median HS amounts to $25 \%$ in services, ranging from $18.6 \%$ in OS to $49.3 \%$ in KIS.

\section{A.2 Measurement of closeness to the technological frontier variable in the Dutch data}

A.2.1 Closeness-to-frontier variable based on real labor productivity

In order to define our main closeness-to-the-technological-frontier variable which is based on real labor productivity $\left(C T F_{i t-1}\right)$, we consider the largest possible population of enterprises from the Production Surveys. After some cleaning and trimming on nominal labor productivity levels and growth rates to eliminate outliers and anomalies, we have an unbalanced panel of 381,546 observations corresponding to 130,893 enterprises (35\% in manufacturing and 65\% in services) over the period 1998-2008. In all $1.7 \%$ of the enterprises belong to HT, $12.3 \%$ to MT, $13.8 \%$ to LT, $31.2 \%$ to KIS, and $41.1 \%$ to OS.

A.2.2 Closeness-to-frontier variable based on total factor productivity

In the robustness check using total factor productivity (TFP) as the dependent variable, we include as a covariate the 1-year lagged value of the closeness-to-the-technological-frontier variable which is based on estimates of total factor productivity $\left(C T F_{i t-1}^{T F P}\right)$. We measure the latter as $C T F_{i t}^{T F P}$ as $1-D T F_{i t}^{T F P}=1$ $-\left(\frac{\widehat{T F P}_{F t}-\widehat{T F P}_{i t}}{\widehat{T F P}_{F t}}\right)=\frac{\widehat{T F P}_{i t}}{\widehat{T F P}_{F t}}$ where $\widehat{T F P}$ of the technological frontier firm $F$ is proxied by the $95 \%$ percentile value of $\widehat{T F P}$ at the NACE three-digit industry level. The data that are used to estimate TFP of the technological frontier $F$ stem from the largest possible population of enterprises from the Production Surveys. After some cleaning and trimming on nominal labor productivity levels and growth rates to eliminate outliers and anomalies and restricting the population to enterprises having at least two consecutive years, our estimation sample consists of 292,770 observations corresponding to 74,378 enterprises ( $40.5 \%$ in manufacturing and $59.5 \%$ in services) 
spanning the period $1998-2008$. In all $2.1 \%$ of the enterprises belong to HT, $16.8 \%$ to MT, $19.6 \%$ to LT, $22 \%$ to KIS, and $39.4 \%$ to OS.

\section{A.3 Breakdown of manufacturing and services according to technological intensity}

Table A6 Breakdown of manufacturing and services according to technological intensity

\begin{tabular}{|c|c|}
\hline & NACE (Rev. 1.1) codes \\
\hline \multicolumn{2}{|l|}{ Manufacturing } \\
\hline $\begin{array}{l}\text { High-technology } \\
\text { manufacturing }(\mathrm{HT})\end{array}$ & $\begin{array}{l}\text { 24.4 Pharmaceuticals, medicinal chemicals, and botanical products } \\
\text { 30 Office machinery and computers } \\
\text { 32 Radio, television and communication equipment, and apparatus } \\
\text { 33 Medical, precision and optical instruments, watches, and clocks } \\
\text { 35.3 Aircraft and spacecraft }\end{array}$ \\
\hline $\begin{array}{l}\text { Medium-technology } \\
\text { manufacturing (MT) }\end{array}$ & $\begin{array}{l}23 \text { Coke, refined petroleum products, and nuclear fuel } \\
24 \text { Chemicals and chemical products, excluding } 24.4 \\
25-28 \text { Rubber and plastic products; basic metals, and fabricated } \\
\text { metal products; other nonmetallic mineral products } \\
29 \text { Machinery and equipment n.e.c. } \\
31 \text { Electrical machinery and apparatus n.e.c. } \\
\mathbf{3 4} \text { Motor vehicles, trailers, and semi-trailers; } 35 \text { Other transport } \\
\text { equipment, excluding } \mathbf{3 5 . 3}\end{array}$ \\
\hline $\begin{array}{l}\text { Low-technology } \\
\text { manufacturing (LT) }\end{array}$ & $\begin{array}{l}\text { 15-22 Food products, beverages, and tobacco; textiles and } \\
\text { textile products; leather, and leather products; wood and } \\
\text { wood products; pulp, paper, and paper products, publishing } \\
\text { and printing } \\
\text { 36-37 Manufacturing n.e.c. }\end{array}$ \\
\hline \multicolumn{2}{|l|}{ Services } \\
\hline $\begin{array}{l}\text { Knowledge-intensive } \\
\text { services (KIS) }\end{array}$ & $\begin{array}{l}61 \text { Water transport } \\
62 \text { Air transport } \\
64 \text { Post and telecommunications } \\
\mathbf{6 5 - 6 7} \text { Financial intermediation } \\
\mathbf{7 0 - 7 4} \text { Real estate; renting and business activities }\end{array}$ \\
\hline Other services (OS) & $\begin{array}{l}\mathbf{5 0 - 5 2} \text { Wholesale; retail; motor trade } \\
\mathbf{6 0} \text { Land transport, transport via pipelines } \\
\mathbf{6 3} \text { Supporting and auxiliary transport activities, activities } \\
\text { of travel agencies } \\
90 \text { Sewage and refuse disposal, sanitation, and similar activities }\end{array}$ \\
\hline
\end{tabular}

Notes: Data for hotel and restaurants (55), financial intermediation (65-67), public administration and defense, compulsory social security (75), education (80), health and social work (85), activities of membership organization n.e.c. (91), recreational, cultural and sporting activities (92), other service activities (93), activities of households (95-97), and extra-territorial organizations and bodies (99) are not available. 


\section{Appendix B : Statistical annex}

Table B1 Estimation sample by country and 21-industry

\begin{tabular}{|c|c|c|c|c|c|c|c|c|}
\hline & \multicolumn{4}{|l|}{ Germany } & \multicolumn{4}{|c|}{ The Netherlands } \\
\hline & $\begin{array}{l}\text { Number } \\
\text { of obs. }\end{array}$ & $\%$ & $\begin{array}{l}\text { Number } \\
\text { of firms }\end{array}$ & $\%$ & $\begin{array}{l}\text { Number } \\
\text { of obs. }\end{array}$ & $\%$ & $\begin{array}{l}\text { Number } \\
\text { of firms }\end{array}$ & $\%$ \\
\hline Food & 493 & 4.2 & 298 & 4.5 & 1421 & 5.8 & 810 & 5.5 \\
\hline Textile & 365 & 3.1 & 198 & 3.0 & 405 & 1.6 & 226 & 1.5 \\
\hline Wood & 715 & 6.1 & 411 & 6.2 & 311 & 1.3 & 180 & 1.2 \\
\hline Chemicals & 543 & 4.6 & 316 & 4.8 & 909 & 3.7 & 425 & 2.9 \\
\hline Plastics & 528 & 4.5 & 292 & 4.4 & 590 & 2.4 & 295 & 2.0 \\
\hline Glass & 357 & 3.1 & 205 & 3.1 & 466 & 1.9 & 264 & 1.8 \\
\hline Metal & 1124 & 9.6 & 596 & 9.0 & 1926 & 7.8 & 1134 & 7.6 \\
\hline Machinery & 973 & 8.3 & 539 & 8.1 & 1532 & 6.2 & 855 & 5.8 \\
\hline Electrical engineering & 1349 & 11.5 & 761 & 11.5 & 829 & 3.4 & 471 & 3.2 \\
\hline Vehicles & 402 & 3.4 & 236 & 3.6 & 555 & 2.3 & 324 & 2.2 \\
\hline Furniture/recycling & 337 & 2.9 & 196 & 3.0 & 528 & 2.1 & 332 & 2.2 \\
\hline Wholesale & 468 & 4.0 & 243 & 3.7 & 4624 & 18.8 & 2841 & 19.1 \\
\hline Transport & 801 & 6.8 & 448 & 6.8 & 2954 & 12.0 & 1744 & 11.8 \\
\hline Telecomm. & 64 & 0.5 & 37 & 0.6 & 116 & 0.5 & 74 & 0.5 \\
\hline Computer & 500 & 4.3 & 309 & 4.7 & 1067 & 4.3 & 770 & 5.2 \\
\hline Technical services & 712 & 6.1 & 388 & 5.8 & 964 & 3.9 & 611 & 4.1 \\
\hline Consultancy & 394 & 3.4 & 253 & 3.8 & 1360 & 5.5 & 933 & 6.3 \\
\hline Other business related serv. & 808 & 6.9 & 503 & 7.6 & 2699 & 11.0 & 1697 & 11.4 \\
\hline Renting & 237 & 2.0 & 112 & 1.7 & 218 & 0.9 & 143 & 1.0 \\
\hline Retail & 282 & 2.4 & 137 & 2.1 & 1056 & 4.3 & 668 & 4.5 \\
\hline RD services & 247 & 2.1 & 156 & 2.4 & 56 & 0.2 & 44 & 0.3 \\
\hline Total & 11,699 & 100.0 & 6634 & 100.0 & 24,586 & 100.0 & 14,841 & 100.0 \\
\hline
\end{tabular}

Table B2 Panel structure: number of participations

\begin{tabular}{|c|c|c|c|c|c|c|c|c|}
\hline \multirow[t]{2}{*}{ Number of participation } & \multicolumn{4}{|l|}{ Germany } & \multicolumn{4}{|c|}{ The Netherlands } \\
\hline & $\begin{array}{l}\text { Number } \\
\text { of obs. }\end{array}$ & $\%$ & $\begin{array}{l}\text { Number } \\
\text { of firms }\end{array}$ & $\%$ & $\begin{array}{l}\text { Number } \\
\text { of obs. }\end{array}$ & $\%$ & $\begin{array}{l}\text { Number } \\
\text { of firms }\end{array}$ & $\%$ \\
\hline 1 & 3582 & 30.6 & 3582 & 54.0 & 9177 & 37.3 & 9177 & 61.8 \\
\hline 2 & 3446 & 29.5 & 1723 & 26.0 & 6130 & 24.9 & 3065 & 20.7 \\
\hline 3 & 2391 & 20.4 & 797 & 12.0 & 4395 & 17.9 & 1465 & 9.9 \\
\hline 4 & 1520 & 13.0 & 380 & 5.7 & 3144 & 12.8 & 786 & 5.3 \\
\hline 5 & 760 & 6.5 & 152 & 2.3 & 1740 & 7.1 & 348 & 2.3 \\
\hline Total & 11,699 & 100.0 & 6634 & 100.0 & 24,586 & 100.0 & 14,841 & 100.0 \\
\hline
\end{tabular}

